Portland State University

PDXScholar

1995

\title{
Disequilibrium Transition of the Consumer Goods Market in China, 1954-1991
}

Hui Shu

Portland State University

Follow this and additional works at: https://pdxscholar.library.pdx.edu/open_access_etds

Part of the International Business Commons

Let us know how access to this document benefits you.

\section{Recommended Citation}

Shu, Hui, "Disequilibrium Transition of the Consumer Goods Market in China, 1954-1991" (1995).

Dissertations and Theses. Paper 1161.

https://doi.org/10.15760/etd.1160

This Dissertation is brought to you for free and open access. It has been accepted for inclusion in Dissertations and Theses by an authorized administrator of PDXScholar. Please contact us if we can make this document more accessible: pdxscholar@pdx.edu. 


\title{
DISEQUILIBRIUM TRANSITION OF THE CONSUMER GOODS MARKET \\ IN CHINA, $1954-1991$
}

by

HUI SHU

A dissertation submitted in partial fulfillment of the requirements for the degree of

\section{DOCTOR OF PHILOSOPHY}

in

SYSTEMS SCIENCE

\author{
Portland State University \\ 1995
}


UMI Number: 9530967

UMI Microform 9530967

Copyright 1995, by UMI Company. All rights reserved.

This microform edition is protected against unauthorized copying under Title 17 , United States code.

\section{UMI}

300 North Zeeb Road

Ann Arbor, MI 48103 


\section{DISSERTATION APPROVAL}

The abstract and dissertation of Hui Shu for the Doctor of Philosophy in Systems

Science were presented February 10, 1995, and accepted by the dissertation committee and the doctoral program.

COMMITTEE APPROVAL:

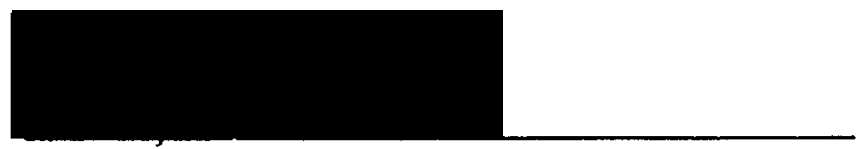

Kuan-pin Lin, Chair

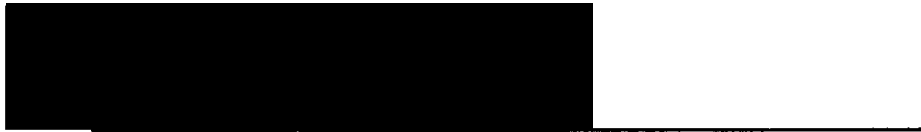

John B. Hall
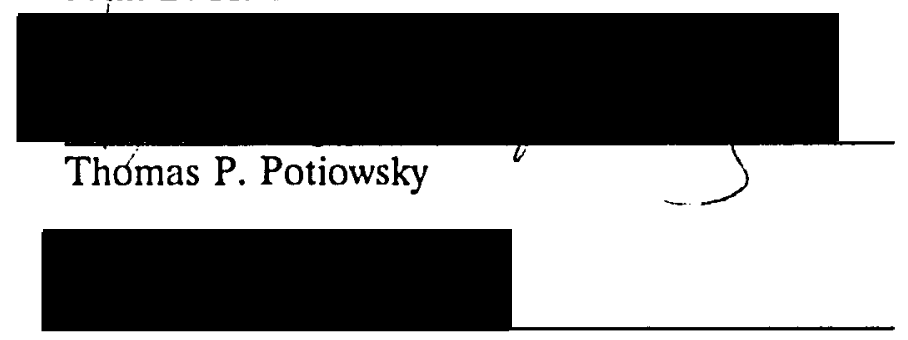

Martin Zwick

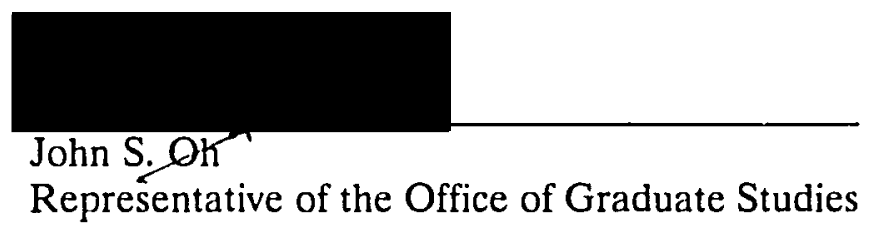

DOCTORAL PROGRAM APPROVAL

Beatrice T. Oshika, Director

Systems Science Ph.D. Program

ACCEPTED FOR PORTLAND STATE UNIVERSITY BY THE LIBRARY

by

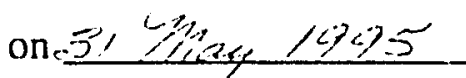




\begin{abstract}
An abstract of the dissertation of Hui Shu for the Doctor of Philosophy in Systems Science presented February 10, 1995.
\end{abstract}

Title: Disequilibrium Transition of the Consumer Goods Market in China, 19541991

This is an in-depth study of the structural change and transition of the Chinese consumer goods market from 1954 to 1991 using disequilibrium econometric methodology. The model for the Chinese consumer goods market is based on the Portes-Winter disequilibrium model for centrally planned economies (1980). The demand function is derived from the Houthakker-Taylor savings function. The supply function is composed of approximations to the government's long-term and short-term plans. The transaction quantity in the market is defined as the smaller of effective demand and supply. Using the traditional global fitting method, three models are evaluated: one model that assumes no structural change, and two models that assume structural change. The estimations show that the structures of the demand and supply functions of 
the Chinese consumer goods market have changed since the economic reform in 1980.

An innovative non-parametric method of locally weighted optimization is applied to further test the variations in model parameters during the period between 1954 and 1991 without assuming explicit functional forms of demand and supply. The estimation results show that the Chinese consumer goods market fits the Portes-Winter model well in the earlier years. The results confirm that the structures of demand and supply functions have changed since the economic reform. In the late 1980's, the Chinese consumer goods market is shown to have shifted away from a pure centrally planned system.

Other main conclusions of this study include, first, that chronic shortage does not exist in the Chinese consumer goods market from 1954 to 1991. Second, a rigid price level has not caused the market to be persistently in disequilibrium. Third, the classical disequilibrium model of consumer goods market in centrally planned economies does not fit the Chinese consumer goods market in the later years. 


\section{ACKNOWLEDGEMENTS}

I take this opportunity to acknowledge the support I have received during the process of working on my dissertation. Without the help of my committee members (Kuan-Pin Lin, John B. Hall, Thomas P. Potiowsky, Martin Zwick and John S. Oh), my dissertation would not have reached its present stage. Especially, I would like to thank the chairman of my committee, Kuan-Pin Lin. His help has extended from the selection of my research topic and the computer software used for the data analysis, to the advice essential to the completion of this dissertation. Without his guidance, encouragement and patience, as well as his collaboration, this dissertation may not have taken form. Also, I would like to thank Martin Zwick for his enlightening discussions and encouragement on my dissertation, as well as on the research projects during the time when I was a graduate assistant for him. Those discussions made it possible for me to avoid many analytical traps. Dawn Kuenle has been instrumental in many intricate times. I would also like to extend my thanks to the Systems Science PhD Program for providing me with assistantships since I entered the program. The financial support enabled me to concentrate on my study and research. 


\section{TABLE OF CONTENTS}

\section{PAGE}

LIST OF TABLES $\ldots \ldots \ldots \ldots \ldots \ldots \ldots \ldots \ldots \ldots \ldots \ldots \ldots$

LIST OF FIGURES $\ldots \ldots \ldots \ldots \ldots \ldots \ldots \ldots \ldots \ldots \ldots \ldots \ldots \ldots \ldots \ldots$

\section{CHAPTER}

I INTRODUCTION $\ldots \ldots \ldots \ldots \ldots \ldots \ldots \ldots \ldots \ldots \ldots$

I.1 Theoretical Background $\ldots \ldots \ldots \ldots \ldots \ldots$

I.2 The Chinese Economy $\ldots \ldots \ldots \ldots \ldots$

I.3 Purpose of the Research ........... 11

II $\quad$ LITERATURE REVIEW $\ldots \ldots \ldots \ldots \ldots \ldots$

II.1 Disequilibrium Economics . . . . . . . . . 13

II.2 Disequilibrium Econometrics $\ldots \ldots \ldots \ldots$

II.3 Disequilibrium Analysis for Centrally Planned

Economies ..............25

II.4 Application of Disequilibrium Econometrics in CPEs ................ 30

III MODEL SPECIFICATIONS $\ldots \ldots \ldots \ldots \ldots \ldots$

III.1 A Model of the Chinese Consumption Goods Market ..................... 35

III.2 Hypothesis $\ldots \ldots \ldots \ldots \ldots \ldots \ldots \ldots \ldots$

Chronic Shortage Structural Change 
Rigid Price

Influential Variables in Government Plans

III.3 Disequilibrium Econometric Models . . . . . . 39

Discrete-Switching Transaction Function

Hyperbolic Transaction Function

III.4 Locally Weighted Optimization . . . . . . . . 46

Local Fitting and Approximation

Normal Kernel Weight

K Nearest Neighbor Kernel Weight

Locally Weighted Disequilibrium Model

An Example of Locally Weighted Optimization

IV MODEL ESTIMATION $\ldots \ldots \ldots \ldots \ldots \ldots$

IV.1 Assuming No Structural Change . . . . . . . . 59

Models 1A and 1B: No Structural Change

Comparison with the Portes-Santorum Model

IV.2 Assuming Structural Change in $1980 \ldots \ldots \ldots 6$

Models 2A and 2B: Dummy Variable Approach

Models 3A and 3B: Sample Separation Approach

IV.3 Locally Weighted Optimization Model . . . . . . . 74

Local Weight with $\mathrm{K}$ Nearest Neighbor Kernel

Models 4A and 4B: Locally Weighted Optimization

V EXCESS DEMAND EVALUATION $\ldots \ldots \ldots \ldots$

V.1 Excess Demand Estimates from the Global

Estimation of Structural Change

(Model 2A) .............. 94

V.2 Excess Demand Estimates from the Locally

Weighted Fitting (Model 4A) . . . . . . 999

VI SUMMARY AND CONCLUSION . . . . . . . . . . . 109 
Non-Persistent Market Disequilibrium Status

Non-Effective Price Change

Market Structure Change due to Shifts of

Government Policies

Variate Fitness of the Portes-Winter Model for the Consumer Goods Market in CPEs

VII FUTURE RESEARCH . . . . . . . . . . . . . . . . . . . 114

Problems in the Current Research

Further Research based on Current Results

Multi-Market Model

REFERENCES

\section{APPENDICES}

A INPUT DATA SERIES . . . . . . . . . . . . . . . 127

Quantity Variables of the Chinese Consumer Goods Market ..................... 128

Price Deflators $\ldots \ldots \ldots \ldots \ldots \ldots \ldots \ldots \ldots \ldots$

B COMPUTER PROGRAMS $\ldots \ldots \ldots \ldots \ldots \ldots \ldots \ldots \ldots$

With or Without Dummy Variable Using Hyperbolic and Discrete-Switching Transaction Functions:

Models 1A, 1B, 2A and 2B ........... 133

Locally Weighted Optimization Using Hyperbolic and Discrete-Switching Transaction Functions:

Models 4A and 4B ............... 140

C SELECTED COMPUTER OUTPUTS $\ldots \ldots \ldots \ldots \ldots 150$

Dummy Variable Approach Using Discrete-Switching

Transaction Function: Model 2B ......... 151

Locally Weighted Optimization Using Hyperbolic

Transaction Function: Model 4A

(Selected Years: 1963, 1980 and 1989) ...... 155

Locally Weighted Optimization Using Discrete-

Switching Transaction Function: Model 4B

(Selected Years: 1963, 1980 and 1989) 
D ESTIMATED RESPONSE COEFFICIENTS FROM

LOC.ALLY WEIGHTED OPTIMIZATION . . . . . . 164

Using Hyperbolic Transaction Function: Model 4A, $1954-1991 \ldots \ldots \ldots \ldots \ldots \ldots \ldots \ldots \ldots . \ldots 165$

Using Discrete-Switching Transaction Function:

Model 4B, 1954 to 1991 . . . . . . . . . . . . 167 


\section{LIST OF TABLES}

I Changes in Chinese Economic Policies $\ldots \ldots \ldots \ldots \ldots \ldots .8$

II Growth Rates since Economic Reform ............. 10

III Parameter Estimates of Model 1A and 1B ..........6 62

IV Comparative Estimates of the Portes-Santorum Model . . . . . 64

V Definitions of Parameters in Different Time Periods $\ldots \ldots 67$

VI Parameter Estimates of Model 2A:

Using Hyperbolic Transaction Function . . . . . . 67

VII Parameter Estimates of Model 2B:

Using Discrete-Switching Transaction Function $\ldots \ldots 70$

VIII Comparative Test Results of Models with a Dummy Variable .. 71

IX Parameter Estimates of Model 3A:

Using Hyperbolic Transaction Function . . . . . . . 73

X Parameter Estimates of Model 3B:

Using Discrete-Switching Transaction Function $\ldots \ldots 74$

XI Average Estimates and Standard Errors of the Response Coefficients of Models 4A and 4B: Using Locally Weighted Optimization, 1954-1991 . . . . . . . . . . . 86

XII Average Estimates and Standard Errors of the Response Coefficients of Models 4A and 4B: Using Locally Weighted Optimization, $1954-1979 \ldots \ldots \ldots \ldots \ldots$. . . . 87

XIII Average Estimates and Standard Errors of the Response Coefficients of Models 4A and 4B: Using Locally Weighted Optimization, 1980-1991 . . . . . . . . . . 88 
XIV Average Estimates and Standard Errors of the Response Coefficients of Model 4A: Using Locally Weighted Optimization, Various Periods ............990

XV Estimated D, S and C from Model $2 A \ldots \ldots . \ldots 5$

XVI Estimated D, $S$ and $C$ from Model $4 \mathrm{~A} \ldots \ldots \ldots$

XVII Differences in Estimates by Global Fitting and Locally

Weighted Fitting ................. 103 


\section{LIST OF FIGURES}

1. Percentage of Consumption and Accumulation in National Income Available $\ldots \ldots \ldots \ldots \ldots \ldots 6$

2. Personal Consumption and Investment in Fixed Assets in National Income Available $\ldots \ldots \ldots \ldots \ldots \ldots$

3. Short-side Transaction Rule $\ldots \ldots \ldots \ldots \ldots \ldots \ldots \ldots . \ldots \ldots$

4. Smoothing by Aggregation $\ldots \ldots \ldots \ldots \ldots \ldots \ldots \ldots 21$

5. Coexistence of Shortage and Slack $\ldots \ldots \ldots \ldots \ldots \ldots \ldots 23$

6. Short-side Transaction Rule in CPEs $\ldots \ldots \ldots \ldots \ldots \ldots, \ldots$

7. Graphical Representation of the Discrete-Switching Transaction Function $\ldots \ldots \ldots \ldots \ldots \ldots \ldots 4$

8. Graphical Representation of the Hyperbolic Transaction Function ................. 44

9. A Global Fitting Example of $\mathrm{Y}=\mathrm{f}(\mathrm{X}) \ldots \ldots \ldots \ldots \ldots$

10. Weights Assigned to the Neighborhoods of Focal Observations in 1967,1975 and $1987 \ldots \ldots \ldots \ldots \ldots \ldots$

11. Locally Weighted Fitting for the Entire Sample $\ldots \ldots \ldots \ldots 5$

12. Weights Assigned to the Neighborhood of Year 1963 . . . . . 79

13. Weights Assigned to the Neighborhood of Year 1980 . . . . . 79

14. Weights Assigned to the Neighborhood of Year 1989 . . . . . 80

15. Weight Surface of $\mathrm{K}$ Nearest Neighbor Kernel Weight $(r=0.5) .81$

16. Weight Surface of $\mathrm{K}$ Nearest Neighbor Kernel Weight $(\mathrm{r}=1.0) .82$ 
17. Weight Surface of Normal Kernel Weight ( $\mathrm{r}=$ infinity) $\ldots \ldots 83$

18. Response Coefficient Estimates Using Locally Weighted

Optimization (Model 4A) . . . . . . . . . . 89

19. Estimated Excess Demand with Two-Standard-Error Range of

Equilibrium from Global Fitting $\ldots \ldots \ldots \ldots 97$

20. Estimated Excess Demand with Two-Standard-Error Range of

Equilibrium from Locally Weighted Fitting ... . . . 102

21. Estimated Excess Demand from Global and Local Weighted

Fittings .................... 105

22. Estimated Excess Supply from Global and Local Weighted

Fittings ..................... 105

23. Savings and Estimated Excess Demand from Global and

Locally Weighted Fittings . . . . . . . . . . . . . . 107

24. Change in Consumer Price Index and Estimated Excess

Demand from Global and Locally Weighted Fittings . . 107 


\section{CHAPTER I}

\section{INTRODUCTION}

This dissertation documents a research on the transition and structural change of the Chinese consumer goods market from 1954 to 1991. Disequilibrium econometric methodology is employed to examine the demand and supply relationships in the market. The demand function is derived from the Houthakker-Taylor savings function. The supply function consists of approximations to the government's long-term and short-term plans.l The transaction function for the market is defined as the smaller of effective demand and supply. Applying the classical disequilibrium econometric analysis, several models with and without structural change are constructed and estimated. A non-parametric optimization is used to further investigate the transition of demand and supply functions over the study period. This chapter describes the background and purposes of the research. Literature review on disequilibrium economics and its application in the centrally planned economies is given in Chapter II. Chapter III discusses the technical aspects of model construction and estimation of the Chinese consumer goods market. Chapter IV and Chapter V summarize the empirical findings. The last two chapters, Chapters VI and VII, conclude the research and suggest related future studies. 


\section{I.1 THEORETICAL BACKGROUND}

Markets are the places where goods and services are exchanged through the transactional activities of buyers and sellers. Both sides of the markets are satisfied when buyers can get what they want to buy and sellers can sell what they plan to sell. That is, there is neither shortage (excess demand) nor surplus (excess supply) in the markets. However, this is not usually the case, since to clear a market, both sides should have perfect information regarding the demand and supply, and prices should be able to adjust freely and efficiently. The presence of many sellers and buyers with imperfect information, and the existence of institutional bureaucratic interferences can prevent the market from ever being in equilibrium. Disequilibrium, or non-equilibrium, is the normal state of a market, while equilibrium is a special case.

In economics, equilibrium and disequilibrium refer to whether demand and supply are equal. Based on various studies of equilibrium theory, the price level in a market will adjust in accordance with the excess demand or excess supply and settle at the point where demand and supply curves intersect. That is, the equilibrium price level is the one corresponding to the quantity demanded and supplied which clears the market. In contrast, the disequilibrium theory suggests that, for some reasons, prices may not adjust fast enough or they may not adjust at all. This results in excess demand and/or excess supply. Thus, one side of the market, either buyers or sellers, is constrained by the quantity 
available. In this case, the realized transactions are determined not only by the price level but also by the quantity which is the minimum of demand and supply.

Ideally, an economic system should optimize the utilization and allocation of its resources to produce goods and services. However, unbalanced demand and supply may result in either waste or shortage, or both. To minimize misallocation, it is necessary to understand if such disequilibrium situation exists in an economy.

Many disequilibrium studies have been applied to centrally planned economies (CPEs). The reason is that in CPEs, prices are set by government agencies in plans, rather than adjusted by demand and supply relationships in markets. Price changes are not usually made until the next planning period, which may well be another year. As a matter of fact, one purpose of the plans is to keep the price level stable with minimal fluctuations. Price adjustment in CPEs is not just "sticky," which is claimed by many economists to be the cause of disequilibrium, but is, in fact, fixed.

\section{I.2 THE CHINESE ECONOMY}

Due to its nature as a centrally planned and controlled economy, it is appropriate to study the Chinese economy using disequilibrium methodology. After the founding of the communist regime in 1949, the structure of the Chinese government was basically a copy of the former Soviet government: 
central control and vertical communication along specific functional divisions. Government agencies make most of the decisions concerning what and how much should be produced, with what inputs, and where the investments should go, etc. Consumption has been regulated by wage rate settings and quantity rationing.

The yearly planning procedure starts with the reporting from grass-root government agencies. At the end of each year, the local government agencies report to the corresponding ministries and bureaus in the central government on how much has been produced during the past year based on the statistics collected from all the local enterprises, and what their next year's plans are. Each ministry and bureau then makes their plans on what and how much to be needed and produced in the coming year. The Ministry of Foreign Economic Relations and Trade coordinates the foreign trade plans of the ministries and the lower level governments, and determines the national foreign trade plan. Finally, the Planning Commission designs the comprehensive plan for the next period. Plans, which may be adjusted slightly during implementation, are made at the end of each year for the next calendar year. Five-year planning cycles are used to set targets and project growth of the economy. The five-year plans are longterm and strategic in nature and are the basis for the short-term annual plans during the five-year period.

The majority of the Chinese labor force was assigned by government agencies to work in certain places according to plans. Also, government policies 
guaranteed that when workers retire, their children would succeed them in the enterprises although they might have completely different positions. This was true especially in rural areas. Private enterprises may hire people according to needs. Now some state-owned enterprises hire their workers on a contract basis too, and people have some degree of freedom in choosing what jobs they want to take. In recent years, many workers have been on "long vacations" because of the unprofitability of their enterprises in some areas. However, the labor market is yet to be active: the number of enterprises which may hire people from the labor market is limited; the information channel which facilitates the flow of labor is insufficient; it is difficult for people to move from one location to another; and the majority of the people is still not accustomed to changing jobs.

Households provide labor services and in turn receive wages for their consumption. In general, households do not have much choice of whether to go to work or to remain unemployed because of forced work assignment and low household income level. The households' consumption depends mainly on current income and savings since there is almost no credit issued to households for consumption purposes.

Along with Chinese economic development, almost all the investments were controlled by the government. Heavy industry had always been considered an important infrastructure for future economic development, and it had been at the sacrifice of the households' consumption. The funds used for investments are a portion of the national income accumulated based on plans. According to 
Liu et. al. (1987), the most efficient allocation of the investment funds was about $25 \%$ of the national income ${ }^{1}$. As pondered by many experts in the country, the relatively low proportion of consumption in the national income available (Figure 1), and relatively slow growth of personal consumption (Figure 2) have long been the cause of low living standard for households.

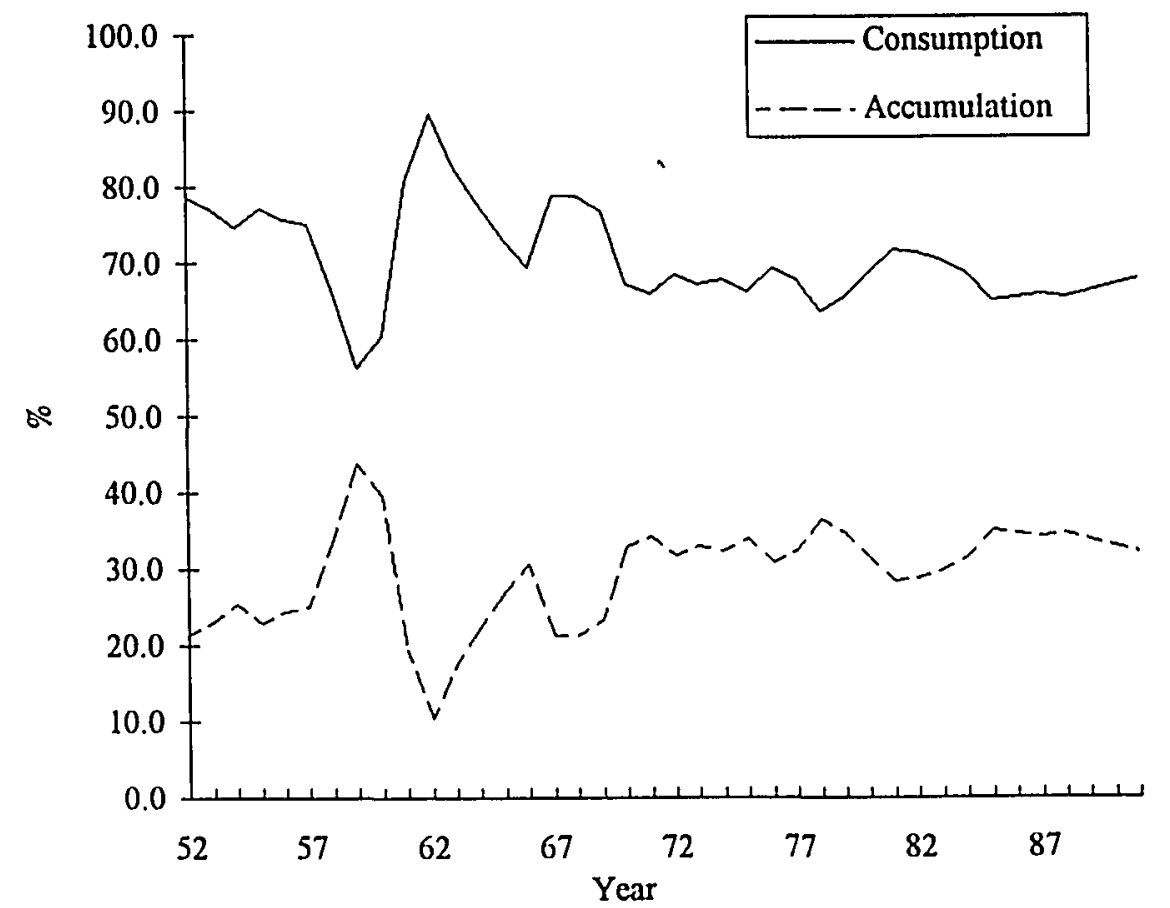

Figure 1. Percentage of consumption and accumulation in national income available.

Since the founding of socialist China, the Chinese macroeconomic policy has been very much influenced by the shift of the government's political

1. Accumulation is used for expanded reproduction, non-productive construction and increase of productive and non-productive stock of the society. Consumption is the total expenditure of consumer goods by individuals and public entities. National income is the sum of the above two. National income available is national income plus net of import and export. 


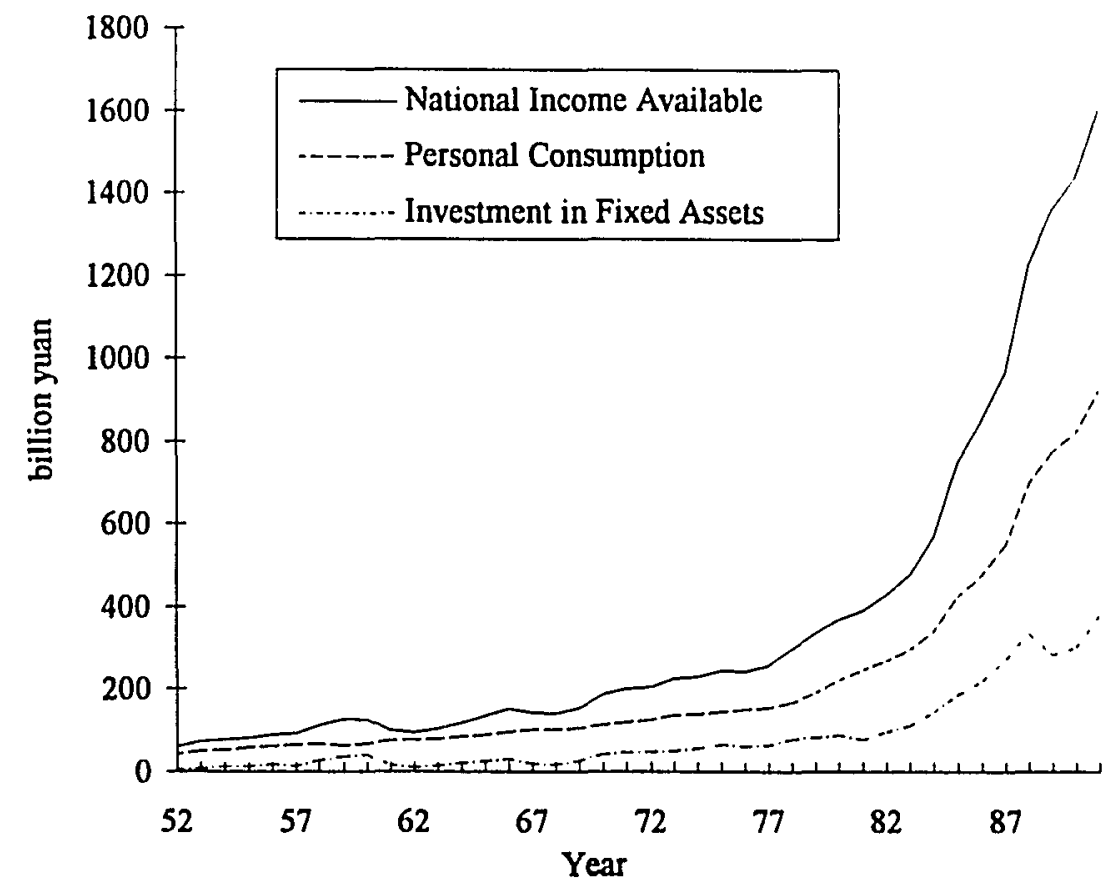

Figure 2. Personal consumption and investment in fixed assets in national income available.

emphases. Adelman and Sunding (1988) divided these political changes into several periods. (See Table I.) In the early stage of the communist regime, the emphasis was to recover from the condition that existed when it took power from the Nationalist government. The period from 1950 to 1952 is called the "rehabilitation" period. During the Great Leap Forward, from 1957 to 1960, the blind enthusiasm for the high output of the economy resulted in inefficient utilization, even damage, of many sources of production materials. Then at the beginning of 1960 's, bad weather conditions and concurrent withdrawal of Soviet aid caused hardship in various sectors of the economy. Necessities, especially foodstuffs, were in severe shortage. From 1961 to 1966, the economic 


\section{TABLE I}

\section{CHANGES IN CHINESE ECONOMIC POLICIES}

\begin{tabular}{|c|c|c|c|}
\hline Period & Incentive System & Choice of Technique & Sectoral Priority \\
\hline $1952-58$ & Material & Capital intensive & Heavy industry ${ }^{2}$ \\
\hline $1958-61$ & Nonmaterial & Labor intensive & Heavy industry \\
\hline $1961-66$ & Material & Capital and labor intensive & Agriculture \\
\hline $1966-78$ & Nonmaterial & Labor intensive & Heavy industry \\
\hline 1978 & Material & Technology intensive & Balanced \\
\hline
\end{tabular}

adjustment and reform resulted in decentralization of government power. The policy of "more plots for private use, more free markets, more enterprises with sole responsibility for their own profits and losses, as well as fixing output quotas on a household basis" was introduced to peasants. Living conditions improved. These improvements were interrupted by the next destructive period, the Cultural Revolution from 1966 to 1976. Pursuit of high production output and a high living standard was considered non-proletarian and, therefore, abolished. Then in later 1978, economic reform was announced at the Third Plenum of the Chinese Communist Party. Begun in later 1979, the reform was directed mainly at the macroeconomic issues. The goal was to transform an absolute centrally planned economy to a market adjusted socialist system. Many new policies were

2. There are five sectors in Chinese national income reported: agriculture, industry, construction, transport and commerce. Industry is further divided as heavy industry and light industry, with the former producing means of production, and latter concentrating on consumer goods. 
made to build a healthy economy with a balanced structure and high living standard. The main changes in the economic system included reduced central government control over economic activities carried out by enterprises in the industrial and agricultural sectors. Since the recent economic reform, rigid central plans have relaxed somewhat to stimulate enterprises' incentives to supply more and better products to the market.

The current economic structure is called "centrally planned with market adjustment." The central government now focuses more on macroeconomic issues. Plans made by government agencies are currently of two types: compulsory and directive. The production and allocation of important products, and the production activities of large-scale enterprises are regulated by compulsory plans. Directive plans and market forces regulate other enterprises, including privately owned and foreign invested enterprises. The products and economic activities not directly subject to mandatory plans are still affected by them, as the meaning of "directive plans" has not been clarified.

After more than ten years of economic reform, some old problems have been alleviated or resolved. Personal income level is higher and more consumer goods are available. Between 1979 and 1984, national income increased 11\% annually on average, while household financial assets (mainly accumulated savings) increased $28 \%$. These changes were accompanied by problems of impatience for quick outcomes which resulted in overheated economic development. Between 1984 and 1988, national income, investment in fixed 
assets, personal consumption and household financial assets have increased drastically at annual rates of $20 \%, 23 \%, 20 \%$ and $29 \%$, respectively. Repressed inflation seemed to be obvious as suggested by many economists. In order to curb inflation, restructure the economic system, balance the growth of various sectors, control the proliferation of unproductive companies, reduce demand, and slow the overheated economy, a retrenchment was undertaken in the Fall of 1988. At the beginning of 1989 , sales became sluggish signaling emerging stagnation. Many enterprises were operating at less than normal capacity. The problem of surplus in the labor market appeared. High inflation rates have been reported. Growth rates in all the aspects decreased. Table II summarizes the fluctuation in some of the growth rates over the period since economic reform began.

TABLE II

GROWTH RATES SINCE ECONOMIC REFORM

\begin{tabular}{|c|c|c|c|c|c|}
\hline Year & $\begin{array}{l}\text { National } \\
\text { Income }\end{array}$ & $\begin{array}{c}\text { Total } \\
\text { Consumption }\end{array}$ & $\begin{array}{c}\text { Personal } \\
\text { Consumption }\end{array}$ & $\begin{array}{l}\text { Fixed } \\
\text { Assets }\end{array}$ & $\begin{array}{c}\text { Household } \\
\text { Financial Assets }\end{array}$ \\
\hline $79-84$ & 11 & 12 & 12 & 12 & 28 \\
\hline $84-88$ & 20 & 20 & 20 & 23 & 29 \\
\hline 88-91 & 11 & 11 & 10 & 4 & 28 \\
\hline 79-91 & 14 & 14 & 14 & 13 & 28 \\
\hline
\end{tabular}




\section{I.3 PUIRPOSE OF THE RESEARCH}

From the existing literature about the Chinese economy, there is no clear indication of whether the economy is at equilibrium or at any type of disequilibrium. Most of the economic studies on China are either from the viewpoint of political economics, or from the market equilibrium viewpoint using the input-output analysis.

The purpose of this research is to study the transition of the Chinese economy using disequilibrium economics and econometrics in an attempt to provide insight on the status and development of the economy, as well as to show the effects of government policies. As stated earlier, although by now there is more freedom for people to choose among jobs, the job market in China is still not very active to the extent that it will greatly affect household income and in turn affect the consumer goods demand and/or supply at the macroeconomic level. 'Thus, in this study, only the consumer goods market is analyzed. Portes and Santorum (1988) estimated the Chinese consumer goods market from 1954 to 1983 . In addition to extending the data series to 1991 , this study will discuss further the ichanges in the demand and supply relationships brought by the shifts in government policies over the years.

To summarize, the purpose of this research is to:

- Construct and estimate a disequilibrium macroeconometric model for the supply and demand relationships in the consumer goods market. 
- Determine whether the market has ever been in disequilibrium; if so, show whether the market has excess demand or excess supply, or both.

- Test the hypotheses of chronic excess demand and/or chronic excess supply.

- Test the hypothesis of structural change in the demand, supply and transaction functions due to shifts in government policies.

- Apply the locally weighted optimization technique to estimate and test the variation in structure of the demand and supply functions.

Since the Chinese economy underwent major changes over the period of 1954 to 1991, the focus of this study will be on the transition of demand and supply relationships in the Chinese consumer goods market during this period. Such transition will be reflected by the structural changes and parameter variations in the demand and supply functions within a disequilibrium framework. 


\section{CHAPTER II}

\section{LITERATURE REVIEW}

Disequilibrium economics is a branch of economics which studies the phenomenon that price adjustments may not be sufficient to clear the market. Disequilibrium econometrics studies such phenomenon quantitatively. Disequilibrium methodology is frequently applied to centrally planned economies because of the nature of fixed price settings and institutional interferences in their economic activities. This chapter reviews the literature in the related fields.

\section{II.1 DISEQUILIBRIUM ECONOMICS}

According to the traditional General Equilibrium Theory, price can always be adjusted freely to reach market equilibrium state. At the equilibrium state, demand equals supply. If a market has been disturbed from the equilibrium state, it will go to another equilibrium state at a different price level, or come back to restore the original state. Under the equilibrium assumption, price adjustments in markets will always be sufficient to clear markets promptly there is neither unsatisfied demand nor unfulfilled supply.

In the 1930's, Keynes postulated the idea that rigidity of prices results in disequilibrium. The transaction in one market may be affected by the activities 
in the other markets. For instance, a household may decide how many hours to work in the labor market in order to buy a certain quantity of commodities in the goods market. This indirect and unsynchronized trading makes it difficult to have both markets cleared simultaneously. The slow process of price adjustments may create disequilibrium, while the nonexistence of stimuli due to the lack of necessary information may cause firms/households not to change their prices (Drazen, 1980) ${ }^{1}$. Unless there is a perfect match for the trading, buyers and sellers in the markets may have to experience unbalanced demand and supply. Therefore, disequilibrium is more common than equilibrium.

The concept of Walrasian equilibrium is a special case of disequilibrium where there is neither excess demand nor supply in any market. The transition from one state of the market to the Walrasian equilibrium state may not have a direct route, since there are hardly precise adjustments on prices which will cause excess demand or excess supply in a market to disappear completely and simultaneously. More likely, there will be transition from one state to another before the market reaches an equilibrium, if it will ever reach it. If this is the case, then demands and supplies in markets may never be equal. Therefore, the

1. Further discussion on why disequilibrium exists can be found in Quandt and Rosen, 1988; Leijonhufvud, 1981; Drazen, 1980. 
disequilibrium can be a stable equilibrium state of the system as far as motion is concerned (Felderer, 1987; Quandt, 1988)².

When there is disequilibrium in a market, assuming price is rigid, the excess demand or supply can be "eliminated" by quantity adjustments (constraints). The side of the market which has excess quantity is constrained and is called the long side, while the side which does not have excess quantity is called the short side. The "short-side transaction rule" denotes that the actual transaction in a market equals the minimum of demand and supply (Figure 3). That is, the quantity constraints are realized by imposing quantity rationing on the long side of the market. In Figure 3, at price level p1, quantity demanded (D) is smaller than quantity supplied (S). Therefore, $\mathrm{S}$ is the long side.

Indicated by the dark line, the quantity transacted in the market is the short side of the market which is the demand side. In contrast, at price level $\mathrm{p} 2, \mathrm{~S}$ is smaller than D. Thus, demand side is constrained and the transacted quantity equals $\mathrm{S}$ under this scenario.

Disequilibrium economic theory studies this phenomenion to provide a means of predicting regime and trend of an economy. As discussed by Broer and Siebrand (1985), disequilibrium theory offers the theoretical base for the

2. Hence, the usage of "disequilibrium", as pointed out by many authors, is somewhat misleading. Usually the word of "equilibrium" is associated with the state of rest, and disequilibrium is the opposite of this meaning. However, disequilibrium in the current context indicates unbalanced demand and supply in goods and labor markets. Many authors choose to call it "temporary equilibrium", "non-Walrasian equilibrium", or "equilibrium with quantity rationing". For convenience, "disequilibrium" is used in the current context. 


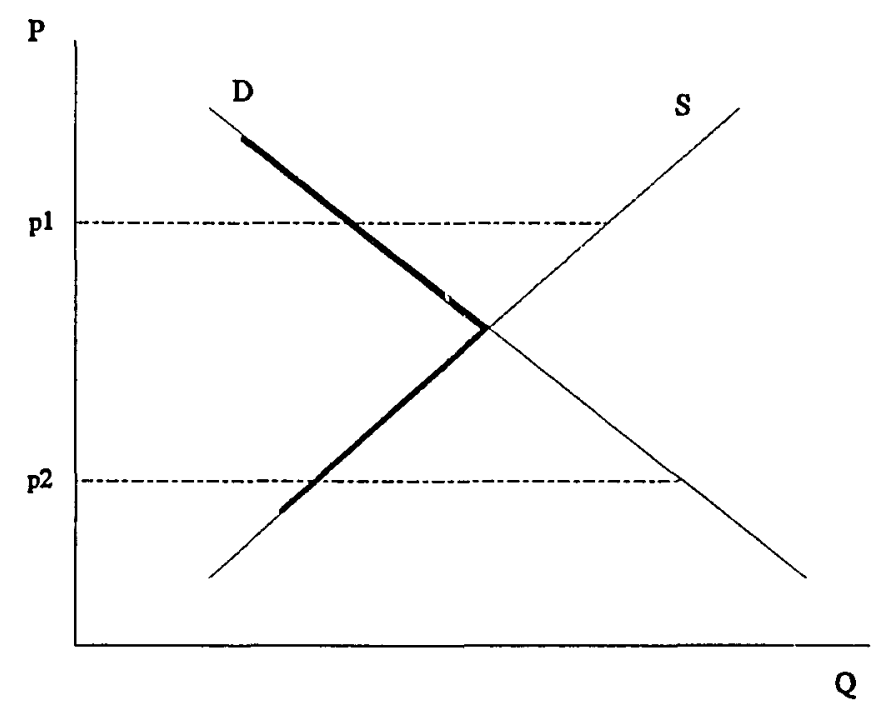

Figure 3. Short-side transaction rule.

differentiation between planned variables and realized variables. Planned variables refer to notional demand and notional supply which are functions of prices solely. Realized variables refer to effective demand and effective supply which are functions not only of prices but also quantity signals — the availability of goods or labor in the markets.

\section{II.2 DISEQUILIBRIUM ECONOMETRICS}

Based on disequilibrium theory, the disequilibrium econometric model is the whole class of models in which some degree of rationing occurs (Quandt, 1988). Disequilibrium analysis operates under the assumption that quantity adjusts faster than prices in a short period to equalize demand and supply. The 
application of the "short-side transaction rule" implies that no one in a market is forced to buy or sell more than wanted, and only one side of the market is rationed, satisfying voluntary and efficiency requirements.

The basic structure of a disequilibrium econometric model in a single market is:

$$
\begin{gathered}
Q^{d}=f_{1}(X 1) ; \\
Q^{s}=f_{2}(X 2) ; \\
Q=\min \left(Q^{d}, Q^{s}\right),
\end{gathered}
$$

with

$\mathrm{Q}^{\mathrm{d}}=$ quantity demanded;

$\mathrm{Q}^{\mathrm{s}}=$ quantity supplied;

$\mathrm{Q}=$ quantity transacted, and

X's are exogenous variables;

f's define functions.

When there is more than one market in the economy, the spill-over factor, the effect of unsatisfied demand or supply in one market on the other markets, must be included. This spill-over effect is, in fact, an important feature in disequilibrium economics. In the above model, where only one market is explicitly described, the spill-over factor from other markets is implicit in the demand and supply functions. That is, the demand and supply are effective functions. When both the labor market and the consumer goods market are considered, there will be spill-over terms from the labor market to the consumer 
goods market, and vice versa. The model, based on Lin (1990), may be outlined as follows:

$$
\begin{gathered}
Q^{d}=g_{11}(X 11)+\text { spill-over induced by unfulfilled labor supply; } \\
Q^{s}=g_{12}(X 12)+\text { spill-over induced by unfulfilled labor demand; } \\
Q Q=\min \left(Q^{d}, Q^{s}\right) \\
L^{d}=g_{21}(X 21)+\text { spill-over induced by unfulfilled goods supply; } \\
L^{s}=g_{22}(X 22)+\text { spill-over induced by unfulfilled goods demand; } \\
L=\min \left(L^{d}, L^{s}\right)
\end{gathered}
$$

where

$\mathrm{Q}^{\mathrm{d}}=$ quantity of goods demanded;

$\mathrm{Q}^{\mathrm{s}}=$ quantity of goods supplied;

$\mathrm{Q}=$ transaction of goods,

$L^{d}=$ quantity of labor demanded;

$\mathrm{L}^{\mathrm{s}}=$ quantity of labor supplied;

$\mathrm{L}=$ transaction of labor, and

X's are exogenous variables explaining the demand and supply relationships in goods and labor markets, respectively. These variables may include inventories, investment, productivity, export and import, other non-household consumptions, savings, etc.;

g's are notional demand and supply functions;

$Q^{d}, Q^{s}, L^{d}$ and $L^{s}$ are effective demands and supplies in goods and labor market because of the inclusion of spill-over factors, and $\mathrm{Q}$ and $\mathrm{L}$ satisfy the short-side rule. 
There could be price and wage rate adjustment equations in the model (Grourieroux, Laffont and Monfort, 1980; Ito, 1980; Quandt and Rosen, 1988), or they may be treated as exogenous variables. The latter has been suggested by many authors to describe the slow process of adjustments, particularly in many centrally planned economies. In fact, for some models a fixed price (or wage rat:e) assumption is not implausible because in reality they may not change in the short term. That is, price can be considered fixed in the short run but variable in a longer time frame.

The disequilibrium status of an economy may be considered at both the microeconomic and macroeconomic levels. When disequilibrium is considered at the microeconomic level, goods and labor are assumed to be heterogeneous throughout all the microeconomic markets. For example, the labor markets of different industries at different geographic locations are treated as different micro-markets. The short-side rule is assumed in each micro-market. A macroeconomic market is the aggregation of those micro-markets in the same category, such as consumption goods or labor. At one time, some micro-markets may be in equilibrium while the others are in disequilibrium, The macro-market consisting of these micro-markets is considered to be in disequilibrium as long as there is one micro-market in disequilibrium. When disequilibrium is discussed at the macroeconomic level, the detailed information in individual micro-markets is lost. With the macro-demand (supply) as simple summations of micro-demands (supplies), the model may show equilibrium at the macro-market while there are 
disequilibria in micro-markets. In such a case, the excess demand in one micromarket is offset by the excess supply in another micro-market within the same macro-market.

Smoothing by aggregation is another approach used to obtain macromarkets from micro-markets beyond simple summation. Using this approach, the aggregated transaction in a macro-market, rather than demand and supply, is the sum of the realized transactions in all the micro-markets. Unless all the micro-markets are in the same status, such aggregated transaction is always smaller than the transaction resulted from simple summation, because in the former only the minimum of demand and supply of each market is considered and incorporated into the aggregated transaction, while the latter includes the demands and supplies in all the micro-markets. Then, in the macro-market the realized transaction is no longer the minimum between demand and supply. It may be smaller than both: the coexistence of excess demand and excess supply. Figure 4 shows the idea of smoothing by aggregation in a macro-market (Lambert, 1988). In Figure 4, (a) and (b) represent two micro-markets with different demand and supply curves. Figure (c) shows the macro-market aggregated from the two micro-markets, (a) and (b). That is, $s$ and $d$ in Figure 4 (c) are the sums of s1 and s2, and d1 and d2 from (a) and (b) at each price level p, respectively. The dark line in Figure 4 (c) is the total transaction quantity of the two micro-markets. Figure 4 (d) demonstrates a smoother transaction curve for the aggregated macro-market when the number of micro-markets is large. 


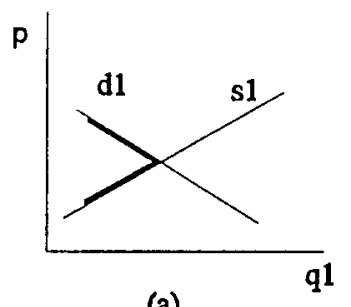

(a)

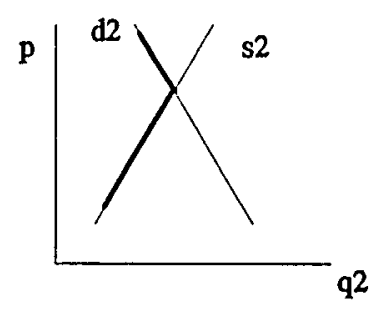

(b)

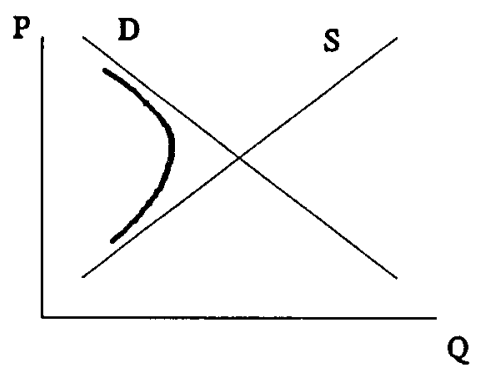

(d)

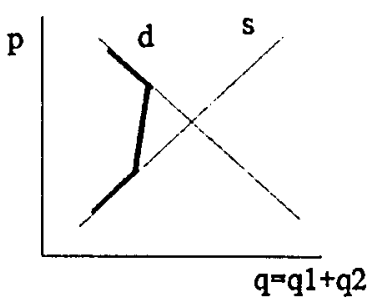

(c)

Figure 4. Smoothing by aggregation.

The choice of either a micro- or macro-economic model in disequilibrium analysis depends upon the focus of the study. If the focus is on how household income and overall price level affect the demand and supply relations in a macro-market, macro-market from aggregation with application of short-side rule at microeconomic level may be more desirable. In such a case, because of the intertwined nature of micro-markets, it is difficult to understand the macromarket through the demand and supply relationships in micro-markets, and policy changes may not be as effective in micro-markets as in macro-markets. As a matter of fact, in most empirical studies, the realized transactions in macromarkets are the aggregated transactions in micro-markets. 
Excess demand (or shortage), and excess supply (or slack), in a market can be described in terms of gross excess, relative excess and net excess. In a consumer goods market with the demand as $Q^{d}$, supply as $Q^{s}$, and realized transaction as $Q$, the unbalanced demand and supply are defined as

$$
\begin{gathered}
\text { gross shortage }=Q^{d}-Q, \\
\text { gross slack }=Q^{s}-Q \\
\text { relative shortage }=\frac{Q^{d}-Q}{Q^{d}}, \\
\text { relative slack }=\frac{Q^{s}-Q}{Q^{s}}, \\
\text { net shortage }=\mathrm{Q}^{\mathrm{d}}-\mathrm{Q}^{\mathrm{s}}, \text { or } \\
\text { net slack }=\mathrm{Q}^{\mathrm{s}}-\mathrm{Q}^{\mathrm{d}} \text {, and } \\
\text { net shortage }=- \text { net slack. }
\end{gathered}
$$

Adding gross shortage and gross slack, the measure of total imbalance is $\left(Q^{d}-Q\right)+\left(Q^{s}-Q\right)$. Using total imbalance, as long as there is shortage and/or slack, the system will show a level of disequilibrium. The shortage and slack are not differentiated. Only net shortage can tell whether there is an imbalance and whether the imbalance is shortage or slack or both. As indicated in Figure 4, aggregation of micro-markets may result in coexistence of shortage and slack in macro-markets. Such coexistence is depicted again in Figure 5.

Applying the terms defined above, Figure 5 shows that at a given price level,

$$
v=\text { gross shortage, }
$$




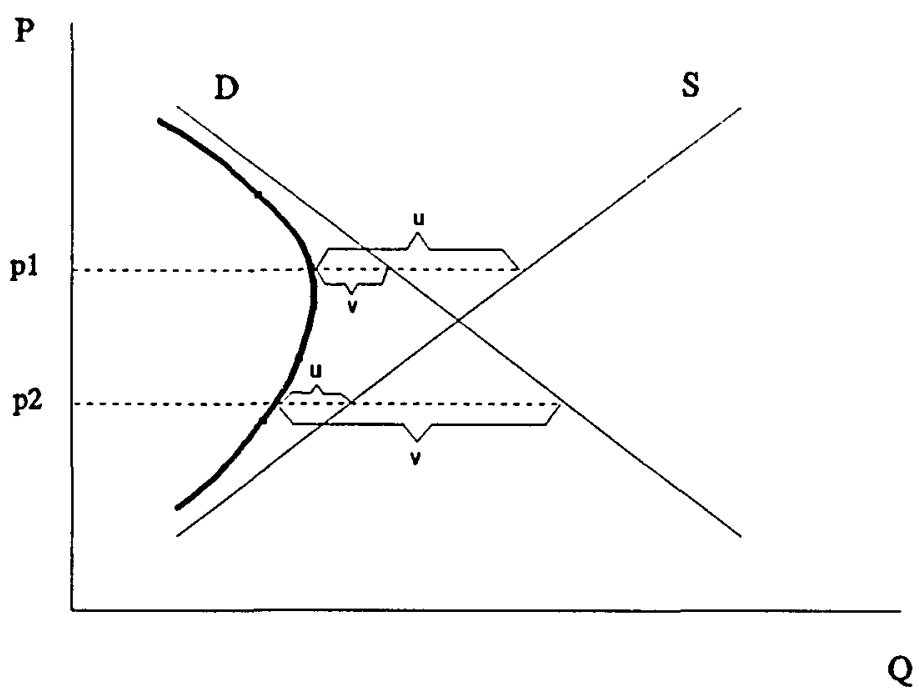

Figure 5. Coexistence of shortage and slack.

$$
\begin{gathered}
\mathrm{u}=\text { gross slack, } \\
\mathrm{v}-\mathrm{u}=\text { net shortage, when } \mathrm{u}<\mathrm{v} \\
\mathrm{u}-\mathrm{v}=\text { net slack, when } \mathrm{u}>\mathrm{v}, \text { and } \\
\mathrm{u}+\mathrm{v}=\text { total imbalance. }
\end{gathered}
$$

At a higher price level, p1, quantity supplied is more than quantity demanded.

There is slack. Because the quantity transacted is smaller than quantity demanded, there is also a shortage at the same time. Since slack is larger than shortage, the net slack in the market is $u-v$. On the other hand, when the price level is lower, at $\mathrm{p} 2$, the amount of shortage is greater than slack. There is a net shortage, v - u.

To estimate the model following the short-side transaction rule, the transaction function may be defined exactly as the minimum of demand and 
supply. However, when shortage and slack coexist due to aggregation of micromarkets, the quantity transacted may be less than the minimum of demand and supply. Assuming coexistence $\mid$ of shortage and slack, Burkett (1988) suggested a simpler representation, which can avoid the estimation difficulties brought by applying the minimum condition. The model assumes a hyperbolic relation between relative slack and relative shortage:

$$
\begin{gathered}
Q^{d}=f_{1}(X 1) \\
Q^{s}=f_{2}(X 2) \\
\left(\left(Q^{d}-Q\right) / Q^{d}\right)\left(\left(Q^{s}-Q\right) / Q^{s}\right)=f_{3}(X 3),
\end{gathered}
$$

with

$$
\begin{aligned}
& Q^{d}=\text { quantity demanded; } \\
& Q^{s}=\text { quantity supplied; } \\
& Q=\text { quantity transacted, } \\
& \left(Q^{d}-Q\right) / Q^{d}=\text { relative shortage; and } \\
& \left(Q^{s}-Q\right) / Q^{s}=\text { relative slack. }
\end{aligned}
$$

f's define functions. X's are lists of exogenous variables. $f_{3}(X 3)$ measures the market friction. X3 may include such variables as mobility of goods and buyers, storage capacity, and flexibility in production and consumption.

Alternative representation of coexistence of shortage and slack is the constant elasticity of substitution (CES) transaction function, as used by several authors in estimating disequilibrium in labor markets (Franz and König, 1990; Lambert, 1990; Schioppa, 1990): 


$$
L=\left[\left(L^{d}\right)^{-\rho}+\left(L^{s}\right)^{-\rho}+\left(L^{c}\right)^{-\rho}\right]^{-1 / \rho}
$$

with

$$
\begin{aligned}
& L^{d}=\text { quantity of labor demanded; } \\
& L^{s}=\text { quantity of labor supplied; } \\
& L^{c}=\text { the capital capacity in employing labor; } \\
& L=\text { transaction of labor, or employment, and } \\
& \rho \text { as a measure of mismatched demand and supply. }
\end{aligned}
$$

$\rho$ is predetermined according to information about the percentage of micromarkets in excess demand or excess supply. Thus, estimation of this CES model requires in-depth research and survey of the micro-markets.

\section{II.3 DISEQUILIBRIUM ANALYSIS FOR CENTRALLY PLANNED ECONOMIES}

As discussed earlier, disequilibrium results from rigid price and/or wage adjustments and imperfect information. In a competitive market economy, even with quantity rationing, price and quantity relations are adjusted by the market force itself. However, only in exceptional cases are markets completely free from government regulations which makes complete free flow of information impossible. Artus et. al. (1984) studied a two-market disequilibrium model of France using quarterly data, besides surveying the earlier quantity rationing models. Based on the above work, Laroque (1985) estimated and compared 
disequilibrium models for France, Germany, the United Kingdom and the United States. The main conclusions made by Laroque included that unemployment was a basic feature in the study period, and there were underconsumption and repressed inflation in the U.S. Lambert (1988) estimated a micro labor market (Belgian manufacturing industry) using business survey data and concluded that overemployment existed, that is, many inefficient workers were employed.

It seems that in centrally planned economies (CPEs), disequilibrium may not be present because there are strong government agencies managed and centralized information processing systems. Yet, this is not true. A great amount of information is needed to make and execute a comprehensive macroeconomic plan. Such information is rarely complete or accurate. Even if planners were able to know the demand and supply within the controlled domain, it could still be impossible to make perfect plans and achieve perfect implementation of them. There remains part of the macroeconomic market not constrained by plans when market adjustment is used one way or another. In fact, in CPEs rigid price settings are more likely to occur because the government agencies plan and control prices of goods and labor, and because it takes time for the market information to flow and feed back into the planning mechanism. Furthermore, as pointed out by Chang (1989), government agencies control all the enterprises in a $\mathrm{CPE}$, and there is no incentive for prices to change due to lack of competition. 
It is commonly argued that conventional macroeconomic analysis used for Western economies are irrelevant to CPEs (Portes, 1981). The IS-LM framework is not applicable since it implicitly assumes equilibrium in markets (Quandt and Rosen, 1988). Neither is the input-output model adequate, although it is frequently used in CPEs.

Controversy still exists regarding whether government policies can influence an economy effectively in Western countries, while it is obvious that government policies can alter the performance of a CPE by means of centrally designed and closely monitored plans. All the sectors, even individual industries and enterprises, of the economy are explicitly interdependent. The failure to fulfill quotas in one area may result in the failure to achieve planned targets in other areas. To avoid unfulfilled plans, government agencies must consider the capacities of enterprises, the relation between intended and actual output of the economy. If the planned target is low, it will be easy to reach but will not utilize available resources at the maximum possible level. On the other hand, a higher target may cause negative impact. Not only may the plans be unfulfilled, but also the actual output may be less than what the capacity allows due to higher possibility of failure of obtaining supplies in complementary input materials (Ickes, 1990). If planners could successfully avoid unwanted over-production, there might be excess demand. Imperfect information may produce excess supply of goods although Portes and Ickes both hinted this does not usually occur (Portes, 1981; Ickes, 1990). 
Differing from Western economies where governments may use fiscal or monetary policies to deal with economic problems, CPEs' governments can change the state of an economy directly through price control and/or quantity rationing. Equilibrating mechanisms are served by: the planning process and planners' response to the existing disequilibrium condition of the economy (Portes, 1981).

Currently, there are mainly two schools of thought concerning disequilibrium in CPEs: the chronic shortage and disequilibrium approaches (van Brabant, 1990). According to the chronic shortage/ approach, stemmed from Kornai's anti-equilibrium theory (1971), in CPEs it is not just demand and supply being out of equilibrium, but there is always repressed inflation (or suppressed inflation, excess demand). Kornai also argues that in CPEs, because of the persistent goods shortage and the existence of "discouraged customers," there are situations where excess demand and excess supply coexist resulting from forced substitution and/or forced savings. When this does/ occur, the realized goods transaction and labor employment are less than both demand and supply. Both sides of the market are rationed. In general, unbalanced demand and supply is an inevitable fact in CPEs. The focus of disequilibrium approach is on aggregated household assets and income, price level, and goods and services provided to the macro-market, instead of relative prices of goods and services in the micro-markets. The disequilibrium approach does not assume any kind of market status. It argues that repressed inflation and other disequilibrium 
phenomena can only be conjectures about the macroeconomic relationships in CPEs which require empirical verifications (Portes, 1980). Based on studies about Eastern European countries in the period of 1954-1975, Portes and his asisociates even pointed out that excess supply was more common than excess demand (see also Burkett, 1988).

There are three main types of decision makers in CPEs' markets: households, enterprises and government agencies. Each can affect the behavior of the markets. Those who use the disequilibrium approach regard the latter two as being similar in terms of meeting the former's needs, so that there are only two decision making siectors: private and state (Portes, 1981; Charemza, and Gronicki, 1988). Demand and supply relationships are determined by the behaviors of these two sectors. Government agencies control the majority of the production and pricing activities with limited information about demand and supply of the entire economy. Such exercise has rendered sufficient conditions for disequilibrium to exist in the economy. On the other hand, the shortage advocates believe in that the interactions among enterprises and with government agencies make households suffer from shortage (van Brabant, 1990). In his dissertation, Chang (1989) discussed extensively government behavior under various planning regimes in CPEs which lead to disequilibrium.

Figure 6 shows the short-side transaction rule as applied to CPEs (Portes, 1980). In CPEs, price is not a determinant factor in the demand and supply equations. Demand is a function of income (Y) while supply is mainly 


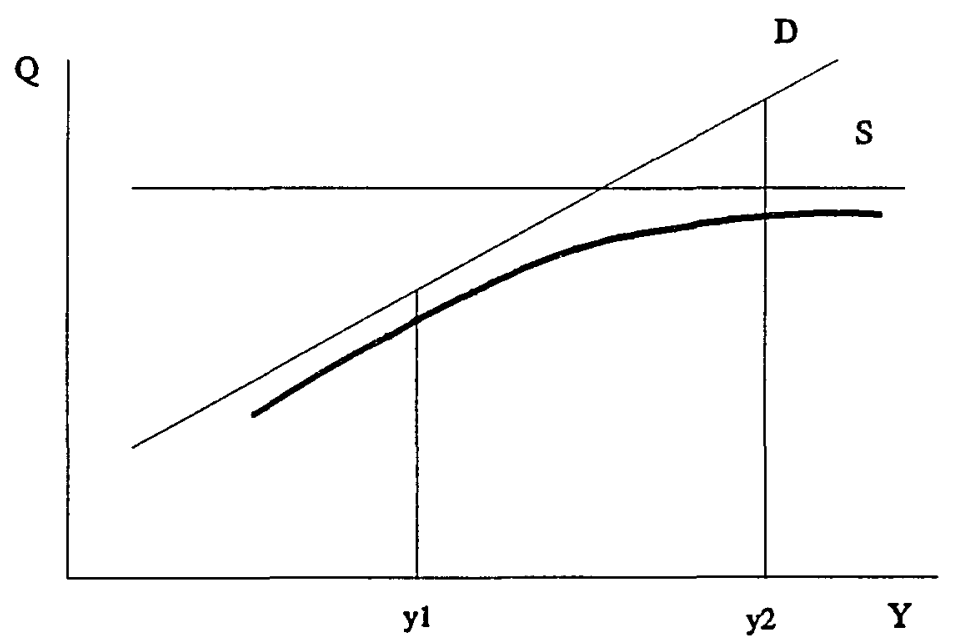

Figure 6. Short-side transaction rule in CPEs.

determined by plans and not related to income directly. In particular, demand increases with respect to income while supply remains at a fixed level. The dark curve beneath demand and supply is the quantity transacted in accordance with the short-side transaction rule. That is, at a given income level, the quantity realized in the market is the smaller between demanded and supplied.

\section{II.4 APPLICATION OF DISEQUILIBRIUM ECONOMETRICS IN CPES}

Portes and Winter (1980) proposed an econometric model of consumer goods market in CPEs. The variables and functional structure of the model are as follows:

$$
D=\alpha_{1} S A V 1+\alpha_{2} D Y D+\alpha_{3} Y D 1
$$




$$
\begin{gathered}
S=\aleph_{1} C T+\beta_{2} N M P X+\beta_{3} M X+\beta_{4} C Z X \\
C \leq \min (D, S)
\end{gathered}
$$

where

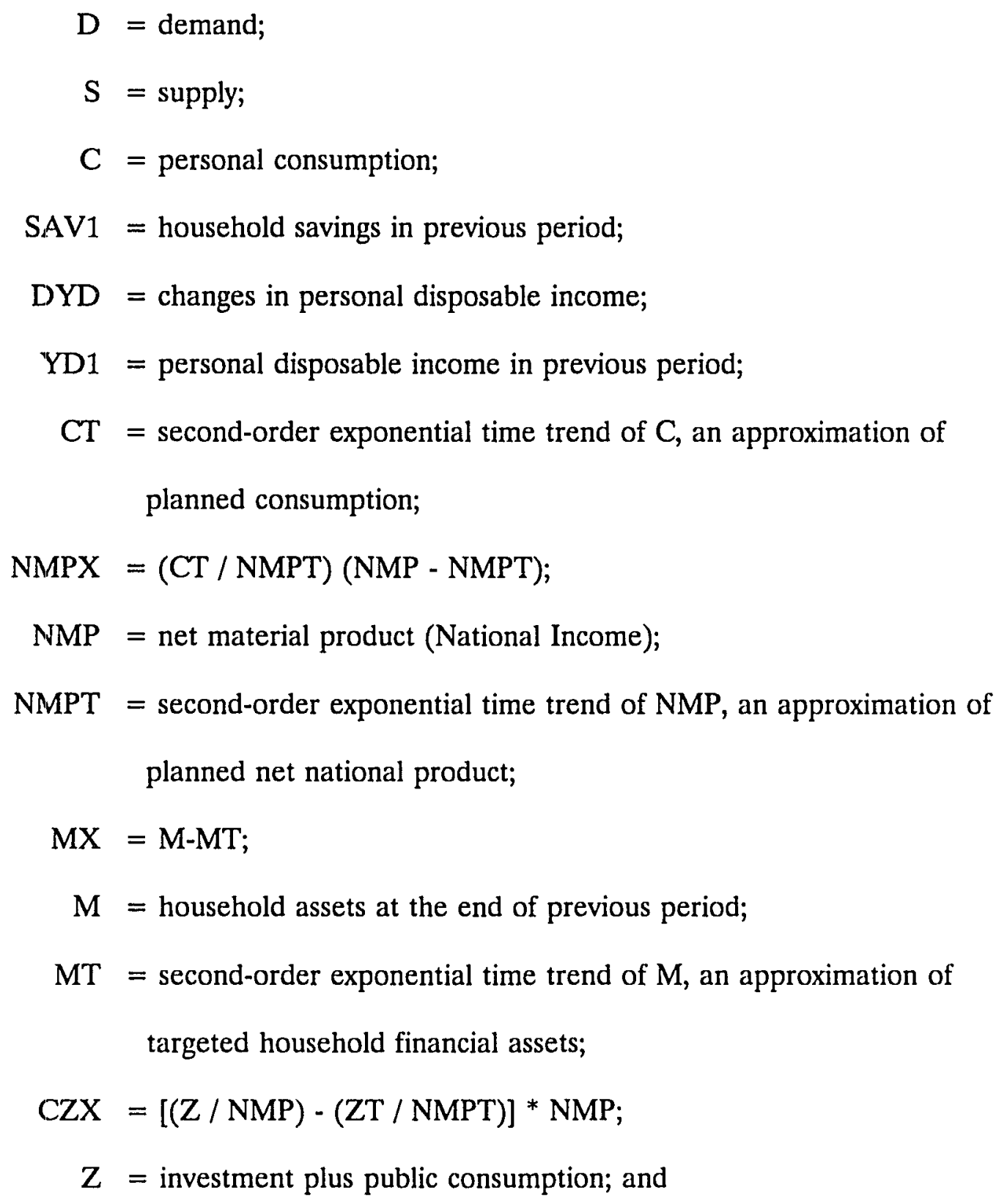


$\mathrm{ZT}=$ second-order exponential time trend of $\mathrm{Z}$, an approximation of planned investment and public consumption.

$\alpha$ 's are the coefficients of the demand equation, and B's are the coefficients of the supply equation.

Prices of goods are assumed not to vary, at least not significantly, to alter the quantities of demand and supply. Thus, the model does not have a price equation, reflecting the fixed-price characteristic of a typical CPE.

The demand function is derived from Houthakker-Taylor savings function for househplds. Since the labor market is not considered to be very active and CPEs in general have excess labor supply (or overemployment), households' disposable income is taken as an exogenous variable reflecting the spill-over factor from the labor market.

The supply function represents the results of the production plans which are made by central planners and executed by enterprises. It is composed of variables representing long-run plans and short-run adjustments to plans (Ports and Winter, 1977). The long-run plans are the time trends, which may not be the annual plans but the actual realization of plans and allocation of consumption goods. The short-run adjustments are the derivatives taken with respect to their long-run ratios. The variable $C T$ indicates that the planned production of consumer goods should follow the historical trend of goods consumption. NMPX is used to approximate the change in the share of personal consumption in national income. CZX is used to demonstrate that public 
spending is in competition with the production of consumer goods. There may be a spill-over factor for the goods supplier from the labor market, planners and enterprises in this case, even though the wage rates are essentially fixed. MX is used as the information available to the planners on excess demand. Therefore, although only one market is explicitly described here, the above model is in fact a two-market disequilibrium model with an exogenous labor market.

Neither demand nor supply functions has constant terms. The ranges of coefficients in demand function are derived from the restrictions in the Houthakker-Taylor savings function: $-1<\alpha_{1}<-1 / 3,0<\alpha_{2}<1$, and $\alpha_{3}=1$. The structure of the supply function suggests that $B_{i}>0(i=1,2$ and 3$)$, and $B_{4}<0$ (Portes and Winter, 1980). When $\aleph_{2}$ equals 1 , personal consumption is said to take the same share from the changes in the national income. When it is greater than 1 , personal consumption acts as the "buffer" of all the economic shocks other components in the national income take precedence over personal consumption.

The Chinese economy is a centrally planned economy. Disequilibrium methodology has been applied to examine the state of its markets. Portes and Santorum (1987) studied the consumer goods market between 1954 and 1983. Lin (1990) attempted to construct and estimate a two-market model of the period from 1959 to 1989 by adding labor market to the above defined consumer goods market. 
It may be safe to say that at present there is no pure centrally planned economy in existence. All the previous CPEs are in transition of one / form or another. Therefore, it is important to identify in what routes an economy has progressed. With the assumption that CPEs may have been in disequilibrium, the traditional structural change analysis in one way will be useful to study the changes in predefined demand and supply functions. Moreover, locally weighted optimization makes it possible to study the transition of the demand and supply relationship. 


\section{CHAPTER III}

\section{MODEL SPECIFICATIONS}

Based on the general model specified in the previous chapter, this chapter further defines the specific model used in this research of the consumer goods market in China. After identifying the hypotheses to be tested, the current chapter proceeds to demonstrate the quantitative tools used in the model estimation.

\section{III.1 A MODEL OF THE CHINESE CONSUMPTION GOODS MARKET}

As discussed in Chapter II, the two schools of thought in studying disequilibrium are the chronic shortage and disequilibrium approaches. One of the major differences between the two is that the former emphasizes the individual micro-markets in an economy, while the latter concentrates on the macroeconomic relationships between demand and supply. In the present study, since the macroeconomic status of the consumer goods market is the focus, and the data on comprehensive micro-markets are difficult, if not impossible, to obtain, the disequilibrium approach is used. 
The Portes and Winter model on CPEs (1980) was used in many studies to estimate several Eastern European economies. With slight modifications it is taken up in this research.

The demand, supply and transaction functions used in this study are:

$$
\begin{gathered}
D=\alpha_{1} S A V 1+\alpha_{2} D Y D+\alpha_{3} Y D 1 ; \\
S=B_{1} C T+B_{2} N M P X+\beta_{3} C Z X ; \\
C \leq \min (D, S),
\end{gathered}
$$

where, as defined by Portes and Winter,

$\mathrm{D}$ = demand;

S = supply;

$\mathrm{C}=$ personal consumption;

SAV1 = household savings in previous period;

DYD = changes in personal disposable income;

YD1 = personal disposable income in previous period;

$\mathrm{CT}=$ second-order exponential time trend of $\mathrm{C}$, an approximation of planned consumption;

$\mathrm{NMPX}=(\mathrm{CT} / \mathrm{NMPT})(\mathrm{NMP}-\mathrm{NMPT}) ;$

NMP = net material product (National Income);

NMPT = second-order exponential time trend of NMP, an approximation of planned net material product;

$\mathrm{CZX}=[(\mathrm{Z} / \mathrm{NMP})-(\mathrm{ZT} / \mathrm{NMPT})]$ * NMP;

$\mathrm{Z}$ = investment plus public consumption; and 
$\mathrm{ZT}=$ second-order exponential time trend of $Z$, an approximation of planned investment and public consumption.

$\alpha$ 's are the coefficients of demand equation, and $B^{\prime}$ 's are the coefficients of supply equation.

Variable NMPX approximates the adjustment made by the planners on the departure of the actual output of the economy and personal consumption from the planned targets, which are assumed to follow their historical trends. The same is true for variable CZX which approximates the adjustment in investment (fixed assets and working capital) and public spending. Portes and Winter used MX, which approximates the deviation of actual household assets from its targeted value, to represent the information on excess demand which is to be reflected in the plans. Portes and Santorum also used this variable in their model for the Chinese consumer goods market. However, it is not included here due to difficulties in estimation brought by longer and revised time series. The ill behavior of this variable in the current model may signify that it is not suitable as such an indicator, or that it is not used in the planning for the Chinese consumer goods market.

The implicit restrictions on the coefficients of demand and supply equations are:

$$
-1<\alpha_{1}<-1 / 3,0<\alpha_{2}<1, \alpha_{3}=1, B_{1}>0, B_{2}>0 \text {, and } B_{3}<0 \text {. }
$$




\section{III.2 HYPOTHESIS}

\section{$\underline{\text { Chronic Shortage }}$}

It is suggested that due to rigid prices, CPEs suffer from chronic shortage of consumer goods, which leads to forced savings and substitution. Portes et. al. have argued that this may not be true. The study by Portes $\mid$ and Winter on several Eastern European countries (1980) showed that there were shortages in the consumer goods markets in some periods of time, but that the shortages were not persistent. This study intends to test such a hypothesis in the Chin consumer goods market.

\section{$\underline{\text { Structural Change }}$}

In previous researches, the disequilibrium models for CPEs have been estimated for a single time span. As with other econometric models, structural changes are possible for the long time series of the Chinese economy since its founding. In addition, the economic policies in CPEs tend to follow closely the political changes in the country, which may consequently shift the demand and supply relationships. Possibly, the most significant change in China is the economic reform began in late 1979 . The economy gradually changed from a totally centralized system to a more open and more competitive market type. Enterprises now have more control over what and how much they produce. But there are still plans and government controls. Thus, it is reaisonable to argue that there may have been a structural change in the demand and supply 
relationships in such a CPE. In this study, the disequilibrium models with structural change will be constructed, estimated and tested. The change in the functional forms of demand and supply is later contemplated to determine if the Chinese consumer goods market can still fit the Portes-Winter model after the economic reform.

\section{$\underline{\text { Rigid Price }}$}

The changes in price indexes will be compared with the pattern of disequilibrium, that is, the pattern of excess demand. It is suggested that, during the period of tight government control, prices did not vary significantly to regulate the demand and supply in the market, while after the reform the consumer goods market has been open. Hence, the prices began to fluctuate.

\section{Influential Variables in Government Plans}

According to the specification, the supply function is an approximation of the government's plans. This study intends to show that the responses of those variables are different before and after 1980 due to the policy changes of government control over the activities of households and enterprises.

\section{III.3 DISEQUILIBRIUM ECONOMETRIC MODELS}

Maximum likelihood is an efficient technique of estimating parameters in a model. In short, if all the observations of the dependent variable are drawn 
independently, the maximum likelihood technique maximizes the probability of all the observations being present in the same population. For a single dependent variable, the function to be maximized is

$$
l=\prod_{i=1}^{N} p\left(Y_{i}\right)
$$

which is called the likelihood function, with $\mathrm{Y}_{\mathrm{i}}=$ dependent variable, $\mathrm{p}\left(\mathrm{Y}_{\mathrm{i}}\right)=$ probability density or likelihood of $\mathrm{Y}_{\mathrm{i}}$ being present, and $\mathrm{N}=$ number of observations. Commonly, the logarithm of the likelihood function, or

$$
l l=\log l=\sum_{i=1}^{N} \log p\left(Y_{i}\right)
$$

is used in the estimation. When there is more than one dependent variable, $p\left(Y_{i}\right)$ will be replaced with the joint probability density of the dependent variables.

Two specifications commonly used to estimate disequilibrium models are characterized by the forms of the transaction function: the discrete-switching transaction function and the hyperbolic transaction function.

\section{Discrete-Switching Transaction Function}

When using the discrete-switching method, the market is assumed to have either excess demand or excess supply. The transaction function is a minimum condition as displayed in Figure 7. That is, the disequilibrium econometric model for CPEs is

Demand:

$$
D=f_{1}(X 1)+\epsilon_{1}
$$




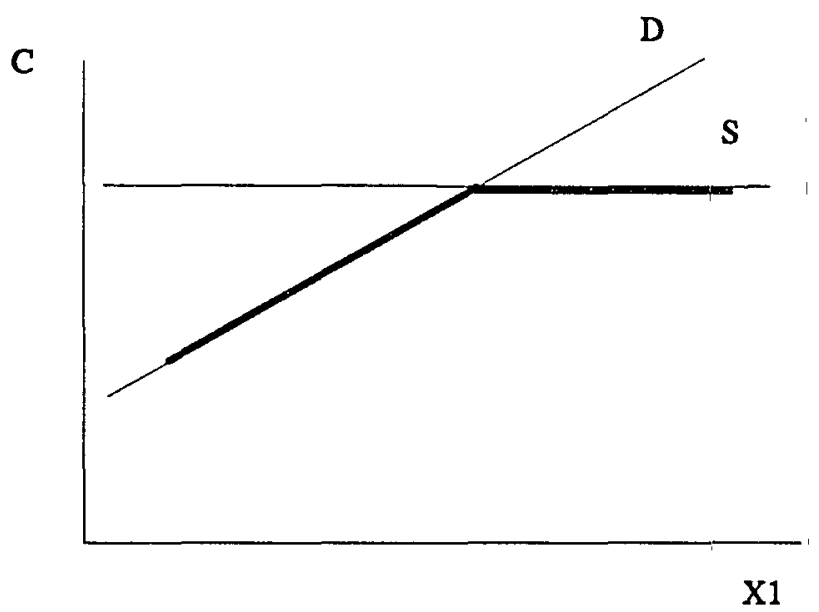

Figure 7. Graphical representation of the discrete-switching transaction function.

Supply:

$$
S=f_{2}(X 2)+\epsilon_{2} \text {, and }
$$

Transaction:

$$
C=\min (D, S) \text {. }
$$

The error terms, $\epsilon_{1}$ and $\epsilon_{2}$, are assumed to be independently normally distributed with zero mean and variance-covariance matrix of

$$
\Sigma=\left[\begin{array}{cc}
\sigma_{1}^{2} & 0 \\
0 & \sigma_{2}^{2}
\end{array}\right] .
$$

The joint probability density function $\mathrm{g}$ for each observation is

$$
g\left(\epsilon_{1}, \epsilon_{2}\right)=\frac{1}{(2 \pi)(\operatorname{det} \Sigma)^{1 / 2}} \exp \left[-\frac{1}{2}\left(\epsilon_{1} \epsilon_{2}\right) \Sigma^{-1}\left({ }_{\epsilon_{2}}^{\epsilon_{1}}\right)\right]
$$


Thus the joint probability density function $h(D, S)$ of the dependent variables, $\mathrm{D}$ and $\mathrm{S}$, which are also unobservable, is

$$
h(D, S)=\frac{1}{(2 \pi)(\operatorname{det} \Sigma)^{1 / 2}}|\operatorname{det} J| \exp \left[-\frac{1}{2}\left(\epsilon_{1} \epsilon_{2}\right) \Sigma^{-1}\left(_{\epsilon_{2}}^{\epsilon_{1}}\right)\right]
$$

with $\mathrm{J}$ as the Jacobian matrix of the transformation from error terms to endogenous variables, which is equal to

$$
J=\left[\begin{array}{ll}
\frac{\partial \epsilon_{1}}{\partial D} & \frac{\partial \epsilon_{1}}{\partial S} \\
\frac{\partial \epsilon_{2}}{\partial D} & \frac{\partial \epsilon_{2}}{\partial S}
\end{array}\right]
$$

In the above single market model, the determinant of $\mathrm{J}$ is equal to 1 . Therefore,

$$
h(D, S)=\frac{1}{(2 \pi)(\operatorname{det} \Sigma)^{1 / 2}} \exp \left[-\frac{1}{2}\left(\epsilon_{1} \epsilon_{2}\right) \Sigma^{-1}\left(\begin{array}{c}
\epsilon_{1} \\
\epsilon_{2}
\end{array}\right)\right]
$$

Since $C=\min (D, S)$, the probability density function $H(C)$ of the observable endogenous variable $\mathrm{C}$ for each observation is obtained by integrating out the unobservable $\mathrm{D}$ and $\mathrm{S}$ on each side of the market:

$$
H(C)=\int_{C}^{\infty} h(C, S) d S+\int_{C}^{\infty} h(D, C) d D
$$

The first term is the probability density of the marketing being on the demand side or $\mathrm{C}=\mathrm{D}$, while the second is that of the marketing being on the supply side or $\mathrm{C}=\mathrm{S}$.

The log-likelihood function of this model over the sample period is then

$$
l l=\sum_{i=1}^{N} \log H\left(C_{i}\right)=\sum_{i=1}^{N} \log \left[\int_{C_{i}}^{\infty} h\left(C_{i}, S_{i}\right) d S_{i}+\int_{C_{i}}^{\infty} h\left(D_{i}, C_{i}\right) d D_{i}\right]
$$


To expand the joint normal probability density function $h\left(D_{i}, S_{i}\right)$, and applying the assumption that $\epsilon_{1}$ and $\epsilon_{2}$ are independently distributed, that is,

$$
h(D, S)=h_{1}(D) * h_{2}(S)
$$

the log-likelihood function can be rewritten as

$$
l l=\sum_{i=1}^{N} \log \left[h_{1}\left(C_{i}\right) \int_{c_{i}}^{\infty} h_{2}\left(S_{i}\right) d S_{i}+h_{2}\left(C_{i}\right) \int_{c_{i}}^{\infty} h_{1}\left(D_{i}\right) d D_{i}\right]
$$

where $h_{1}$ and $h_{2}$ are the marginal probability density functions of D and $S$ respectively, and are defined as

$$
\begin{aligned}
& h_{1}\left(D_{i}\right)=\frac{1}{\sqrt{2 \pi \sigma_{1}^{2}}} \exp \left(-\frac{\epsilon_{1 i}^{2}}{2 \sigma_{1}^{2}}\right)=\frac{1}{\sqrt{2 \pi \sigma_{1}^{2}}} \exp \left(-\frac{\left[D_{i}-f_{1}\left(X 1_{i}\right)\right]^{2}}{2 \sigma_{1}^{2}}\right), \\
& h_{2}\left(S_{i}\right)=\frac{1}{\sqrt{2 \pi \sigma_{2}^{2}}} \exp \left(-\frac{\epsilon_{2 i}^{2}}{2 \sigma_{2}^{2}}\right)=\frac{1}{\sqrt{2 \pi \sigma_{2}^{2}}} \exp \left(-\frac{\left[S_{i}-f_{2}\left(X 2_{i}\right)\right]^{2}}{2 \sigma_{2}^{2}}\right) .
\end{aligned}
$$

\section{Hyperbolic Transaction Function}

Burkett (1988) introduced the concepts of relative excess demand and relative excess supply to incorporate the possibility of the coexistence of shortage and slack in a market. Relative shortage and relative slack are said to follow the following hyperbolic relationship:

$$
\frac{(D-C)}{D} \frac{(S-C)}{S}=\gamma^{2} .
$$


When $\gamma=0$, shortage and slack do not coexist; otherwise they do. That is, when $\gamma$ equals zero, the distance between the dark curve and the lines in Figure 8 reduces to zero, and the model is the same as in the discrete-switching case. $\gamma$ can be considered to be the measure of that distance, the measure of "market friction".

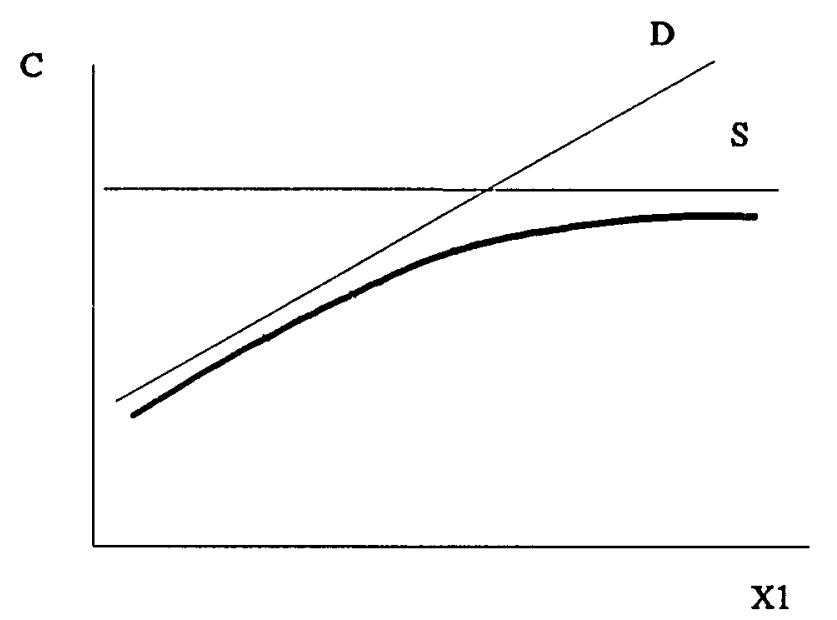

Figure 8. Graphical representation of the hyperbolic transaction function.

To satisfy the constraint that $\mathrm{C} \leq \min (\mathrm{D}, \mathrm{S})$, neither relative excess demand $(D-C)$, nor relative excess supply $(S-C)$ can be negative. While in the iterative process of parametric estimation, negative values may appear. Therefore, $\gamma^{2}$ instead of $\gamma$ is used to ensure a positive value.

Solving for $\mathrm{C}$ from the hyperbolic transaction function with the consideration of $\mathrm{C} \leq \min (\mathrm{D}, \mathrm{S})$ yields

$$
C=\frac{1}{2}(D+S)-\frac{1}{2} \sqrt{(D-S)^{2}+4 \gamma^{2} D S}
$$


The econometric model of this system thus is:

Demand:

$$
D=f_{1}(X 1)
$$

Supply:

$$
S=f_{2}(X 2) \text {, and }
$$

Transaction:

$$
C=\frac{1}{2}(D+S)-\frac{1}{2} \sqrt{(D-S)^{2}+4 \gamma^{2} D S}+\epsilon .
$$

$\epsilon$ is the added error term, assuming to be independently normally distributed with zero mean and constant variance.

The probability density function of $\mathrm{C}$ for a single observation is simply

$$
H(C)=\frac{1}{\sqrt{2 \pi \sigma^{2}}} \exp \left[-\frac{\epsilon^{2}}{2 \sigma^{2}}\right]
$$

The log-likelihood function over the sample-period is then

$$
l l=\sum_{i=1}^{N} \log H\left(C_{i}\right)=-\frac{N}{2} \log (2 \pi)-\frac{N}{2} \log \sigma^{2}-\frac{1}{2 \sigma^{2}} \sum_{i=1}^{N} \epsilon_{i}^{2},
$$

where

$$
\epsilon_{i}=C_{i}-\left[\frac{1}{2}\left(D_{i}+S_{i}\right)-\frac{1}{2} \sqrt{\left(D_{i}-S_{i}\right)^{2}+4 \gamma^{2} D_{i} S_{i}}\right] .
$$

Utilizing the feature that the maximum likelihood estimator of variance is

$$
\sigma^{2}=\frac{1}{N} \sum_{i=1}^{N} \epsilon_{i}^{2}
$$

a concentrated log-likelihood function (Greene, 1990) is used in the estimation of this study: 


$$
l l=\sum_{i=1}^{N} \log H\left(C_{i}\right)=-\frac{N}{2}[1+\log (2 \pi)]-\frac{N}{2} \log \left(\frac{1}{N} \sum_{i=1}^{N} \epsilon_{i}^{2}\right) .
$$

\section{III.4 LOCALLY WEIGHTED OPTIMIZATION}

Recently, locally weighted optimization has become a popular technique in data exploration and diagnoses (Cleveland, et. al., 1988; Härdle, 1990). The technique works like a weighted moving average process in estimating the expected value of a dependent variable. The model estimation is centered at each observation with regard to its surrounding neighborhood. Such a neighborhood may simply be the $\mathrm{K}$ closest chronological neighbors in a time series, or the observations whose explanatory variables' values are close to the values of the one under consideration. Using locally weighted optimization, there is no presumption about whether the regression relationship will fit a specific form of function. Instead, the functional form may vary along the focal observation and its neighbors, and the optimization will search for the best fit in the neighborhood without prior assumption of the functional form. Thus, locally weighted optimization is also regarded as a non-parametric optimization method.

\section{Local Fitting and Approximation}

In the non-parametric estimation, the interest is on estimating $E(Y \mid X)$, the expected value of dependent variable $\mathrm{Y}$ given a set of explanatory variables X. The regression relationship between the dependent variable and explanatory 
variables may be complex and highly non-linear. The function representing such a relationship can be estimated through a polynomial approximation, which can be a constant, linear, quadratic, or higher-order fitting. The popular NadarayaWatson constant fitting method has been studied extensively in econometrics (Härdle, 1990, Ullah 1988a, 1988b). Linear and quadratic local regression were introduced by Stone (1977) and recently formalized by Cleveland $(1979,1988)$ and Fan (1992a). When constant fitting is adopted, the dependent variable is approximated by the weighted mean of its value in the neighborhood. The result of such a constant fitting, particularly at the boundary, may be distorted because of the embedded trend in the dependent variable. Using linear fitting, in addition to fitting the mean, the derivatives of the function are estimated. That is, in addition to having better boundary estimation, the estimation will identify the responses of the dependent variable with respect to the explanatory variables which are the first-order derivatives of the approximation. Higher order derivatives may be estimated as well when the boundary effects of response coefficients are of concern.

If $\mathrm{N}$ observations are used to fit a function of $\mathrm{P}$ explanatory variables, $\mathrm{X}$ :

$$
Y \approx E(Y \mid X)=f(X),
$$

its first-order polynomial (linear) approximation at $\mathrm{X}=\mathrm{X}_{\mathrm{i}}$ is the following:

$$
\begin{aligned}
Y & \approx f\left(X_{i}\right)+f^{\prime}\left(X_{i}\right)\left(X-X_{i}\right) \\
& =A_{1}+\alpha_{i}\left(X-X_{i}\right),
\end{aligned}
$$


where $\mathrm{f}$ represents the unknown functional relationship between $\mathrm{Y}$ and $\mathrm{X}$.

Given a sample size $\mathrm{N}, \mathrm{Y}$ is an $\mathrm{N}$ by 1 vector of dependent variable; $\mathrm{X}$ is a $\mathrm{N}$ by $P$ matrix of explanatory variables; $X_{i}$ is a 1 by $P$ vector of explanatory variables at observation $i$, which is the reference or focal observation used in the local fitting of $Y$. And, clearly, $A_{i}$ is the estimator of $Y$ given $X=X_{i}$. Furthermore, $\alpha_{\mathrm{i}}$ is the first derivative, or the slope, of $\mathrm{f}$ evaluated at $\mathrm{X}_{\mathrm{i}}$. Since the approximation is observation-based, the values of $A_{i}$ and $\alpha_{i}$ may be different from observation to observation.

Another important component in a locally weighted optimization process is the weight applied to a neighborhood of observations. There are extensive discussions on the types of weights used in the local fitting with the consideration of smoothness (Hastie and Loader, 1993; Härdle, 1990; Cleveland, Delvlin and Grosse, 1988). The frequently used ones include Normal kernel weight and $\mathrm{K}$ Nearest Neighbor kernel weight.

\section{Normal Kernel Weight}

The multivariate Normal kernel weight in a local fitting around the neighborhood of observation $i, n w_{i}$, is a vector of size $N$ by 1 :

$$
n w_{i}=\exp \left[-\frac{1}{2} \sum_{k=1}^{P}\left(\frac{X_{k}-X_{i k}}{d_{k}}\right)^{2}\right]
$$

where $X_{k}$ is the kth column of the $N$ by $P$ matrix of the explanatory variables $X$, and $X_{i k}$ is the kth explanatory variable of $X$ at focal observation $i$. The data- 
based window size or bandwidth $\mathrm{d}$, which is assumed to be the same for the entire sample, is defined as a vector of size 1 by $P$. Its kth element is

$$
d_{k}=N^{-\frac{1}{2 r+P}} \sqrt{\frac{1}{N} \sum_{j=1}^{N}\left(X_{j k}-\bar{X}_{k}\right)^{2}},
$$

where $\bar{X}$ is a vector of sample means of explanatory variables of size 1 by $\mathrm{P}$, and $\bar{X}_{k}$ is the kth element of $\bar{X}$. N and $\mathrm{P}$ are the number of observations in the sample and number of explanatory variables in the model, respectively. $r$ is a scaler from 0 to infinity, and together with $\mathrm{N}$ and $\mathrm{P}$ it controls the window size which determines the closeness of observations and number of neighbors to be included. That is, the weights applied to the observations in a local fitting depend on the difference in explanatory variables' values from the focal observation $\mathrm{i}$. The ith element in $\mathrm{nw}_{\mathrm{i}}$, which is the weight for the focal observation, has a value of 1 since the corresponding exponent in vector $n w_{i}$ is 0 . Vinod and Ullah (1988) cited the properties of the above defined normal kernel weights to include asymptotic normality, convergence, and mean-squared error reduction. As $\mathrm{r}$ approaches infinity, $\mathrm{d}$ is exactly a vector of one asymptotic standard error of the explanatory variables with its kth element as:

$$
d_{k}=\sqrt{\frac{1}{N} \sum_{j=1}^{N}\left(X_{j k}-\bar{X}_{k}\right)^{2}},
$$

and the local neighborhood will include the maximum possible number of observations of one standard error of each explanatory variable. 


\section{$\underline{\text { K Nearest Neighbor Kernel Weight }}$}

In the definition of $\mathrm{K}$ Nearest Neighbor kernel weight, the number of neighbors to be included is determined by $\mathrm{K}=\mathrm{r} * \mathrm{~N}$, with $\mathrm{N}$ being the number of observations in the sample and $\mathrm{r}$ a fraction scaler between 0 and 1 . In their discussion on regression by local fitting, Cleveland et. al. (1988) defined the $\mathrm{K}$ Nearest Neighbor kernel weight for observations in the local fitting of observation $\mathrm{i}, \mathrm{kw}_{\mathrm{i}}$, to be

$$
\mathrm{kw}_{\mathrm{i}}= \begin{cases}{\left[\left[1-\left(\frac{d_{i}}{d \max }\right)_{i}^{3}\right]^{3}\right]} & \text { when } \frac{d_{i}}{d \max } \leq 1, \\ 0 & \text { otherwise. }\end{cases}
$$

$\mathrm{kw}_{\mathrm{i}}$ and $\mathrm{d}_{\mathrm{i}}$ are both vectors of size $\mathrm{N}$ by 1 . dmax $\mathrm{dis}_{\mathrm{i}}$ the maximal element in $\mathrm{d}_{\mathrm{i}}$. Window bandwidth $d_{i}$ is the Euclidean distance between explanatory variables of neighboring observations and that of the focal observation, $\mathrm{X}_{\mathrm{i}}$ :

$$
d_{i}=\left[\sqrt{\sum_{k=1}^{P}\left(X_{k}-X_{i k}\right)^{2}}\right] .
$$

The same as defined in $\mathrm{nw}_{\mathrm{i}}, \mathrm{X}$ is a matrix of size $\mathrm{N}$ by $\mathrm{P}, \mathrm{X}_{\mathrm{k}}$ is the kth explanatory variable of $\mathrm{X}$, and $\mathrm{X}_{\mathrm{ik}}$ is the kth explanatory variable of $\mathrm{X}$ at focal observation i. The observations not included in the neighborhood have zerovalued weights, and the ith element of $d_{i}$ equals 0 by definition. According to Cleveland et. al., the choice of tricube form is based on its properties including that by which it enhances distributional approximations and has a smooth contact 
with zero at dmax $_{\mathrm{i}}$. Further discussions on $\mathrm{K}$ Nearest Neighbor kernel weights can be found in Hastie and Tibshirani (1990) ${ }^{1}$.

\section{Locally Weighted Disequilibrium Model}

Adding a classical error term to the linear approximation of a general function $Y=f(X)$ at $X=X_{i}$, the non-parametric model

$$
Y=A_{i}+\alpha_{i}\left(X-X_{i}\right)+\epsilon
$$

can be estimated using the previously mentioned maximum likelihood technique with the neighboring data of $\mathrm{X}$ and $\mathrm{Y}$ for each focal observation. The neighborhood of each observation $i$ is reflected by the weight assigned to each observation, which have values between 0 and 1 .

During the optimization process, the error term is calculated as

$$
\epsilon=Y-\left[A_{i}-\alpha_{i}\left(X-X_{i}\right)\right]
$$

1. The tricube kernel can be written as

$\mathrm{kw}_{\mathrm{i}}= \begin{cases}\left(1-\mathrm{u}_{\mathrm{i}}^{3}\right)^{3} & \text { for }\left|\mathrm{u}_{\mathrm{i}}\right| \leq 1, \\ 0 & \text { otherwise, }\end{cases}$

where $0 \leq \mathrm{u}_{\mathrm{i}} \leq 1$, and $\mathrm{i}=1,2, \ldots, \mathrm{N}$.

Other popular forms used in defining the $\mathrm{K}$ Nearest Neighbor kernel weights are Epanechnikov kernel:

$$
\mathrm{kw}_{\mathrm{i}}= \begin{cases}3 / 4\left(1-\mathrm{u}_{\mathrm{i}}^{2}\right) & \text { for }\left|\mathrm{u}_{\mathrm{i}}\right| \leq 1, \\ 0 & \text { otherwise, }\end{cases}
$$

which minimize (asymptotic) mean squared error, and the minimum variance kernel:

$\mathrm{kw}_{\mathrm{i}}= \begin{cases}3 / 8\left(3-5 \mathrm{u}_{\mathrm{i}}{ }^{2}\right) & \text { for }\left|\mathrm{u}_{\mathrm{i}}\right| \leq 1, \\ 0 & \text { otherwise, }\end{cases}$ which minimizes asymptotic variance of the estimate. 
and weights are attached to the error terms in the likelihood functions to reflect the different emphases on the observations. For each local optimization, the error of focal observation $i$ has the full weight of 1 , while others are discounted depending on how far away the observations are from the one under consideration. For the disequilibrium model with different transaction functions described in Section III.3, the kernel weights of observations are incorporated in the likelihood functions.

In a model with the discrete-switching transaction function,

$$
\begin{aligned}
& \epsilon_{1}=D-f_{1}(X I), \\
& \epsilon_{2}=S-f_{2}(X 2) .
\end{aligned}
$$

Log-likelihood function for such a model is then

$$
l l=\sum_{i=1}^{N} \log \left[h_{1}\left(C_{i}\right) \int_{C_{i}}^{\infty} h_{2}\left(S_{i}\right) d S_{i}+h_{2}\left(C_{i}\right) \int_{C_{i}}^{\infty} h_{1}\left(D_{i}\right) d D_{i}\right],
$$

where $h_{1}$ and $h_{2}$ are weighted accordingly using kernel weights:

$$
\begin{aligned}
& h_{1}\left(D_{i}\right)=\frac{1}{\sqrt{2 \pi \sigma_{1}^{2}}} \exp \left(-\frac{\epsilon_{1 i}^{2} * \text { kernel } i}{2 \sigma_{1}^{2}}\right)=\frac{1}{\sqrt{2 \pi \sigma_{1}^{2}}} \exp \left(-\frac{\left[D_{i}-f_{1}\left(X 1_{i}\right)\right]^{2} * \text { kernel } i}{2 \sigma_{1}^{2}}\right) \\
& h_{2}\left(S_{i}\right)=\frac{1}{\sqrt{2 \pi \sigma_{2}^{2}}} \exp \left(-\frac{\epsilon_{2 i}^{2} * \text { kernel }}{2}\right)=\frac{1}{2 \sigma_{2}^{2}} \exp \left(-\frac{\left[S_{i}-f_{2}\left(X 2_{i}\right)\right]^{2} * \text { kernel } i}{\sqrt{2 \pi \sigma_{2}^{2}}}\right) .
\end{aligned}
$$

In the model with the hyperbolic transaction function, there is only one error term:

$$
\epsilon=C-\left[\frac{1}{2}(D+S)-\frac{1}{2} \sqrt{(D-S)^{2}+4 \gamma^{2} D S}\right] .
$$


Applying weights to the error term in the hyperbolic transaction function results in

$$
l l=\sum_{i=1}^{N} \log H\left(C_{i}\right)=-\frac{N}{2}[1+\log (2 \pi)]-\frac{N}{2} \log \left[\frac{1}{N} \sum_{i=1}^{N}\left(\epsilon_{i}^{2} * \text { kernel }_{i}\right)\right]
$$

In the present study, the first-order polynomial approximation of the previously defined demand and supply functions for the Chinese consumer goods market are;

$$
\begin{aligned}
& D=A_{i}^{D}+\alpha_{1 i}\left(S A V I-S A V 1_{i}\right)+\alpha_{2 i}\left(D Y D-D Y D_{i}\right)+\alpha_{3 i}\left(Y D I-Y D 1_{i}\right) \\
& S=A_{i}^{S}+B_{1 i}\left(C T-C T_{i}\right)+B_{2 i}\left(N M P X-N M P X_{i}\right)+B_{3 i}\left(C Z X-C Z X_{i}\right) .
\end{aligned}
$$

$A^{D}{ }_{i}$ and $A_{i}^{S}$ are the estimates of $D$ and $S$ at focal observation $i$, respectively. $\alpha_{i}$ 's are the slope coefficients or responses of $\mathrm{D}$ with respect to its corresponding explanatory variables, SAV1, DYD, and YD1. Similarly, $B_{i}$ 's are the responses of S with respect to its corresponding explanatory variables, CT, NMPX and CZX. Since the transaction function enforces the discrete-switching or hyperbolic relationship between $\mathrm{D}$ and $\mathrm{S}$, it retains its original form:

$$
C=\min (D, S),
$$

or

$$
C=\frac{1}{2}(D+S)-\frac{1}{2} \sqrt{(D-S)^{2}+4 \gamma^{2} D S}
$$

\section{An Example of Locally Weighted Optimization}

An example of the local fitting process using first-order approximation starts with a scatter plot of variable $\mathrm{Y}$ against variable $\mathrm{X}$ as seen in Figure 9. In 


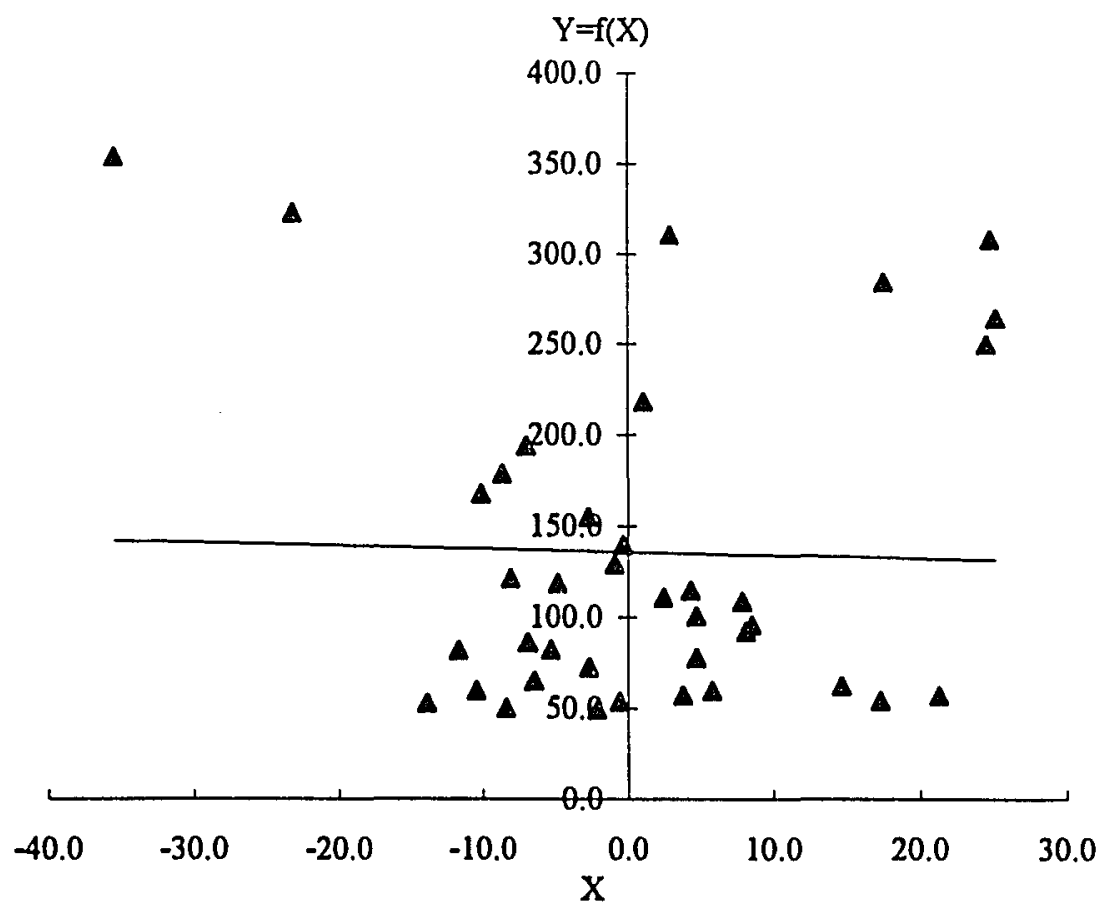

Figure 9. A global fitting example of $Y=f(X)$.

this example, the $\mathrm{Y}$ and $\mathrm{X}$ are personal consumption (C) and government shortterm adjustment plans (NMPX), respectively, which are defined earlier in this chapter. The solid line is from a linear global fitting using the entire data sample. From such a global fitting, it seems that $\mathrm{Y}$ is independent of $\mathrm{X}$. However, the scatter plot exhibits a higher-order non-linear relationship between the two variables. The locally weighted optimization can be used here to explore the relationship. Because the form of the relationship between $\mathrm{Y}$ and $\mathrm{X}$ may not be easy to identify, and it may not be of interest in the research, the functional form is approximated as

$$
Y=A_{i}+\alpha_{i}\left(X-X_{i}\right)
$$


for the locally weighted optimization around focal observation i. As discussed earlier, $A_{i}$ is the value of the unknown function evaluated at observation $i$, and $\alpha_{\mathrm{i}}$ is the response of $\mathrm{Y}$ with respect to $\mathrm{X}$ around observation i. $\mathrm{X}_{\mathrm{i}}$ is the explanatory variable at the focal observation.

The weights calculated based on the explanatory variable $\mathrm{X}$ determine the size of the local fitting neighborhoods. In addition, because of the weights, the effects of some extreme observations will be discounted and the relationship between the variables can be revealed. For this example, the K Nearest Neighbor weights are used, and in calculating the distance $d_{i}$ (refer to page 50) there is only one explanatory variable. Figure 10 shows the weights of all the neighboring observations for three focal observations, 1967, 1975 and 1987. It is clear that the close chronological neighbors of a focal observation may not necessarily have higher weights than others. Only when the difference between the explanatory variables is small, the observation receives higher weight.

In this example, the data sample has 38 observations. Therefore, there are 38 sets of weights and 38 locally weighted regressions, each corresponding to a focal observation. There are two coefficients estimated for the unknown function around each focal observation i: intercept and slope of the function in the neighborhood defined as $A_{i}$ and $\alpha_{i}$, respectively. Since the $Y$ function is approximated as a line function, it is estimated using the ordinary least squared method. An error term is added to the $\mathrm{Y}$ function. The effect of the weighted error term is transformed, and the weights are multiplied with the terms on both 

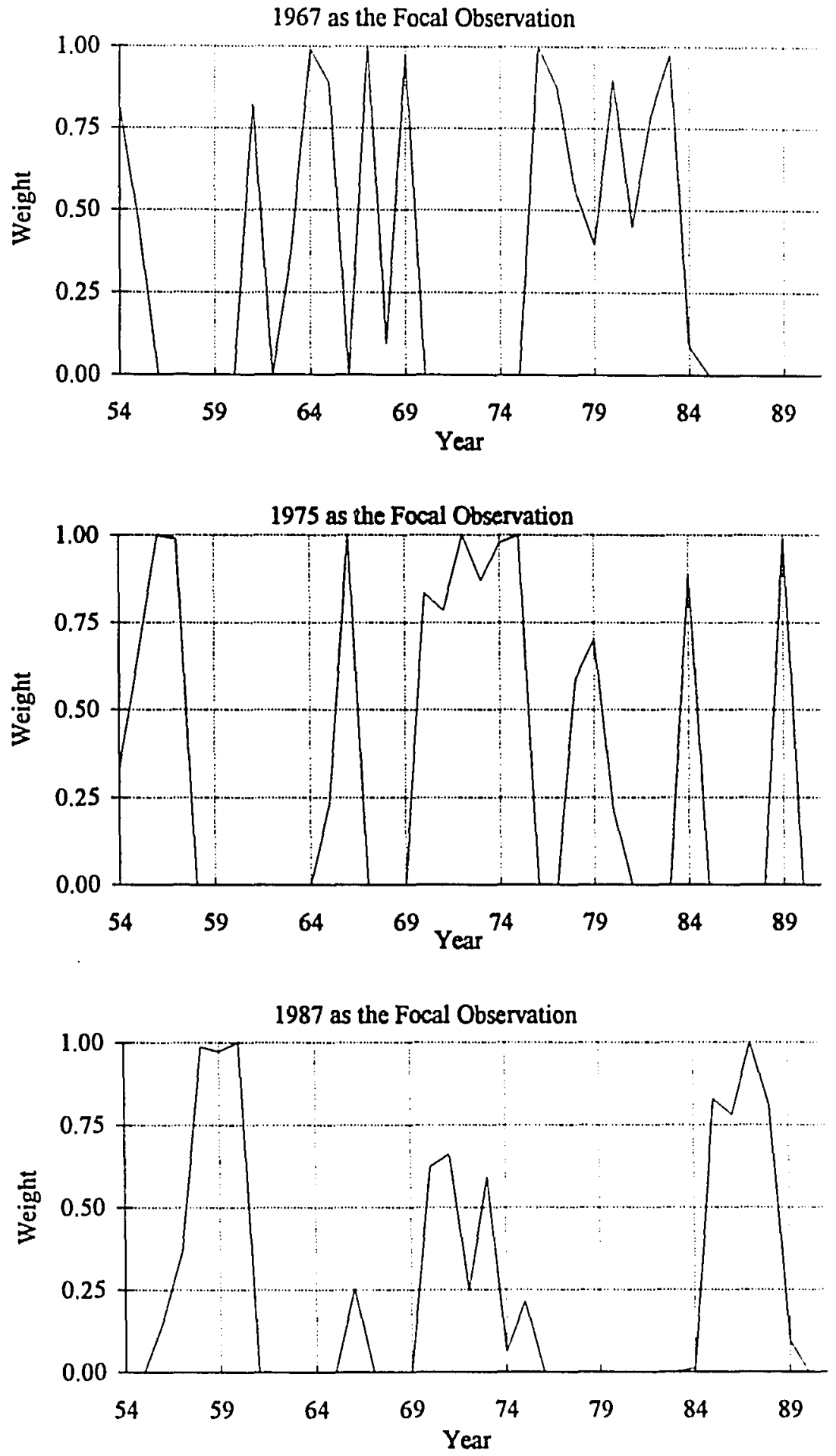

Figure 10. Weights assigned to the neighborhoods of focal observations in 1967, 1975 and 1987. 
sides of the equation. Figure 11 displays 38 estimated $A_{j}$ 's for the entire sample together with the original scatter dots. The original data for the years of 1967 , 1975 and 1987 are represented by the square dots. The curve shows that variable $\mathrm{Y}$ clearly depends on variable $\mathrm{X}$. Therefore, the relationship is estimated through a locally weighted fitting without identifying the functional form between the two variables. Such relationship is obviously not linear and may be higher than second-order.

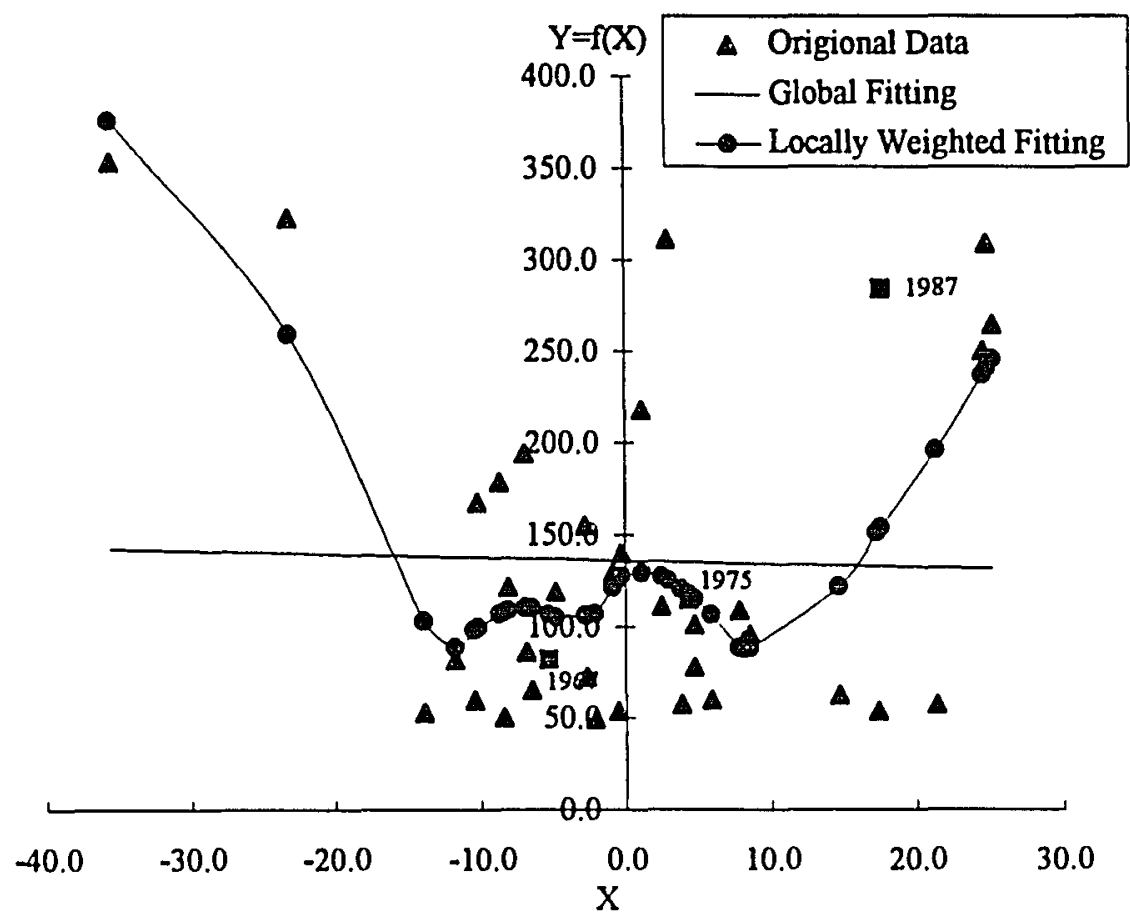

Figure 11. Locally weighted fitting for the entire sample. 


\section{CHAPTER IV}

\section{MODEL ESTIMATION}

Using the techniques described in Chapter III, this chapter summarizes the empirical estimation results of disequilibrium models using the hyperbolic and discrete-switching transaction functions. Neither model makes assumptions on whether the market status is at equilibrium or disequilibrium. The use of the Ihyperbolic transaction function is superior to the discrete-switching transaction function in that the former allows the coexistence of excess demand and excess supply.

In Section IV.1, the model is first estimated with the assumption that there is no structural change from 1954 to 1991 . Using the similar explanatory variables, a model is constructed, estimated and compared with the PortesSantorum model of the period from 1954 to 1983 . In Section IV.2, structural change is assumed in 1980 when the economic reform began, and the model is estimated using the dummy variable approach and sample separation approach. In Section IV.3, locally weighted optimization technique is applied to study the transition of the demand and supply functions during the sample period. In each section, the disequilibrium econometric model of the Chinese consumer goods market is presented in parallel of two specifications of transaction functions: hyperbolic and discrete-switching functions. 
Annual data series of all variables are obtained from the China Statistical Yearbook (State Statistical Bureau of the People's Republic of China). Appendix A lists the data series and their descriptions. The values of all the model variables are in real terms: they are adjusted by the corresponding price indices with the base year 1952. Because of the lagged variables, the actual estimation data range is $1954-1991$. The parameters that need to be estimated are the coefficients in the demand (D) and supply (S) functions, $\alpha$ 's and B's, as well as $\gamma$ in the transaction (C) function. The valid parameter ranges are: $1<\alpha_{1}<-1 / 3,0<\alpha_{2}<1, \alpha_{3}=1, B_{1}>0, B_{2}>0$, and $B_{3}<0$.

\section{IV.1 ASSUMING NO STRUCTURAL CHANGE}

In this section, the estimated models having no structural change are given in detail. The Portes-Santorum model for the Chinese consumer goods market is re-visited using the latest revised data as well as the algorithms designed for the present study.

\section{Models 1A and 1B: No Structural Change}

With no structural change, two models are estimated using the entire time span from 1954 to 1991 . These models are later referred to as Models $1 \mathrm{~A}$ and 1B corresponding to the hyperbolic and discrete-switching transaction functions, respectively. Model $1 \mathrm{~A}$ with the hyperbolic transaction function is

$$
D=\alpha_{1} S A V I+\alpha_{2} D Y D+\alpha_{3} Y D I
$$




$$
\begin{gathered}
S=\beta_{1} C T+\beta_{2} N M P X+\beta_{3} C Z X ; \\
C=\frac{1}{2}(D+S)-\frac{1}{2} \sqrt{(D-S)^{2}+4 \gamma^{2} D S}+\epsilon .
\end{gathered}
$$

The $\log$-likelihood function to be maximized for Model $1 \mathrm{~A}$ is

$$
\begin{gathered}
l l=\sum_{i=1}^{N} \log H\left(C_{i}\right)=-\frac{N}{2}[1+\log (2 \pi)]-\frac{N}{2} \log \left(\frac{1}{N} \sum_{i=1}^{N} \epsilon_{i}^{2}\right), \\
\epsilon=C-\left[\frac{1}{2}(D+S)-\frac{1}{2} \sqrt{(D-S)^{2}+4 \gamma^{2} D S}\right]
\end{gathered}
$$

Model 1B with the discrete-switching transaction function is

$$
\begin{gathered}
D=\alpha_{1} S A V 1+\alpha_{2} D Y D+\alpha_{3} Y D 1+\epsilon_{1} ; \\
S=\beta_{1} C T+\beta_{2} N M P X+\beta_{3} C Z X+\epsilon_{2}, \\
C=\min (D, S) .
\end{gathered}
$$

The log-likelihood function to be maximized for Model 1B is,

$$
l l=\sum_{i=1}^{N} \log \left[h_{1}\left(C_{i}\right) \int_{c_{i}}^{\infty} h_{2}\left(S_{i}\right) d S_{i}+h_{2}\left(C_{i}\right) \int_{C_{i}}^{\infty} h_{1}\left(D_{i}\right) d D_{i}\right]
$$

where $h_{1}$ and $h_{2}$ are the marginal probability density functions of $D$ and $S$, respectively, and are defined as

$$
\begin{gathered}
h_{1}\left(D_{i}\right)=\frac{1}{\sqrt{2 \pi \sigma_{1}^{2}}} \exp \left(-\frac{\epsilon_{1 i}^{2}}{2 \sigma_{1}^{2}}\right) ; \\
h_{2}\left(S_{i}\right)=\frac{1}{\sqrt{2 \pi \sigma_{2}^{2}}} \exp \left(-\frac{\epsilon_{2 i}^{2}}{2 \sigma_{2}^{2}}\right), \\
\epsilon_{1}=D-\left[\alpha_{1} S A V 1+\alpha_{2} D Y D+\alpha_{3} Y D 1\right] ;
\end{gathered}
$$




$$
\epsilon_{2}=S-\left[\beta_{1} C T+\beta_{2} N M P X+\beta_{3} C Z X\right] .
$$

The maximum likelihood estimates of the parameters using the hyperbolic transaction function are in the second column of Table III. Numbers in parentheses are standard errors of the estimates. Zero-valued $\gamma$ indicates that excess demand and excess supply do not coexist. In such a case, a discreteswitching model may be more appropriate. The results of the discrete-switching model are presented in the last column of Table III. $\sigma_{1}$ and $\sigma_{2}$ are the standard errors of demand and supply functions, respectively.

Most of the parameter estimates of models 1A and 1B (in columns 2 and 3 of Table III) are very close. The differences between the two may be caused by the difference in the specifications of log-likelihood functions that the two models optimize.

All parameters in the hyperbolic transaction function, except $\gamma$, are significantly different from zero at the $95 \%$ confidence level, and are consistent with the theory - correct signs and within the theoretical ranges as specified in the literature and at the beginning of this chapter.

The household demand behavior closely follows the Houthakker-Taylor specification. Note that the value of $\alpha_{3}$, the effect of lagged disposable income, is not statistically different from 1 . In the supply function $B_{2}$, coefficient of NMPX, is not significantly different from 1 , which means that personal consumption is not used as the buffer to economic shocks; and the sign and significance of $B_{3}$, coefficient of CZX, show that public spending and investment 
TABLE III

PARAMETER ESTIMATES OF MODELS 1A AND 1B

\begin{tabular}{|c|c|c|}
\hline Parameter & $\begin{array}{c}\text { Hyperbolic } \\
\text { Transaction Function } \\
\text { Model 1A }\end{array}$ & $\begin{array}{c}\text { Discrete-Switching } \\
\text { Transaction } \\
\text { Function } \\
\text { Model 1B }\end{array}$ \\
\hline$\alpha_{1}$ & $\begin{array}{c}-0.484 \\
(0.115)\end{array}$ & $\begin{array}{c}-0.561 \\
(0.044)\end{array}$ \\
\hline$\alpha_{2}$ & $\begin{array}{r}0.704 \\
(0.102)\end{array}$ & $\begin{array}{c}0.699 \\
(0.069)\end{array}$ \\
\hline$\alpha_{3}$ & $\begin{array}{r}0.987 \\
(0.011)\end{array}$ & $\begin{array}{r}1.008 \\
(0.006)\end{array}$ \\
\hline$B_{1}$ & $\begin{array}{c}1.011 \\
(0.004)\end{array}$ & $\begin{array}{r}1.010 \\
(0.008)\end{array}$ \\
\hline$B_{2}$ & $\begin{array}{c}1.083 \\
(0.078)\end{array}$ & $\begin{array}{r}0.848 \\
(0.152)\end{array}$ \\
\hline $\mathrm{B}_{3}$ & $\begin{array}{c}-0.938 \\
(0.124)\end{array}$ & $\begin{array}{c}-0.391 \\
(0.272)\end{array}$ \\
\hline$\gamma$ & $\begin{array}{r}0.000 \\
(0.001)\end{array}$ & \\
\hline$\sigma_{1}$ & & $\begin{array}{r}1.205 \\
(0.265) \\
0\end{array}$ \\
\hline$\sigma_{2}$ & & $\begin{array}{r}5.945 \\
(1.291) \\
\end{array}$ \\
\hline $\begin{array}{l}\text { Likelihood Function } \\
\text { Value }\end{array}$ & -94.849 & -90.954 \\
\hline
\end{tabular}

are in competition with the supply of consumer goods. However, the differences in $B_{2}$ and $B_{3}$ using different transaction functions are large and seem to suggest 
that the model may have unexplained variations, due to missing explanatory variables in the supply function.

\section{Comparison with the Portes-Santorum Model}

In 1987, Portes and Santorum estimated the Chinese consumption goods market from 1954 to 1983 . Their model, similar to Model 1A above, is as follows:

$$
\begin{gathered}
D=\alpha_{1} S A V 1+\alpha_{2} D Y D+\alpha_{3} Y D 1 ; \\
S=\beta_{1} C T+\beta_{2} N M P X+\beta_{3} M X+\beta_{4} I F X \\
C=\frac{1}{2}(D+S)-\frac{1}{2} \sqrt{(D-S)^{2}+4 \gamma^{2} D S}+\epsilon,
\end{gathered}
$$

where the definitions of D, S, C, SAV1, DYD, YD1, CT, NMPX and MX are the same as defined earlier. IFX is a modification of CZX:

$$
I F X=(I T / N M P T)(N M P-N M P T),
$$

where IT is the second-order exponential time trend of capital construction from state-owned units.

An effort was made to duplicate their results using the latest revised data. It is apparent that there is no convergent result due to the data revisions and possibly due to the usage of computer hardware, software and algorithms. One of the variables in the Portes-Santorum model is slightly modified: IFX is replaced by $\mathrm{CZX}$, and the estimation data range of this study is forced to be 
1954-1983. Table IV presents the comparative estimation results of this study and those of Portes-Santorum.

TABLE IV

COMPARATIVE ESTIMATES OF PORTES-SANTORUM MODEL

\begin{tabular}{|c|c|c|}
\hline Parameter & $\begin{array}{c}\text { Current } \\
\text { Study } \\
(1954-1983)\end{array}$ & $\begin{array}{l}\text { Portes- } \\
\text { Santorum }\end{array}$ \\
\hline$\alpha_{1}$ & $\begin{array}{c}-0.995 \\
(0.016)\end{array}$ & $\begin{array}{c}-0.630 \\
(0.072)\end{array}$ \\
\hline$\alpha_{2}$ & $\begin{array}{r}0.660 \\
(0.006)\end{array}$ & $\begin{array}{c}0.658 \\
(0.032)\end{array}$ \\
\hline$\alpha_{3}$ & $\begin{array}{c}1.018 \\
(0.002)\end{array}$ & $\begin{array}{c}1.010 \\
(0.003)\end{array}$ \\
\hline$B_{1}$ & $\begin{array}{c}1.024 \\
(0.002)\end{array}$ & $\begin{array}{r}1.049 \\
(0.004)\end{array}$ \\
\hline$B_{2}$ & $\begin{array}{c}0.449 \\
(0.017)\end{array}$ & $\begin{array}{c}0.255 \\
(0.073)\end{array}$ \\
\hline$B_{3}$ & $\begin{array}{r}0.633 \\
(0.012)\end{array}$ & $\begin{array}{r}0.254 \\
(0.059)\end{array}$ \\
\hline$\aleph_{4}$ & $\begin{array}{c}-0.306 \\
(0.008)\end{array}$ & $\begin{array}{c}-0.417 \\
(0.034)\end{array}$ \\
\hline$\gamma$ & $\begin{array}{c}0.000 \\
(0.001)\end{array}$ & $\begin{array}{r}0.000 \\
(0.000)\end{array}$ \\
\hline Likelihood Function Value & -45.792 & -45.24 \\
\hline
\end{tabular}

Although the values of parameters are different, the general trend is the same. Again, $B_{4}$ is associated with a slightly different variable in this study. 
The current study goes beyond extending the estimation period covered by the Portes-Santorum model. It also studies the structural change in the model, as well as the transition of the demand and supply functions over the years.

\section{IV.2 ASSUMING STRUCTURAL CHANGE IN 1980}

One of the objectives of this research is to test whether there is a structural change in the Chinese consumer goods market in 1980 when the economic reform began.

There are two approaches to test the structural change: (a) use a dummy variable in $\mathrm{D}, \mathrm{S}$ and $\mathrm{C}$; or (b) use sub-samples of data for different time periods. The dummy variable approach assumes that the coefficients in $\mathrm{D}(\alpha$ 's), $\mathrm{S}$ (B's) and $C(\gamma)$ may change in the model reflecting the structural differences of the two sample periods. The explicit sample separation approach implies that not only all the coefficients may vary, other statistical measures, such as variances of the estimated errors, may be different in the different periods. In this study of structural change, the data set is divided into two parts: before (but exclusive) 1980, and after and inclusive of 1980.

Models 2A and 2B: Dummy Variable Approach

For the study of structural change using dummy variable approach, a dummy variable is added to $\mathrm{D}, \mathrm{S}$ and $\mathrm{C}$ functions. This is to assume that the 
patterns of demand and supply differ before and after the economic reform begun in 1980 , which in turn leads to different equilibrium status of the economy denoted by the value of $\gamma$ in the transaction function. Incorporating the dummy variable, Model $2 \mathrm{~A}$ using the hyperbolic transaction function is defined as:

$$
\begin{gathered}
D=\left(\alpha_{11}+\alpha_{12} * d m y\right) S A V I+\left(\alpha_{21}+\alpha_{22} * d m y\right) D Y D+\left(\alpha_{31}+\alpha_{32} * d m y\right) Y D 1 ; \\
S=\left(B_{11}+B_{12} * d m y\right) C T+\left(B_{21}+B_{22} * d m y\right) N M P X+\left(B_{31}+B_{32} * d m y\right) C Z X, \\
C=\frac{1}{2}(D+S)-\frac{1}{2} \sqrt{(D-S)^{2}+4\left(\gamma_{1}^{2}+\gamma_{2}^{2} * d m y\right) D S}+\epsilon .
\end{gathered}
$$

where dmy $=0$ before 1980; 1 after 1980, inclusive.

Adding error terms to $\mathrm{D}$ and $\mathrm{S}$, and applying the discrete-switching transaction function, Model 2B is:

$$
\begin{gathered}
D=\left(\alpha_{11}+\alpha_{12} * d m y\right) S A V 1+\left(\alpha_{21}+\alpha_{22} * d m y\right) D Y D+\left(\alpha_{31}+\alpha_{32} * d m y\right) Y D 1+\epsilon_{1} \\
S=\left(B_{11}+\beta_{12} * d m y\right) C T+\left(\beta_{21}+\beta_{22} * d m y\right) N M P X+\left(\beta_{31}+\beta_{32} * d m y\right) C Z X+\epsilon_{2}, \\
C=\min (D, S) .
\end{gathered}
$$

The formulas of log-likelihood functions for Model 2 are the same as the ones for Model 1. The definitions of parameters in the two periods are in Table V. The maximum likelihood parameter estimates and their standard errors from Model 2A are presented in Table VI.

With the exception of $\alpha_{1}$ after 1980 and $\gamma$ 's in both periods, the low standard errors associated with the parameters demonstrate that they are significantly different from zero. And the statistical significance of the changes suggests that there is indeed a structural change that occurred in 1980 during the 
TABLE V

DEFINITIONS OF PARAMETERS IN DIFFERENT TIME PERIODS

\begin{tabular}{|c|c|c|c|}
\hline Parameter & Before 1980 & After 1980 & Change \\
\hline$\alpha_{1}$ & $\alpha_{11 \ldots}$ & $\alpha_{11}+\alpha_{12}$ & $\alpha, \ldots$ \\
\hline$\alpha_{2} \ldots$ & $\alpha_{21}$ & $\alpha_{21}+\alpha_{22}$ & $\alpha_{22} \ldots$ \\
\hline$\alpha_{3}$ & $\alpha_{31}$ & $\alpha_{31}+\alpha_{32}$ & $\alpha_{32 \ldots}$ \\
\hline$B_{1}$ & $B_{11 \ldots}$ & $B_{11}+B_{12}$ & $\beta_{12 \ldots}$ \\
\hline $\mathbb{B}_{3}$ & $\beta_{31 \ldots}$ & $B_{21}+B_{22}$ & $B_{n 2 \ldots}$ \\
\hline$B_{3}$ & $B_{31 \ldots}$ & $B_{31}+B_{32}$ & $B_{32 \ldots}$ \\
\hline$\gamma$ & $\gamma_{1}$ & $\gamma_{1}+\gamma_{2}$ & $\gamma_{2}$ \\
\hline
\end{tabular}

TABLE VI

PARAMETER ESTIMATES OF MODEL 2A: USING HYPERBOLIC TRANSACTION FUNCTION

\begin{tabular}{|c|c|c|c|}
\hline Parameter & Before 1980 & After 1980 & Change \\
\hline$\alpha_{1 \ldots}$ & $\begin{array}{c}-1.017 \\
(0.211)\end{array}$ & $\begin{array}{c}-0.083 \\
(0.309)\end{array}$ & $\begin{array}{r}0.933 \\
(0.225)\end{array}$ \\
\hline$\alpha_{2 \ldots}$ & $\begin{array}{r}0.618 \\
(0.066)\end{array}$ & $\begin{array}{r}0.765 \\
(0.108)\end{array}$ & $\begin{array}{r}0.148 \\
(0.086) \\
.0 .0 .\end{array}$ \\
\hline$\alpha_{3}$ & $\begin{array}{r}1.018 \\
(0.007) \\
.\end{array}$ & $\begin{array}{r}0.944 \\
(0.013)\end{array}$ & $\begin{array}{c}-0.075 \\
(0.011)\end{array}$ \\
\hline$B_{1}$ & $\begin{array}{r}1.057 \\
(0.006)\end{array}$ & $\begin{array}{r}1.006 \\
(0.008)\end{array}$ & $\begin{array}{r}-0.052 \\
(0.006)\end{array}$ \\
\hline$B_{2}$ & $\begin{array}{r}0.701 \\
(0.132)\end{array}$ & $\begin{array}{r}1.268 \\
(0.211)\end{array}$ & $\begin{array}{r}0.567 \\
(0.165) \\
. . . . . .1\end{array}$ \\
\hline$B_{3}$ & $\begin{array}{c}-0.769 \\
(0.155)\end{array}$ & $\begin{array}{c}-1.279 \\
(0.327)\end{array}$ & $\begin{array}{c}-0.511 \\
(0.288)\end{array}$ \\
\hline$\gamma$ & $\begin{array}{r}0.000 \\
(0.001) \\
\end{array}$ & $\begin{array}{r}0.000 \\
(0.006) \\
\end{array}$ & $\begin{array}{r}0.000 \\
(0.006) \\
\end{array}$ \\
\hline Likelihood Function Value & \multicolumn{3}{|c|}{-62.885} \\
\hline
\end{tabular}


time span from 1954 to 1991 . The likelihood ratio test also confirms the structural change: the likelihood ratio between Model 2A and Model $1 \mathrm{~A}$ is 63.93 , which is much higher than the $\chi^{2}$ critical value of 14.07 with 7 degrees of freedom at the $95 \%$ confidence level.

The parameter values in the second time period are derived by adding the changes to the values before 1980 (see Table V). Because of a relatively high positive change, $\alpha_{1}$ is not significantly different from zero in the second time period. That is, the savings will affect the level of consumption in pre-1980 period, but not in the post-1980 period. Before 1980, the impact of households' savings on consumption is greater. I After 1980, savings does not have any effect on present consumption. This may be due to the fact that before the reform, salaries and wages were the only income, job security was high, the inflation rate was low, and old-fashioned parents tended to consider the well-being of their children in that they tended to save for the next generation. However, since 1980 more goods became available, inflation risk became higher, income level was boosted and savings constituted only a small portion of it, and the "next generation" might be more affluent and have different considerations about following generations. 'Therefore, after 1980 savings was no longer an important factor in determining consumption. An asymptotic $t$ test shows that the value of $\alpha_{1}$ before 1980 is not significantly different from -1 .

Parameter $B_{2}$ is the coefficient of NMPX in the supply function, which approximates the adjustment made by the planners on the departure of the 
actual output of the economy from its historical trend as well as the trend of the personal consumption. After 1980, the difference between/national income and personal consumption increased sharply (refer to Figure 2 in Chapter I). Such deviation causes $B_{2}$ to increase, and its value indicates that personal consumption behaves nearly like a buffer to absorb economic shocks although it is still not significantly different from 1.

The magnitude of $B_{3}$, coefficient of CZX, is greater after 1980 than before. This may be induced by the changes in planning and control at the enterprise level. When government agencies delegate a certain level of authority to enterprises over their production activities, these enterprises are expected to produce according to market information to maximize their profits. Under such conditions, the magnitude of planned investment and government spending may have more influence on how much enterprises will produce for consumption. However, the change in $B_{3}$ is not statistically significant at the $95 \%$ confidence level. Thus, the difference in $B_{3}$ before and after 1980 may not have been substantial.

Because the market friction coefficient $\gamma$ in the transaction function is zero in both periods, for comparison purposes, the same data set is fitted to a discrete-switching model, Model 2B. The estimates are shown in Table VII. $\sigma_{1}$ and $\sigma_{2}$ are the standard errors of demand and supply functions, respectively. All the coefficients are essentially the same as those estimated /using the hyperbolic function and shown in Table VI. 
TABLE VII

PARAMETER ESTIMATES OF MODEL 2B:

USING DISCRETE-SWITCHING TRANSACTION FUNCTION

\begin{tabular}{|c|c|c|c|}
\hline Parameter & Before 1980 & After 1980 & Change \\
\hline$\alpha_{1}$ & $\begin{array}{c}-0.926 \\
(0.190)\end{array}$ & $\begin{array}{c}-0.088 \\
(0.276)\end{array}$ & $\begin{array}{c}0.838 \\
(0.201)\end{array}$ \\
\hline$\alpha_{2}$ & $\begin{array}{c}0.644 \\
(0.061) \\
\end{array}$ & $\begin{array}{c}0.765 \\
(0.098)\end{array}$ & $\begin{array}{c}0.121 \\
(0.077) \\
\end{array}$ \\
\hline$\alpha_{3}$ & $\begin{array}{c}1.015 \\
(0.007)\end{array}$ & $\begin{array}{r}0.944 \\
(0.012)\end{array}$ & $\begin{array}{c}-0.071 \\
(0.010)\end{array}$ \\
\hline$B_{1}$ & $\begin{array}{c}1.079 \\
(0.019)\end{array}$ & $\begin{array}{r}1.006 \\
(0.026)\end{array}$ & $\begin{array}{c}-0.073 \\
(0.019)\end{array}$ \\
\hline $\mathrm{B}_{2}$ & $\begin{array}{c}0.810 \\
(0.275)\end{array}$ & $\begin{array}{r}1.250 \\
(0.414)\end{array}$ & $\begin{array}{c}0.440 \\
(0.310)\end{array}$ \\
\hline$B_{3}$ & $\begin{array}{c}-0.933 \\
(0.300)\end{array}$ & $\begin{array}{c}-1.233 \\
(0.551)\end{array}$ & $\begin{array}{c}-0.300 \\
(0.462)\end{array}$ \\
\hline$\sigma_{1}$ & \multicolumn{3}{|c|}{$\begin{array}{c}1.038 \\
(0.146)\end{array}$} \\
\hline$\sigma_{2}$ & \multicolumn{3}{|c|}{$\begin{array}{c}1.870 \\
(0.451) \\
\end{array}$} \\
\hline Likelihood Function Value & \multicolumn{3}{|c|}{-60.106} \\
\hline
\end{tabular}

Comparing results shown in the last column of Table III, where no structural change is considered, with results in Table VII, it is apparent that the latter results with structural change are better. $: \sigma_{1}$ and $\sigma_{2}$ are much smaller in Model 2B, and the likelihood ratiol test statistic between Model 1B and Model $2 \mathrm{~B}$ is 60.69 , which is much higher than the critical $\chi^{2}$ value of 12.59 with 6 degrees of freedom at the $95 \%$ confidence level. Furthermore, the significant 
changes in $B_{2}$ and $B_{3}$ before and after 1980 may account for the discrepancy in the supply patterns estimated by different methods shown in Table III. That is, there exists a structural change, and the two methods using different optimization algorithms manifest inconsistent results when the structural change is suppressed.

Other forms of dummy variable models are also considered and tested.

Those models include a dummy variable in demand (D) and supply (S) functions, as well as in transaction (C) function only. The hyperbolic transaction function is used for all these alternative models. The comparison against Model 1A, along with Model 2A, is listed in Table VIII. The likelihood ratio tests clearly indicate that all the models with a dummy variable are better than the one without it: structural change obviously exists.

TABLE VIII

COMPARATIVE TEST RESULTS OF MODELS WITH A DUMMY VARIABLE

\begin{tabular}{|c|c|c|c|c|}
\hline Model & $\begin{array}{l}\text { Likelihood } \\
\text { Function } \\
\text { Value }\end{array}$ & $\begin{array}{l}\text { Degree of } \\
\text { Freedom }\end{array}$ & $\begin{array}{l}\text { Likelihood } \\
\text { Ratio }\end{array}$ & $\begin{array}{c}\text { Critical } \chi^{2} \\
\text { Value at } \\
95 \% \text { Level }\end{array}$ \\
\hline $\begin{array}{l}\text { Model 1A } \\
\text { (base case) }\end{array}$ & -94.849 & --- & $-\cdots$ & --- \\
\hline Model 2A & -62.885 & 7 & 63.93 & 14.07 \\
\hline $\begin{array}{l}\text { Dummy Variable } \\
\text { in } D \text { and } S\end{array}$ & -62.885 & 6 & 63.93 & 12.59 \\
\hline $\begin{array}{l}\text { Dummy Variable } \\
\text { in } C\end{array}$ & -78.625 & 1 & 32.39 & 3.84 \\
\hline
\end{tabular}




\section{Models 3A and 3B: Sample Separation Approach}

To incorporate changes in the model parameters, Model 1 is expandeid to two separate equations corresponding to two non-overlapping sub-samples, which allows the error variances in the two time periods to adjust. The data set is split into two subsets (before and after 1980), and each is fitted to the same models. Model $3 \mathrm{~A}$, using the hyperbolic transaction function, has the same format as: Model 1A. Similarly, Model 3B, using the discrete-switching transaction function, has the same format as Model 1B. The formulas of log-likelihood functions for Model 3 are the same as the ones for Model 1. The estimates using the । hyperbolic and discrete-switching transaction functions are given in Table IX and Table X, respectively. It is evident that the estimated parameter values for different transaction functions are very close. All the parameters agree with those from Model 2.

Several conclusions can be drawn from the above analyses, There is definitely a structural change before and after the economic reform in 1980.। The household savings in the previous year (SAV1) affects the level of consumer | goods demand before 1980, but not so after 1980 due to changes in income level, expectation about future consumption, and changes in households $y^{y}$ attitudes : toward savings. The changes in income level (DYD) and income in the previous year (YD1) influence the level of consumer goods demand, with little difference in magnitude before and after 1980. The planned consumption (CT), adjustments to national income (NMPX), as well as investment and public । 
TABLE IX

PARAMETER ESTIMATES OF MODEL 3A: USING HYPERBOLIC TRANSACTION FUNCTION

\begin{tabular}{|c|c|c|}
\hline Parameter & Before 1980 & After 1980 \\
\hline$\alpha_{1}$ & $\begin{array}{c}-1.015 \\
(0.157)\end{array}$ & $\begin{array}{c}-0.083 \\
(0.108)\end{array}$ \\
\hline$\alpha_{2}$ & $\begin{array}{r}0.618 \\
(0.050)\end{array}$ & $\begin{array}{r}0.766 \\
(0.075)\end{array}$ \\
\hline$\alpha_{3}$ & $\begin{array}{r}1.018 \\
(0.005) \\
. . . \cdots\end{array}$ & $\begin{array}{r}0.944 \\
(0.012) \\
\ldots \ldots \ldots\end{array}$ \\
\hline$B_{1}$ & $\begin{array}{r}1.057 \\
(0.004)\end{array}$ & $\begin{array}{r}1.006 \\
(0.003)\end{array}$ \\
\hline $\mathrm{B}_{2}$ & 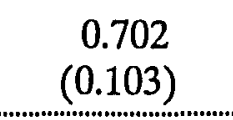 & $\begin{array}{r}1.268 \\
(0.137)\end{array}$ \\
\hline $\mathrm{B}_{3}$ & $\begin{array}{c}-0.769 \\
(0.119) \\
\cdots\end{array}$ & $\begin{array}{c}-1.279 \\
(0.338)\end{array}$ \\
\hline$\gamma$ & $\begin{array}{c}0.000 \\
(0.000)\end{array}$ & $\begin{array}{c}0.000 \\
(0.009)\end{array}$ \\
\hline Likelihood Function Value & -35.664 & -23.825 \\
\hline
\end{tabular}

consumption (CZX) determine the level of consumer goods supply. The effects of NMPX and CZX are more influential after 1980 because of the increasing deviation in the plans of national income and personal consumption, and more opportunities for enterprises resulted from the less centralized governmental authority. 
TABLE X

PARAMETER ESTIMATES OF MODEL 3B: USING DISCRETE-SWITCHING TRANSACTION FUNCTION

\begin{tabular}{|c|c|c|}
\hline Parameter & Before 1980 & After 1980 \\
\hline$\alpha_{1}$ & $\begin{array}{c}-0.839 \\
(0.198)\end{array}$ & $\begin{array}{c}-0.089 \\
(0.060)\end{array}$ \\
\hline$\alpha_{2}$ & $\begin{array}{c}0.663 \\
(0.069)\end{array}$ & $\begin{array}{c}0.763 \\
(0.042)\end{array}$ \\
\hline$\alpha_{3}$ & $\begin{array}{c}1.012 \\
(0.007) \\
. . .1\end{array}$ & $\begin{array}{c}0.944 \\
(0.006)\end{array}$ \\
\hline$B_{1}$ & $\begin{array}{r}1.066 \\
(0.006)\end{array}$ & $\begin{array}{r}1.006 \\
(0.003)\end{array}$ \\
\hline $\mathrm{B}_{2}$ & $\begin{array}{c}0.691 \\
(0.087)\end{array}$ & $\begin{array}{c}1.247 \\
(0.166)\end{array}$ \\
\hline$B_{3}$ & $\begin{array}{c}-0.766 \\
(0.094)\end{array}$ & $\begin{array}{c}-1.225 \\
(0.407)\end{array}$ \\
\hline$\sigma_{1}$ & $\begin{array}{c}1.132 \\
(0.183)\end{array}$ & $\begin{array}{c}0.895 \\
(0.269) \\
\cdots\end{array}$ \\
\hline$\sigma_{2}$ & $\begin{array}{r}0.562 \\
(0.324)\end{array}$ & $\begin{array}{r}2.300 \\
(0.654)\end{array}$ \\
\hline Likelihood Function Value & -35.847 & -21.516 \\
\hline
\end{tabular}

IV.3 LOCALLY WEIGHTED OPTIMIZATION MODEL

As discussed in previous sections, the Chinese consumer goods market underwent a structural change over the period studied. Because of the economic reform 
initiated in late 1979, the structural change is assumed to have occurred in 1980. However, the selection of this cut-off point is subjective. The changes which may have been brought about by other policy shifts during the course of economic development are neglected. This section intends to further investigate the structural variations of the demand and supply equations of the Chinese consumer goods market for the entire sample period, using the locally weighted optimization technique. With this method, the time span is not divided with specific cut-off points. Instead, the structural changes, if any, are reflected by the changes in estimated coefficients based on each individual observation and those of its close neighbors. In this process of locally weighted optimization, weights are used to determine the neighborhood of the local fitting and to adjust the effects of error terms of all the observations. The value of the weight for each observation is calculated based on the distance of explanatory variables between such an observation and the focal observation to be locally fitted. The error of the focal observation is assigned the full weight of 1 , whereas the errors of other observations are discounted with weights between 0 and 1 . The further away from the focal observation, the smaller the weight will be applied. When the weight is zero, the corresponding observation is excluded from the local fitting. Because the functional form between the dependent and explanatory variables is not specified, the locally weighted optimization is a non-parametric technique. The function to be fitted may be rather complex and non-linear. In 
general, a continuous function can be approximated with polynomial functions of any order. The zero-order polynomial approximation of $Y=f(X)$ at $X=X_{i}$ is

$$
Y \approx A_{i}
$$

where $A_{i}$ is the local mean of $Y$ around observation $i$. The first-order (linear) polynomial approximation is

$$
\begin{aligned}
Y & =A_{i}+f^{\prime}\left(X_{i}\right)\left(X-X_{i}\right) \\
& =A_{i}+\alpha_{i}\left(X-X_{i}\right),
\end{aligned}
$$

where $\alpha_{i}$ is the first derivative of $f(X)$ evaluated at $X=X_{i}$. Similarly, $A_{i}$ is the estimator of $f(X)$, or $Y$, given $X=X_{i}$.

When the fitting is focused on finding the responses of the dependent variable with respect to the explanatory variables, the function may be approximated by a polynomial function of first or higher order.

The global fitting, discussed in the previous sections, is a special case of the local fitting where the neighborhood encompasses the entire data sample, and all the observations are weighted equally.

Traditional global estimation methods are pattern fitting oriented, while locally weighted optimization is data fitting. The choice between the methods depends on the focus of the study - whether it is to find the predefined trend or pattern, or to find a best fit to the data. If the focus is to find the change in the dependent variable / with respect to the explanatory variables around the focal observations, and the relation between them is either difficult to specify or not of interest, then locally weighted optimization will be a better choice. The mean 
response of the dependent variable can be obtained by averaging the locally weighted responses.

\section{Local Weight with K Nearest Neighbor Kernel}

The K Nearest Neighbor kernel weight (see Section III.4) is used in this study because of the convenience of obtaining feasible solutions. For a particular observation $i$ under consideration, the weights for all observations in the neighborhood are calculated as an $\mathrm{N}$ by 1 vector:

$$
\mathrm{kw}_{\mathrm{i}}= \begin{cases}{\left[\left[1-\left(\frac{d_{i}}{d \max }\right)_{i}^{3}\right]^{3}\right]} & \text { when } \frac{d_{i}}{d \max } \leq 1 \\ 0 & \text { otherwise. }\end{cases}
$$

Window bandwidth $d_{i}$ is the Euclidean distance between $X$ of any observation and $X_{i}$ of the focal observation:

$$
d_{i}=\left[\sqrt{\sum_{k=1}^{P}\left(X_{k}-X_{i k}\right)^{2}}\right] .
$$

$\mathrm{X}$ is a $\mathrm{N}$ by $\mathrm{P}$ matrix of explanatory variables, $\mathrm{X}_{\mathrm{k}}$ is the kth explanatory variable of $\mathrm{X}$, and $\mathrm{X}_{\mathrm{ik}}$ is the kth explanatory variable of $\mathrm{X}$ at focal observation $\mathrm{i}$. $\operatorname{dmax}_{\mathrm{i}}$ is the maximal element of $d_{i}$ within $K=r * N$ member observations in the neighborhood of $X_{i}$, with $N$ being the number of sample observations and $r$ a scaler between 0 and 1 . 
The focal observation $i$ has the full weight of 1 because the ith element of $d_{i}$ is, by definition, 0 . Other observations in the group are weighted depending on how far away they are from the observation $i$. The weights of the observations which do not belong to the specified neighborhood are defined as zero.

Window size and weights play very important roles in the locally weighted optimization because they control how each observation is used for every local fitting. In choosing window size $\mathrm{K}=\mathrm{r} * \mathrm{~N}$, the value of scaler $\mathrm{r}$ determines the size of the neighborhood around each observation and the smoothness of the fit. The smaller the $\mathrm{r}$ value, the smaller the neighborhood and the closer the local fit. However, $\mathrm{r}$ values that are too small may cause the fit to incorporate unnecessary variations in the fit. For the present study, the value of 0.5 for scaler $i$ is selected by trial-and-error. Higher $r$ values tend to include more observations in each estimation and distort the coefficient heterogeneity, and lower $r$ values cause too many observations to be excluded and lead to no convergent results. In addition to $r$, as shown by the definition of $d_{i}$, the variations in the data affect the value of the weights assigned to observations in the neighborhood. Figures 12 through 14 depict the weights assigned to three neighborhoods of observations: 1963, 1980 and 1989. Figure 12 shows that the closest chronological neighbors of 1963 may not necessarily have higher weights than others. The period between 1958 and 1961 appears to be very different from other neighboring years. From 1969 onward, weights decline sharply. In 


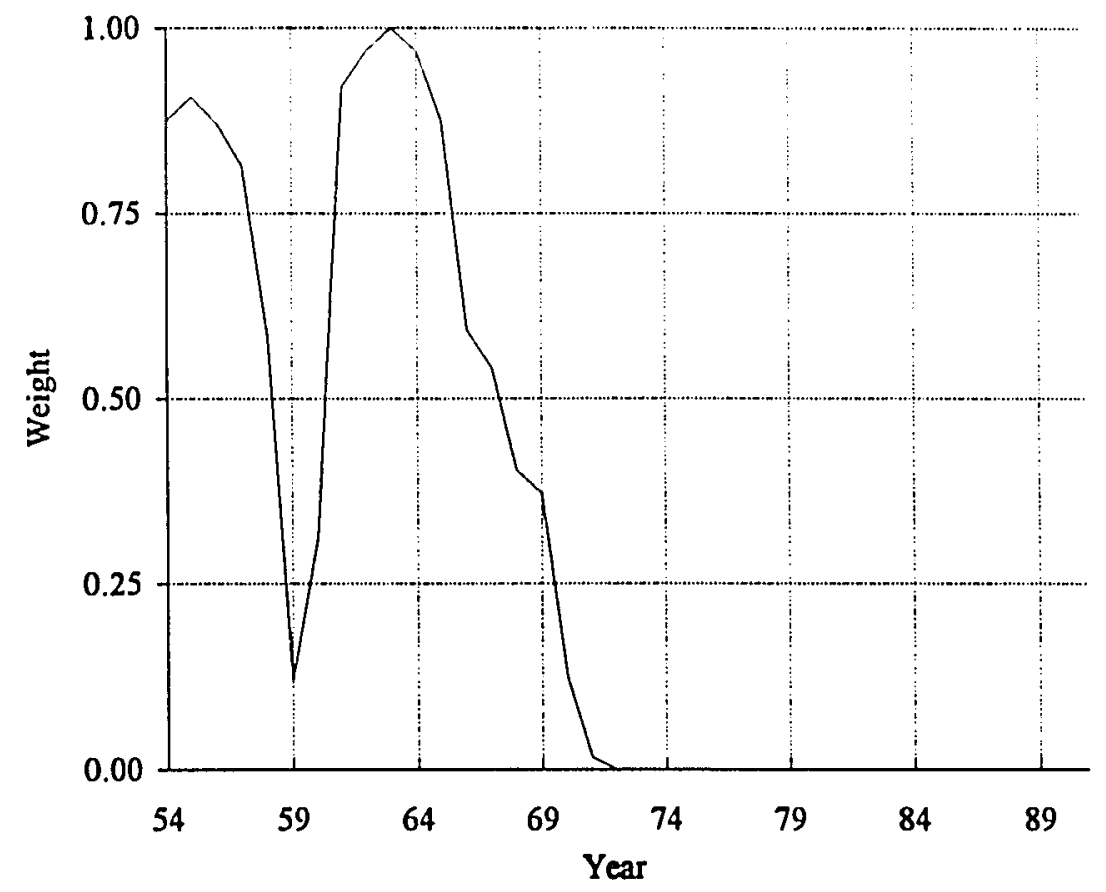

Figure 12. Weights assigned to the neighborhood of year 1963.

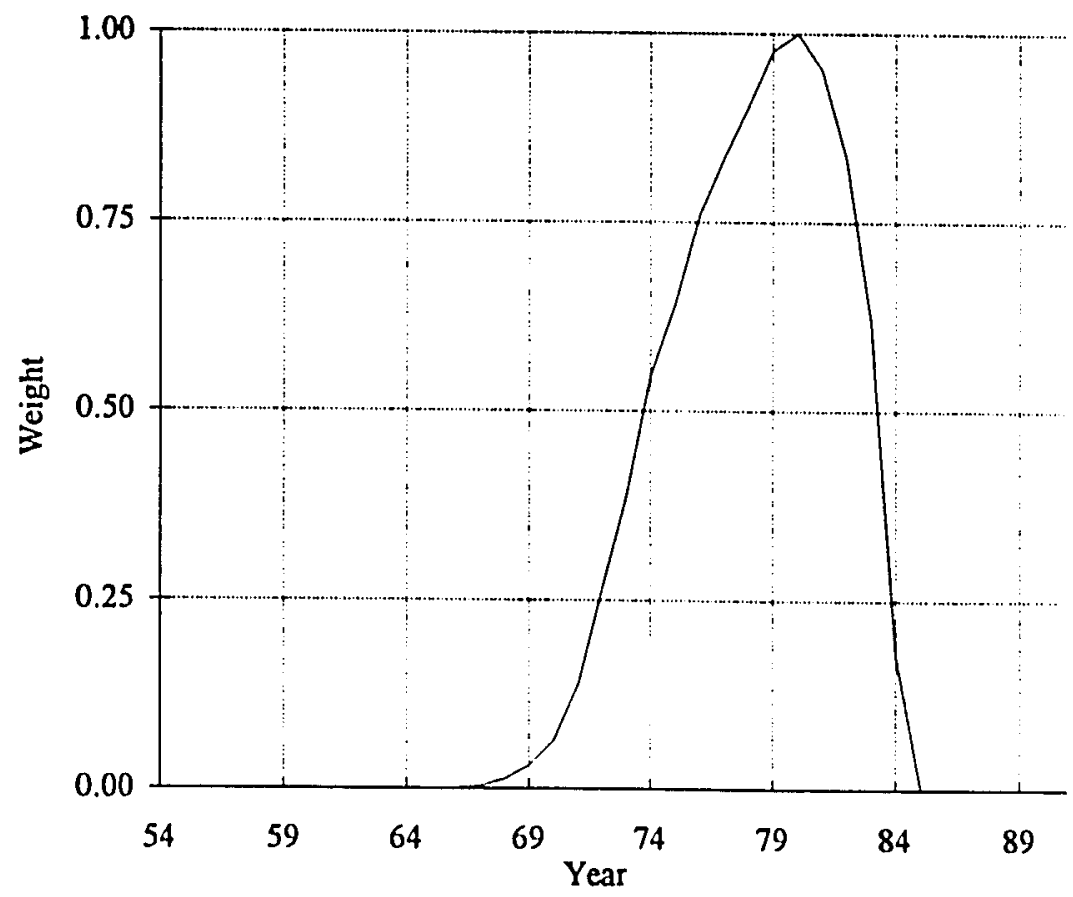

Figure 13. Weights assigned to the neighborhood of year 1980 . 


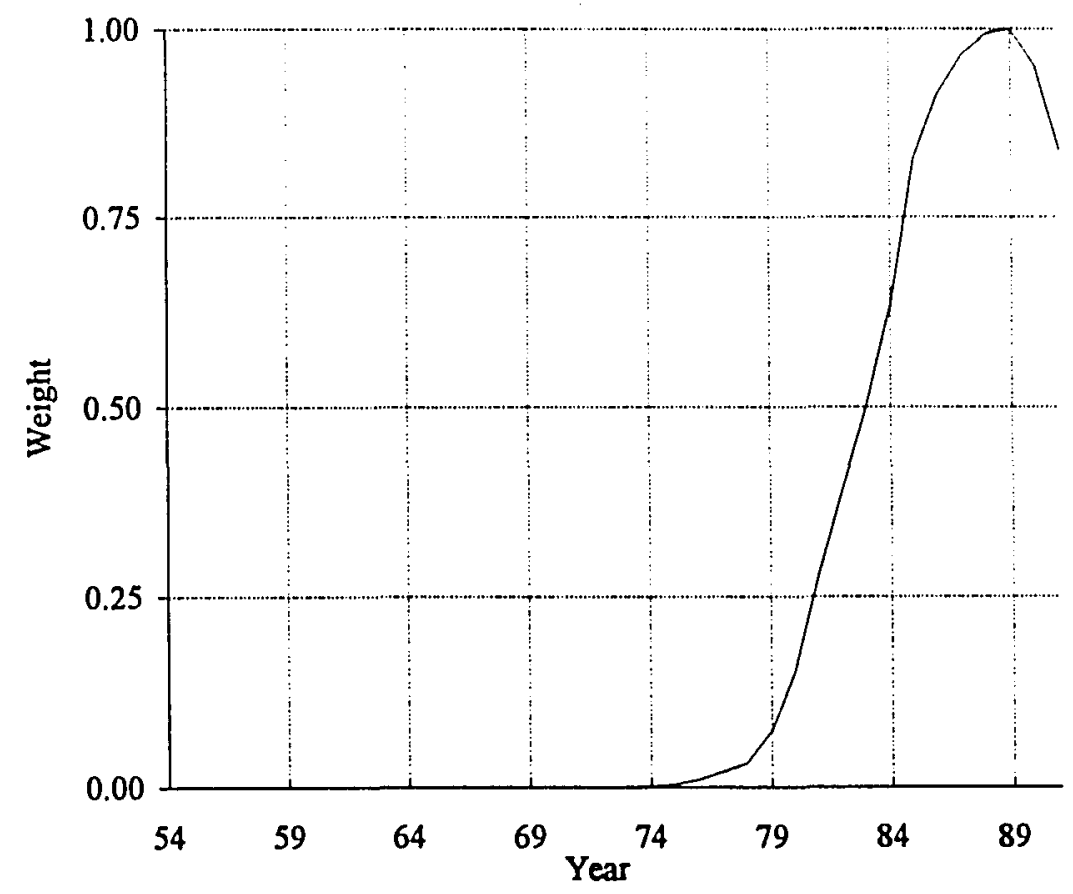

Figure 14. Weights assigned to the neighborhood of year 1989.

Figure 13, 1980 is the focal observation. The weights for neighboring years decrease gradually as they move away from the focal observation, which is expected. Weights in Figure 14 are for a boundary neighborhood of 1989 . The focal observation is no longer close to the center and the neighborhood is skewed. In all of the above figures, it is clear that the focal observations always have the full weight, and other observations receive lesser weights. The further away the observation is, the smaller the weight is in general. When an observation is outside the defined neighborhood, it has a weight of zero value.A $3 \mathrm{D}$ plot, with $\mathrm{r}$ as 0.5 , of the weights in the neighborhood around all the observations is shown in Figure 15. It should be viewed from the "Neighboring 


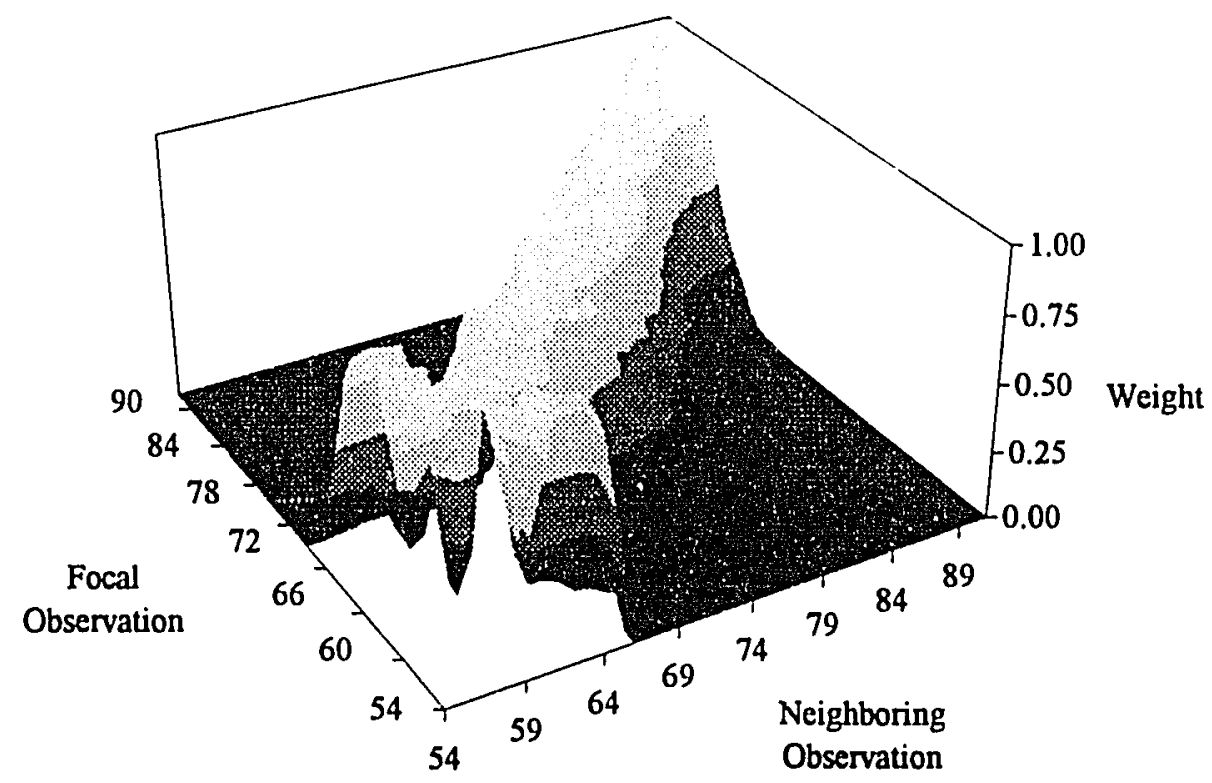

Figure 15. Weight surface of $\mathrm{K}$ Nearest Neighbor kernel weight $(r=0.5)$.

Observation" axis. Slicing at years 1963, 1980 and 1989 on the "Focal

Observation" axis parallel to the "Neighboring Observation" axis yields the 2D graphs shown in Figures 12 through 14. For comparison, Figure 16 shows the weights of all observations around each focal observation with the maximum possible number of neighbors. It is striking to see that the observations in later years are considered differently from other years even with a maximal window size of $r=1.0$. As the focus moves to the later years, the number of neighbors becomes smaller and the discount factors becomes larger, especially when the focal years are in the late 1980 's. Therefore, the fitting of those years with the same functional specification as in the earlier years may be somewhat farfetched. 


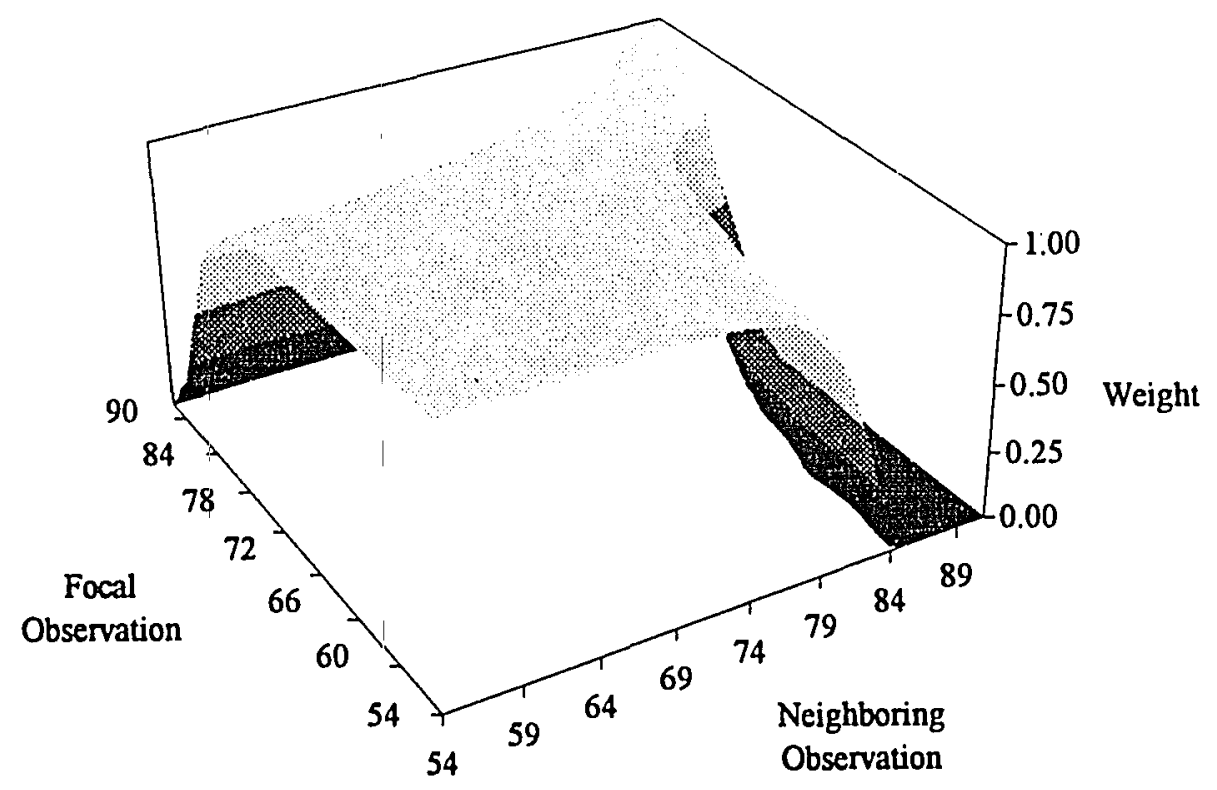

Figure 16. Weight surface of $\mathrm{K}$ Nearest Neighbor kernel weight $(\mathrm{r}=1.0)$.

Furthermore, the choice between Normal kernel and K Nearest Neighbor kernel may be explained by Figure 17 which also uses the maximal possible window size. The relevant observations, after weighting for each local estimation, are obviously limited, which frequently leads to difficulty in obtaining useful results.

\section{Models 4A and 4B: Locally Weighted Optimization}

With the determination of $\mathrm{K}$ Nearest Neighbor kernel weight of 0.5 window size, the next step is to specify the function to be fitted locally. Since there is a hyperbolic or discrete-switching relationship between the demand and supply, the locally weighted optimization model in this case can not be claimed as a pure non-parametric one: even though demand and supply functions do not 


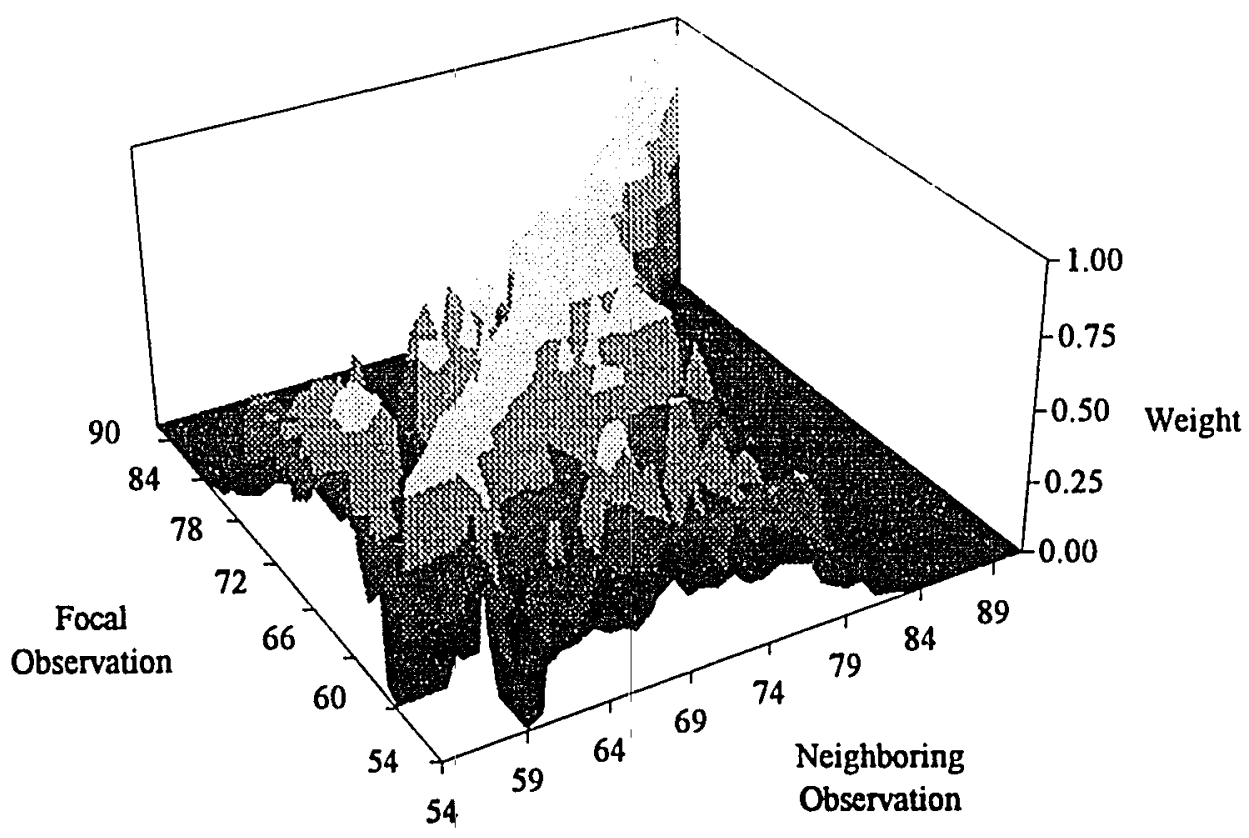

Figure 17. Weight surface of Normal kernel weight ( $r=$ infinity).

have specific parametric forms, transaction function does. The first-order polynomial approximation of the demand and supply functions, together with the

parametric transaction function of a hyperbolic relation between $D$ and $S$ constitute the following Model 4A:

$$
\begin{gathered}
D=A_{i}^{D}+\alpha_{1 i}\left(S A V 1-S A V 1_{i}\right)+\alpha_{2 i}\left(D Y D-D Y D_{i}\right)+\alpha_{3 i}\left(Y D 1-Y D I_{i}\right) \\
S=A_{i}^{S}+B_{1 i}\left(C T-C T_{i}\right)+B_{2 i}\left(N M P X-N M P X_{i}\right)+B_{3 i}\left(C Z X-C Z X_{i}\right) \\
C=\frac{1}{2}(D+S)-\frac{1}{2} \sqrt{(D-S)^{2}+4 \gamma^{2} D S}+\epsilon .
\end{gathered}
$$

The log-likelihood function for Model $4 \mathrm{~A}$ is 


$$
\begin{gathered}
l l=\sum_{i=1}^{N} \log H\left(C_{i}\right)=-\frac{N}{2}[1+\log (2 \pi)]-\frac{N}{2} \log \left[\frac{1}{N} \sum_{i=1}^{N}\left(\epsilon_{i}^{2} * \text { kemel }_{i}\right)\right] \\
\epsilon=C-\left[\frac{1}{2}(D+S)-\frac{1}{2} \sqrt{(D-S)^{2}+4 \gamma^{2} D S}\right] .
\end{gathered}
$$

Adding error terms to $\mathrm{D}$ and $\mathrm{S}$ and maintaining the short-side transaction rule with a discrete-switching transaction function, Model 4B is:

$$
\begin{aligned}
& D=A_{i}^{D}+\alpha_{i 1}\left(S A V 1-S A V 1_{i}\right)+\alpha_{2 i}\left(D Y D-D Y D_{i}\right)+\alpha_{3 i}\left(Y D 1-Y D 1_{i}\right)+\epsilon_{1} ; \\
& S=A_{i}^{S}+B_{1 i}\left(C T-C T_{i}\right)+B_{2 i}\left(N M P X-N M P X_{i}\right)+B_{3 i}\left(C Z X-C Z X_{i}\right)+\epsilon_{2} \text {, } \\
& C=\min (D, S) \text {. }
\end{aligned}
$$

The log-likelihood function for this model is:

$$
l l=\sum_{i=1}^{N} \log \left[h_{1}\left(C_{i}\right) \int_{c_{i}}^{\infty} h_{2}\left(S_{i}\right) d S_{i}+h_{2}\left(C_{i}\right) \int_{c_{i}}^{\infty} h_{1}\left(D_{i}\right) d D_{i}\right]
$$

where $h_{1}$ and $h_{2}$ are weighted accordingly using kernel weights:

$$
\begin{gathered}
h_{1}\left(D_{i}\right)=\frac{1}{\sqrt{2 \pi \sigma_{1}^{2}}} \exp \left(-\frac{\epsilon_{1 i}^{2} * \text { kernel }_{i}}{2 \sigma_{1}^{2}}\right) ; \\
h_{2}\left(S_{i}\right)=\frac{1}{\sqrt{2 \pi \sigma_{2}^{2}}} \exp \left(-\frac{\epsilon_{2 i}^{2} * \text { kernel }_{i}}{2 \sigma_{2}^{2}}\right), \\
\epsilon_{1}=D-\left[A^{D}{ }_{i}+\alpha_{i 1}\left(S A V 1-S A V 1_{i}\right)+\alpha_{2 i}\left(D Y D-D Y D_{i}\right)+\alpha_{3 i}\left(Y D 1-Y D 1_{i}\right)\right] ; \\
\epsilon_{2}=S-\left[A^{S}{ }_{i}+B_{1 i}\left(C T-C T_{i}\right)+B_{2 i}\left(N M P X-N M P X_{i}\right)+B_{3 i}\left(C Z X-C Z X_{i}\right)\right] . \\
A^{\mathrm{D}}{ }_{i} \text { and } A_{i}^{S} \text { are the intercepts in, or the estimated values of, the D and } S
\end{gathered}
$$
functions at observation i, respectively. $\alpha$ 's are the responses of $D$ with respect 
to its corresponding explanatory variables, SAV1, DYD and YD1 by first-order approximation. Similarly, $\mathrm{B}^{\prime} \mathrm{s}$ are the responses of $\mathrm{S}$ with respect to its corresponding explanatory variables, CT, NMPX and CZX.

From 1954 to 1991, coefficients are estimated with respect to each of the observations, which resulted in 38 sets of estimated intercept and response coefficients. The lists of 38 estimated response coefficients from Model 4A and Model 4B are in Appendix D. Taking the entire sample as a whole, the averages of the estimated response coefficients and their standard errors using both the hyperbolic and discrete-switching transaction functions are summarized in Table XI. Table XII and Table XIII present the averages and standard errors of the response coefficients before and after 1980, respectively. It is obvious that the estimates using different transaction functions are not fundamentally different.

The response coefficients in Table XII and Table XIII further confirm that there is a structural change before and after 1980, although the magnitudes of changes in the response coefficients are a little different from the ones shown in Table VI and Table VII using equal weight global fitting with a dummy variable. The values of $B_{3}$, which is the response of $S$ with respect to the changes in variable CZX, in the two time periods as presented in Table XII and Table XIII are not so distinctively different as the ones shown in Table VI and Table VII. The very low absolute values of $B_{3}$ in the later years of the 1980's lead to a lower mean absolute value for the entire second period. Further 
TABLE XI

AVERAGE ESTIMATES AND STANDARD ERRORS OF THE RESPONSE COEFFICIENTS OF MODELS 4A AND 4B: USING LOCALLY WEIGHTED OPTIMIZATION 1954-1991

\begin{tabular}{|c|c|c|}
\hline $\begin{array}{l}\text { Response } \\
\text { Coefficient }\end{array}$ & $\begin{array}{c}\text { Hyperbolic } \\
\text { Transaction Function } \\
\text { Model 4A }\end{array}$ & $\begin{array}{c}\text { Discrete-Switching } \\
\text { Transaction Function } \\
\text { Model 4B }\end{array}$ \\
\hline$\alpha_{1}$ & $\begin{array}{c}-0.575 \\
(0.373)\end{array}$ & $\begin{array}{c}-0.536 \\
(0.404)\end{array}$ \\
\hline$\alpha_{2}$ & $\begin{array}{r}0.587 \\
(0.174)\end{array}$ & $\begin{array}{c}0.576 \\
(0.198)\end{array}$ \\
\hline$\alpha_{3}$ & $\begin{array}{c}0.970 \\
(0.068)\end{array}$ & $\begin{array}{c}0.957 \\
(0.071)\end{array}$ \\
\hline$B_{1}$ & $\begin{array}{c}1.023 \\
(0.065)\end{array}$ & $\begin{array}{r}1.028 \\
(0.080)\end{array}$ \\
\hline$B_{2}$ & $\begin{array}{r}0.862 \\
(0.160)\end{array}$ & $\begin{array}{c}0.903 \\
(0.144)\end{array}$ \\
\hline $\mathrm{B}_{3}$ & $\begin{array}{c}-0.820 \\
(0.173)\end{array}$ & $\begin{array}{r}-0.721 \\
(0.349)\end{array}$ \\
\hline$\gamma$ & $\begin{array}{r}0.000 \\
(0.003)\end{array}$ & \\
\hline$\sigma_{1}$ & & $\begin{array}{c}0.619 \\
(0.461)\end{array}$ \\
\hline$\sigma_{2}$ & & $\begin{array}{r}1.482 \\
(0.904)\end{array}$ \\
\hline
\end{tabular}

investigation of the estimates in Table VI and Table VII reveals that the value of $B_{32}$, which is the coefficient of CZX in the second time period with a dummy variable, is insignificant. That is, there may not be a strong argument to 
TABLE XII

AVERAGE ESTIMATES AND STANDARD ERRORS OF THE RESPONSE COEFFICIENTS OF MODELS 4A AND 4B: USING LOCALLY WEIGHTED OPTIMIZATION 1954-1979

\begin{tabular}{|c|c|c|}
\hline $\begin{array}{l}\text { Response } \\
\text { Coefficient }\end{array}$ & $\begin{array}{c}\text { Hyperbolic } \\
\text { Transaction Function } \\
\text { Model 4A }\end{array}$ & $\begin{array}{c}\text { Discrete-Switching } \\
\text { Transaction Function } \\
\text { Model 4B }\end{array}$ \\
\hline$\alpha_{1}$ & $\begin{array}{c}-0.801 \\
(0.152)\end{array}$ & $\begin{array}{c}-0.786 \\
(0.074)\end{array}$ \\
\hline$\alpha_{2}$ & $\begin{array}{r}0.672 \\
(0.089)\end{array}$ & $\begin{array}{r}0.688 \\
(0.066)\end{array}$ \\
\hline$\alpha_{3}$ & $\begin{array}{c}1.009 \\
(0.028)\end{array}$ & $\begin{array}{c}1.001 \\
(0.021)\end{array}$ \\
\hline$B_{1}$ & $\begin{array}{c}1.033 \\
(0.075)\end{array}$ & $\begin{array}{r}1.046 \\
(0.091)\end{array}$ \\
\hline$B_{2}$ & $\begin{array}{c}0.776 \\
(0.094)\end{array}$ & $\begin{array}{c}0.911 \\
(0.117)\end{array}$ \\
\hline $\mathrm{B}_{3}$ & $\begin{array}{c}-0.836 \\
(0.120)\end{array}$ & $\begin{array}{c}-0.908 \\
(0.115)\end{array}$ \\
\hline$\gamma$ & $\begin{array}{c}-0.001 \\
(0.003)\end{array}$ & \\
\hline$\sigma_{1}$ & & $\begin{array}{c}0.416 \\
(0.179) \\
\end{array}$ \\
\hline$\sigma_{2}$ & & $\begin{array}{c}1.606 \\
(1.029)\end{array}$ \\
\hline
\end{tabular}

conclude that $B_{3}$ is different before and after 1980 in Table VI and Table VII. 
TABLE XIII

AVERAGE ESTIMATES AND STANDARD ERRORS OF THE RESPONSE COEFFICIENTS OF MODELS 4A AND 4B: USING LOCALLY WEIGHTED OPTIMIZATION 1980-1991

\begin{tabular}{|c|c|c|}
\hline $\begin{array}{l}\text { Response } \\
\text { Coefficient }\end{array}$ & $\begin{array}{c}\text { Hyperbolic } \\
\text { Transaction Function } \\
\text { Model 4A }\end{array}$ & $\begin{array}{c}\text { Discrete-Switching } \\
\text { Transaction Function } \\
\text { Model 4B }\end{array}$ \\
\hline$\alpha_{1}$ & $\begin{array}{c}-0.084 \\
(0.177)\end{array}$ & $\begin{array}{r}0.005 \\
(0.265)\end{array}$ \\
\hline$\alpha_{2}$ & $\begin{array}{c}0.403 \\
(0.175)\end{array}$ & $\begin{array}{c}0.334 \\
(0.167)\end{array}$ \\
\hline$\alpha_{3}$ & $\begin{array}{r}0.884 \\
(0.046)\end{array}$ & $\begin{array}{r}0.964 \\
(0.046)\end{array}$ \\
\hline $\mathrm{B}_{1}$ & $\begin{array}{c}1.003 \\
(0.026)\end{array}$ & $\begin{array}{r}0.988 \\
(0.017)\end{array}$ \\
\hline$B_{2}$ & $\begin{array}{c}1.049 \\
(0.104)\end{array}$ & $\begin{array}{r}0.888 \\
.(0.194)\end{array}$ \\
\hline $\mathrm{B}_{3}$ & $\begin{array}{c}-0.787 \\
(0.257)\end{array}$ & $\begin{array}{c}-0.316 \\
(0.345)\end{array}$ \\
\hline$\gamma$ & $\begin{array}{c}0.000 \\
(0.000)\end{array}$ & \\
\hline$\sigma_{1}$ & & $\begin{array}{r}1.058 \\
(0.577) \\
. . . . \cdots\end{array}$ \\
\hline$\sigma_{2}$ & & $\begin{array}{c}1.214 \\
(0.481)\end{array}$ \\
\hline
\end{tabular}

Because the estimates obtained using the discrete-switching transaction function are similar to those obtained using the hyperbolic function, only the response coefficients from the hyperbolic transaction are presented in the 
following Figure 18 and Table XIV for clarity purposes. Figure 18 graphs the estimates of the response coefficients over the years. It demonstrates the fluctuations of the response coefficients between 1954 and 1991. Table XIV summarizes the means and standard errors of the estimated response coefficients in various periods from 1954 to 1991.
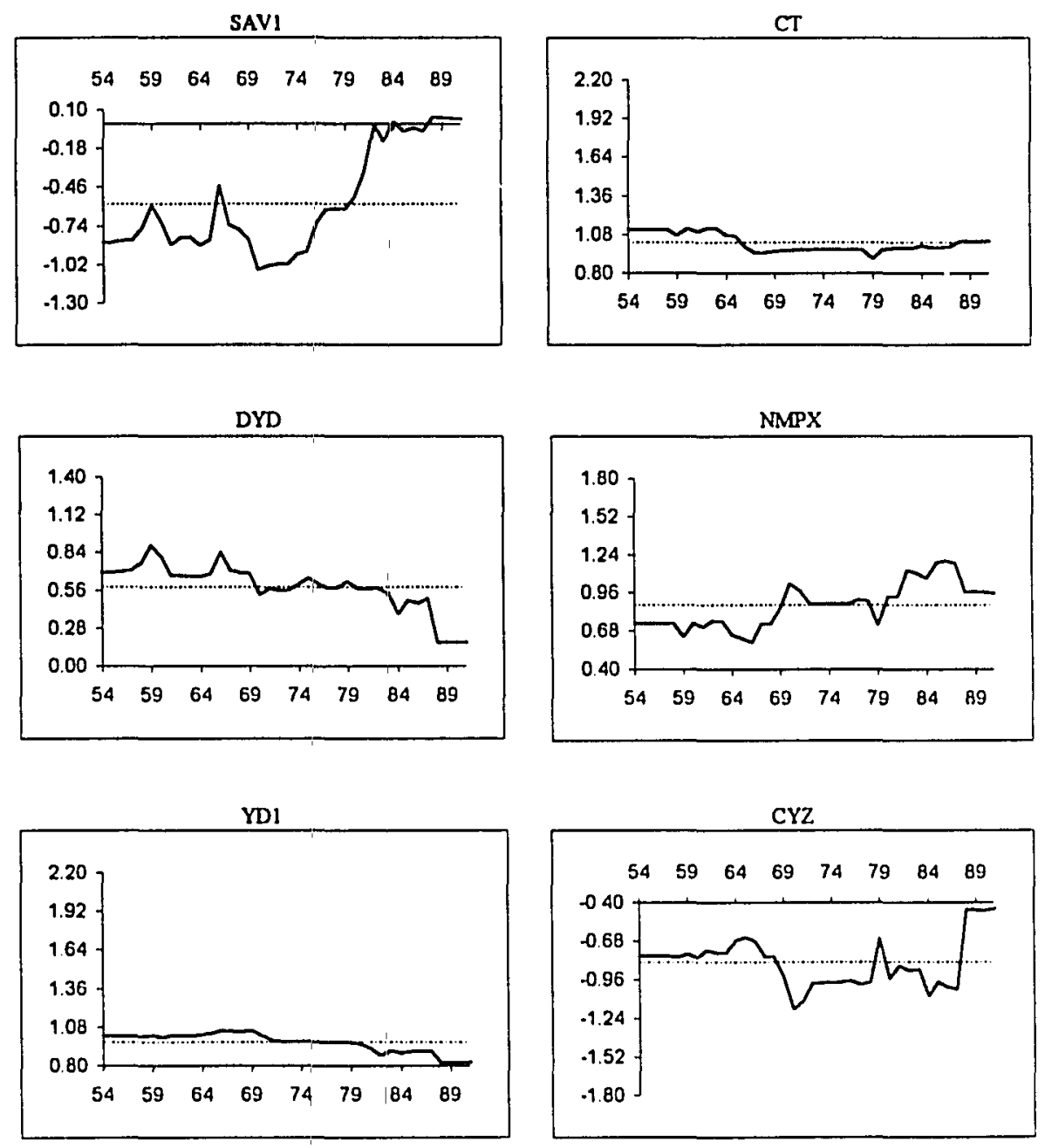

Figure 18. Response coefficient estimates using locally weighted optimization (Model 4A). 
TABLE XIV

AVERAGE ESTIMATES AND STANDARD ERRORS OF

THE RESPONSE COEFFICIENTS OF MODEL 4A:

USING LOCALLY WEIGHTED OPTIMIZATION

VARIOUS PERIODS

\begin{tabular}{|c|c|c|c|c|c|c|c|}
\hline & \multicolumn{3}{|c|}{ D } & \multicolumn{3}{|c|}{$S$} & \multirow{2}{*}{$\begin{array}{l}\mathrm{C} \\
\gamma\end{array}$} \\
\hline & $\alpha_{1}$ & $\alpha_{2}$ & $\alpha_{3}$ & $B_{1}$ & $B_{2}$ & $B_{3}$ & \\
\hline $54-57$ & $\begin{array}{c}-0.847 \\
(0.010)\end{array}$ & $\begin{array}{c}0.701 \\
(0.009)\end{array}$ & $\begin{array}{c}1.018 \\
(0.001)\end{array}$ & $\begin{array}{c}1.113 \\
(0.000)\end{array}$ & $\begin{array}{c}0.736 \\
(0.001)\end{array}$ & $\begin{array}{c}-0.784 \\
(0.002)\end{array}$ & $\begin{array}{c}0.000 \\
(0.000)\end{array}$ \\
\hline $58-66$ & $\begin{array}{c}-0.749 \\
(0.145)\end{array}$ & $\begin{array}{c}0.742 \\
(0.088)\end{array}$ & $\begin{array}{c}1.025 \\
(0.017)\end{array}$ & $\begin{array}{c}1.091 \\
(0.043)\end{array}$ & $\begin{array}{c}0.690 \\
(0.060)\end{array}$ & $\begin{array}{c}-0.737 \\
(0.055)\end{array}$ & $\begin{array}{c}0.002 \\
(0.005)\end{array}$ \\
\hline $67-77$ & $\begin{array}{c}-0.878 \\
(0.152)\end{array}$ & $\begin{array}{c}0.614 \\
(0.061)\end{array}$ & $\begin{array}{c}1.003 \\
(0.035)\end{array}$ & $\begin{array}{c}0.968 \\
(0.010)\end{array}$ & $\begin{array}{c}0.876 \\
(0.087)\end{array}$ & $\begin{array}{c}-0.970 \\
(0.113)\end{array}$ & $\begin{array}{c}0.000 \\
(0.000)\end{array}$ \\
\hline $78-79$ & $\begin{array}{c}-0.613 \\
(0.003)\end{array}$ & $\begin{array}{c}0.603 \\
(0.028)\end{array}$ & $\begin{array}{c}0.974 \\
(0.000)\end{array}$ & $\begin{array}{c}0.941 \\
(0.045)\end{array}$ & $\begin{array}{c}0.813 \\
(0.121)\end{array}$ & $\begin{array}{c}-0.816 \\
(0.220)\end{array}$ & $\begin{array}{c}0.000 \\
(0.000)\end{array}$ \\
\hline $80-84$ & $\begin{array}{c}-0.253 \\
(0.229)\end{array}$ & $\begin{array}{c}0.567 \\
(0.016)\end{array}$ & $\begin{array}{c}0.918 \\
(0.033)\end{array}$ & $\begin{array}{c}0.982 \\
(0.004)\end{array}$ & $\begin{array}{c}1.025 \\
(0.104)\end{array}$ & $\begin{array}{c}-0.896 \\
(0.039)\end{array}$ & $\begin{array}{c}0.000 \\
(0.000)\end{array}$ \\
\hline $85-87$ & $\begin{array}{c}-0.044 \\
(0.016)\end{array}$ & $\begin{array}{c}0.484 \\
(0.017)\end{array}$ & $\begin{array}{c}0.909 \\
(0.004)\end{array}$ & $\begin{array}{c}0.992 \\
(0.005)\end{array}$ & $\begin{array}{c}1.185 \\
(0.011)\end{array}$ & $\begin{array}{c}-1.003 \\
(0.028)\end{array}$ & $\begin{array}{c}0.000 \\
(0.000)\end{array}$ \\
\hline $88-91$ & $\begin{array}{c}0.041 \\
(0.006)\end{array}$ & $\begin{array}{c}0.176 \\
(0.001)\end{array}$ & $\begin{array}{c}0.828 \\
(0.001)\end{array}$ & $\begin{array}{c}1.032 \\
(0.001)\end{array}$ & $\begin{array}{c}0.965 \\
(0.004)\end{array}$ & $\begin{array}{c}-0.449 \\
(0.007)\end{array}$ & $\begin{array}{c}0.000 \\
(0.000)\end{array}$ \\
\hline
\end{tabular}

From 1954 to 1957, there was a recovery period after the communists took the power. Between 1954 and 1957, $\alpha_{3}$, the response of demand with respect to the previous income level, is statistically significantly greater than 1. Then, in later periods of the economic reform, it is significantly smaller than 1. According to the Houthakker-Taylor savings function from which the demand function is derived, $\alpha_{3}$ should be close to 1 . Thus, at the beginning of the 
communist regime and after the economic reform, the relationship of demand and supply in the consumer goods market may not be well explained by the model intended for CPEs. Another response coefficient of interest is $\beta_{1}$, which is the response of government long-term plans with relation to past consumption. Its value oscillates around 1 , with the value of 1 as supply following the historical trend of consumption. Table XIV clearly indicates that the value of $\beta_{1}$ is significantly greater than 1 in periods of 1954-57, 1958-66, and 1988-91, and significantly smaller than 1 in periods of $1967-77$ and 1980-84. Such variation corresponds very well to the shifting of consumption component in national income. Refer back to Figure 1 in Chapter I, where it is shown that during the same periods when $B_{1}$ is greater than 1 , the percentage of consumption in national income increased, whereas during the periods when $B_{1}$ is smaller than 1 , the share of consumption component in national income decreased.

From Table XIV, all the response coefficients in the periods before the economic reform are very close. Yet, they change drastically after 1980, especially in recent years. For example, in the late 1980's, household savings no longer has the same effects on demand as suggested by the theory. In particular, the value of $\alpha_{1}$ has changed from negative to positive. The impact of changes in income level on demand diminishes, reflected by a lower value of $\alpha_{2}$. During the fast growth period, from 1985 to 1987 , the estirnated value of $B_{2}$ is greater than 1. In this period, personal consumption fluctuates to compensate for other 
development in the economy. That is, it behaves as a buffer for the economic shocks as discussed by Portes and Winter (1980).

Until now, the present study has focused on the structural change brought by the economic reform in 1980 . However, examining the response coefficients more closely exhibits the possibility of yet another structural change after 1988 . Due to the limited sample size, this is not tested using traditional methods. This change in the later years may actually be a change in the specifications of demand and supply functions. In fact, it is very difficult to get satisfactory estimation results for the later years with all the response coefficients complying with the preordained restrictions. The estimations may converge more easily and have higher maximum likelihood function values if the response coefficients are not forced to take values within certain ranges. It may be reasonable to suggest another set of explanatory variables for the model, since in recent years the economic policies have changed from passive control to more freedom with active regulation. For example, interest rates and monetary supply have been adjusted, and the stock /market has opened although it is to a limited degree. In summary, it is evident that there is a structural change around 1980, and the results from both global fitting of structural change and locally weighted estimation methods are consistent. In addition to showing the response coefficient changes around 1980 , the results from locally weighted optimization also uncover other response coefficient variations over the years without compromising the degree of freedom in model estimation. It is important to 
emphasize that the functional forms of demand and supply are not specified in the locally weighted estimation. The demand and supply estimated by both global fitting and locally weighted fitting methods show that the Portes-Winter specification can describe the Chinese consumer goods market fairly well, with the exception in the later years when the Chinese economy is no longer a pure centrally controlled system. Except in the late 1980's, the value of response coefficients vary during the recent years, but they are still well within the theoretical ranges. For the later years when the characteristics of the economy changed, the technique of locally weighted fitting makes it possible to estimate the demand and supply without extensive effort to search for the appropriate functional forms to represent them. 


\section{CHAPTER V}

\section{EXCESS DEMAND EVALUATION}

Based on the parameters estimated in Chapter IV, this chapter evaluates the state of consumer goods market in China: the state of excess demand (shortage) and excess supply (surplus). This chapter will also compare the results of excess demand and excess supply obtained from the two fitting methods, global fitting and locally weighted fitting. Because the results from the hyperbolic and discrete-switching transaction functions are essentially the same, parameters estimated using the hyperbolic transaction function (Model 2A and Model 4A) are adopted in the present evaluation of excess demand and excess supply.

\section{V.1 EXCESS DEMAND ESTIMATES FROM THE GLOBAL ESTIMATION OF STRUCTURAL CHANGE (MODEL 2A)}

Recall that Model 2A is a disequilibrium model of structural change using the dummy variable approach. In Table XV, together with the actual transaction, the estimated demand $(\hat{D})$, supply $(\hat{S})$ as well as transaction $\left(\hat{C}=\frac{1}{2}(\hat{D}+\hat{S})-\frac{1}{2} \sqrt{(\hat{D}-\hat{S})^{2}+4 \gamma^{2} \hat{D} \hat{S}}\right)$ are listed for Model $2 \mathrm{~A}$. Also in the table are 
the relative excess demand $((\hat{D}-\hat{C}) / \hat{C})$ and relative excess supply $((\hat{S}-\hat{C}) / \hat{C})$ as percentages of fitted consumption. The asterisk marks the significance of excess demand or excess supply in two standard errors. All quantity series are expressed in real terms, billions of 1952 Chinese yuan.

TABLE XV

ESTIMATED D, S AND C FROM MODEL 2A

\begin{tabular}{|ccccccccc|}
\hline Year & $C$ & $\hat{C}$ & $\hat{D}$ & $\hat{S}$ & $\begin{array}{c}(\hat{D}-\hat{C}) / \hat{C} \\
(\%)\end{array}$ & $\begin{array}{c}(\hat{S}-\hat{C}) / \hat{C} \\
(\%)\end{array}$ \\
\hline 54 & 49.13 & 49.05 & 49.05 & 50.24 & 0.00 & 2.43 & $*$ \\
55 & 53.42 & 52.52 & 52.52 & 53.98 & 0.00 & 2.79 & $*$ \\
56 & 56.90 & 57.29 & 57.47 & 57.29 & 0.32 & 0.00 & \\
57 & 59.76 & 59.33 & 59.33 & 60.65 & 0.00 & 2.21 & \\
58 & 62.11 & 61.71 & 63.31 & 61.71 & 2.60 & 0.00 & \\
59 & 57.07 & 57.03 & 60.43 & 57.03 & 5.97 & $*$ & 0.00 & \\
60 & 53.77 & 54.87 & 54.87 & 60.19 & 0.00 & 9.70 & $*$ \\
61 & 50.04 & 51.48 & 51.48 & 61.42 & 0.00 & 19.31 & $*$ \\
62 & 52.69 & 50.26 & 50.26 & 64.50 & 0.00 & 28.33 & $*$ \\
63 & 59.54 & 60.38 & 60.38 & 66.48 & 0.00 & 10.11 & $*$ \\
64 & 64.71 & 64.60 & 64.60 & 69.09 & 0.00 & 6.94 & $*$ \\
65 & 72.39 & 71.16 & 71.16 & 71.16 & 0.00 & 0.00 & \\
66 & 77.47 & 76.60 & 77.51 & 76.60 & 1.18 & 0.00 & \\
67 & 82.07 & 80.87 & 80.87 & 81.57 & 0.00 & & 0.86 & \\
68 & 81.42 & 81.53 & 83.39 & 81.53 & 2.28 & $*$ & 0.00 & \\
69 & 85.89 & 84.35 & 84.35 & 87.31 & 0.00 & & 3.52 & $*$ \\
70 & 91.92 & 90.92 & 90.92 & 93.45 & 0.00 & & 2.78 & $*$ \\
71 & 95.52 & 96.60 & 97.65 & 96.60 & 1.08 & $*$ & 0.00 & \\
72 & 100.65 & 100.08 & 100.08 & 102.49 & 0.00 & & 2.40 & $*$ \\
73 & 108.42 & 107.99 & 107.99 & 109.43 & 0.00 & & 1.33 & $*$ \\
& & & & & & & & \\
\hline
\end{tabular}


TABLE XV

ESTIMATED D, S AND C FROM MODEL 2A (continued)

\begin{tabular}{|c|c|c|c|c|c|c|c|c|}
\hline \multirow{2}{*}{$\frac{\text { Year }}{74}$} & \multirow{2}{*}{$\frac{C}{110.50}$} & \multirow{2}{*}{$\frac{\hat{C}}{111.61}$} & \multirow{2}{*}{$\frac{\hat{D}}{111.61}$} & \multirow{2}{*}{$\frac{\hat{S}}{113.20}$} & \multicolumn{2}{|c|}{$\begin{array}{c}(\hat{D}-\hat{C}) / \hat{C} \\
(\%)\end{array}$} & \multicolumn{2}{|c|}{$\begin{array}{c}(\hat{S}-\hat{C}) / \hat{C} \\
(\%)\end{array}$} \\
\hline & & & & & 0.00 & & 1.43 & $*$ \\
\hline 75 & 114.53 & 114.62 & 114.62 & 119.16 & 0.00 & & 3.96 & $*$ \\
\hline 76 & 118.40 & 118.84 & 118.84 & 125.90 & 0.00 & & 5.94 & $*$ \\
\hline 77 & 121.26 & 121.33 & 121.33 & 129.91 & 0.00 & & 7.07 & * \\
\hline 78 & 129.12 & 130.23 & 130.23 & 136.28 & 0.00 & & 4.64 & $*$ \\
\hline 79 & 139.58 & 140.58 & 140.58 & 147.54 & 0.00 & & 4.95 & $*$ \\
\hline 80 & 154.72 & 153.97 & 153.97 & 155.40 & 0.00 & & 0.93 & \\
\hline 81 & 167.52 & 166.80 & 166.80 & 172.32 & 0.00 & & 3.31 & $*$ \\
\hline 82 & 178.72 & 177.93 & 177.93 & 187.84 & 0.00 & & 5.57 & * \\
\hline 83 & 193.74 & 195.39 & 195.39 & 204.37 & 0.00 & & 4.60 & $*$ \\
\hline 84 & 217.82 & 219.65 & 228.85 & 219.65 & 4.19 & * & 0.00 & \\
\hline 85 & 249.94 & 247.61 & 251.87 & 247.61 & 1.72 & * & 0.00 & \\
\hline 86 & 264.48 & 266.46 & 274.11 & 266.46 & 2.87 & * & 0.00 & \\
\hline 87 & 284.09 & 282.76 & 301.88 & 282.76 & 6.76 & $*$ & 0.00 & \\
\hline 88 & 308.49 & 308.46 & 308.46 & 322.21 & 0.00 & & 4.46 & $*$ \\
\hline 89 & 310.61 & 310.79 & 310.79 & 330.30 & 0.00 & & 6.28 & * \\
\hline 90 & 322.24 & 325.42 & 364.43 & 325.42 & 11.99 & * & 0.00 & \\
\hline 91 & 353.58 & 350.71 & 401.43 & 350.71 & 14.46 & $*$ & 0.00 & \\
\hline
\end{tabular}

Figure 19 is a graphical display of the estimated net excess demand $(\hat{D}-\hat{S})$ with two-standard-error range of the equilibrium (zero excess demand). The graph demonstrates clearly that the status of the consumer goods market alternates between excess demand and excess supply. 


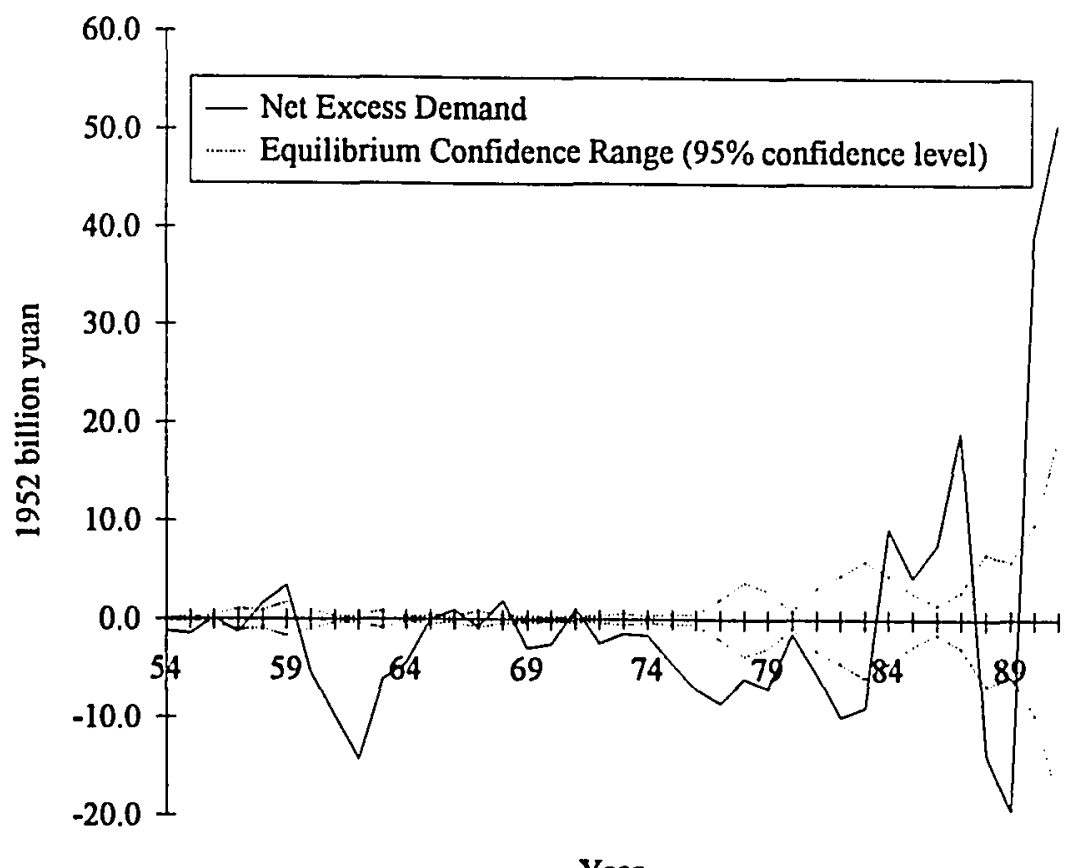

Figure 19. Estimated excess demand with two-standard-error range of equilibrium from global fitting.

The pattern of excess demand and excess supply in the above table agrees fairly well with the history of the Chinese economy ${ }^{1}$. When the economy gradually recovered from what was left by the Nationalist government, there was the "Great Leap Forward" from 1957 to 1960 . Those years were aimed at doubling the output from agriculture and steel production, and the movement distorted the normal proportion of various production departments and damaged

1. Estimation results from the discrete-switching model include the probability of an observation being in excess demand. Those probabilities, in general, agree with the significance shown in Table XV. The probabilities are listed in Appendix C. 
resources. Not only were the goals not achieved, but there was also a shortage of consumer goods.

In the early 1960's, there were severe natural disasters coupled with huge debt repayment in the form of both monetary and physical goods. Table XV does not reflect such a hardship on consumers during those years. This may be the result of different accounting procedures and data problems. There is no data available on the debt payment with physical goods.

Not long after the economy started to recover from the disasters, ten years of turmoil during the Cultural Revolution, between 1966 and 1976, brought the economy to a halt. However, there were years with excess supply. During the decade, purchasing power was hindered due to the slow growth of disposable personal income. In the late 1970's, the enthusiasm of "revolution" declined and production activities partially resumed. Near the end of that period, national income increased without much additional investment in fixed assets. (See Figure 2 in Chapter I.) Moreover, blind production without adequate planning could not meet the demand for many goods at the same time resulting in huge inventories and waste of others.

At the end of 1979, the government started the reform process to stimulate the economy. Due to insufficient information and lack of distribution channels, and due also to the fact that enterprises were in the early stages of managing their own activities, as well as government intervention, the economy 
oscillated between producing too much or not enough to meet the demand of consumer goods.

Non-existence of persistent shortage (excess demand) may seem to be contradictory to the history when consumers have not been satisfied with what they can purchase. However, such dissatisfaction can be of two kinds. First, the goods which consumers want are not available or are insufficient. Second, the: consumer purchasing power is limited. If it has been the former situation for a period of time, there will be persistent shortage. Savings will accumulate as consumers are forced to save. In the latter case, chronic shortage will not be present although customers are dissatisfied. The Chinese economy seems to be of the latter situation. Further discussion of the relationship between excess demand and savings is given in the following section.

\section{V.2 EXCESS DEMAND ESTIMATES FROM THE LOCALLY WEIGHTED FITTING (MODEL 4A)}

Table XVI lists the estimates of demand, supply and transaction in the Chinese consumer goods market using the technique of locally weighted optimization. All columns have the same definitions and interpretations as in Table XV. In particular, the estimates of $D$ and $S$ are the estimates of the constant terms in the non-parametric approximation of demand and supply, $A^{P}$ and $\mathrm{A}_{\mathrm{i}}^{\mathrm{S}}$, respectively. (See section IV.3.) 
TABLE XVI

ESTIMATED D, S AND C FROM MODEL 4A

\begin{tabular}{|ccccccccc|}
\hline & & & & & $(\hat{D}-\hat{C}) / \hat{C}$ & \multicolumn{2}{c|}{$(\hat{S}-\hat{C}) / \hat{C}$} \\
Year & $C$ & $\hat{C}$ & $\hat{D}$ & $\hat{S}$ & $(\%)$ & $(\%)$ \\
\hline 54 & 49.13 & 49.28 & 49.28 & 49.68 & 0.00 & 0.81 \\
55 & 53.42 & 52.89 & 52.89 & 53.58 & 0.00 & 1.31 \\
56 & 56.90 & 57.10 & 57.87 & 57.10 & 1.36 & 0.00 \\
57 & 59.76 & 59.76 & 59.76 & 60.61 & 0.00 & & 1.42 \\
58 & 62.11 & 61.89 & 63.79 & 61.89 & 3.07 & $*$ & 0.00 & \\
59 & 57.07 & 57.43 & 59.74 & 57.43 & 4.01 & $*$ & 0.00 & \\
60 & 53.77 & 54.23 & 54.23 & 60.44 & 0.00 & & 11.45 & $*$ \\
61 & 50.04 & 51.42 & 51.42 & 61.31 & 0.00 & & 19.23 & $*$ \\
62 & 52.69 & 50.29 & 50.29 & 63.72 & 0.00 & & 26.70 & $*$ \\
63 & 59.54 & 60.29 & 60.29 & 66.15 & 0.00 & & 9.71 & $*$ \\
64 & 64.71 & 65.05 & 65.05 & 69.46 & 0.00 & & 6.78 & $*$ \\
65 & 72.39 & 71.98 & 72.10 & 71.98 & 0.17 & & 0.00 & \\
66 & 77.47 & 77.10 & 79.43 & 77.10 & 3.02 & $*$ & 0.00 & \\
67 & 82.07 & 82.04 & 82.54 & 82.04 & 0.60 & $*$ & 0.00 & \\
68 & 81.42 & 81.44 & 84.50 & 81.44 & 3.75 & $*$ & 0.00 & \\
69 & 85.89 & 85.59 & 85.59 & 87.19 & 0.00 & & 1.87 & $*$ \\
70 & 91.92 & 91.85 & 91.85 & 93.63 & 0.00 & & 1.94 & $*$ \\
71 & 95.52 & 95.57 & 98.38 & 95.57 & 2.94 & $*$ & 0.00 & \\
72 & 100.65 & 100.62 & 100.62 & 101.32 & 0.00 & & 0.70 & $*$ \\
73 & 108.42 & 108.10 & 108.10 & 108.10 & 0.00 & & 0.00 & \\
74 & 110.50 & 110.77 & 111.72 & 110.77 & 0.86 & $*$ & 0.00 & \\
75 & 114.53 & 114.67 & 114.67 & 115.87 & 0.00 & & 1.05 & $*$ \\
76 & 118.40 & 118.70 & 118.70 & 121.78 & 0.00 & & 2.59 & $*$ \\
77 & 121.26 & 121.02 & 121.02 & 123.92 & 0.00 & & 2.40 & $*$ \\
& & & & & & & & \\
\hline & & & & & & & & \\
& $*$
\end{tabular}


TABLE XVI

ESTIMATED D, S AND C FROM MODEL 4A

(continued)

\begin{tabular}{|ccccccccc|}
\hline & & & & & $(\hat{D}-\hat{C}) / \hat{C}$ & \multicolumn{2}{c|}{$(\hat{S}-\hat{C}) / \hat{C}$} \\
Year & $C$ & $\hat{C}$ & $\hat{D}$ & $\hat{S}$ & $(\%)$ & 0.00 & \\
\hline 78 & 129.12 & 128.85 & 128.85 & 128.85 & 0.00 & & 0.00 \\
79 & 139.58 & 139.57 & 140.23 & 139.57 & 0.47 & $*$ & 0.00 & \\
80 & 154.72 & 154.77 & 154.77 & 158.14 & 0.00 & & 2.18 & $*$ \\
81 & 167.52 & 167.52 & 167.52 & 172.34 & 0.00 & & 2.88 & $*$ \\
82 & 178.72 & 178.97 & 178.97 & 185.09 & 0.00 & & 3.42 & $*$ \\
83 & 193.74 & 194.54 & 194.54 & 201.20 & 0.00 & & 3.42 & $*$ \\
84 & 217.82 & 218.82 & 218.82 & 221.45 & 0.00 & & 1.20 & $*$ \\
85 & 249.94 & 248.39 & 248.39 & 248.39 & 0.00 & & 0.00 & \\
86 & 264.48 & 266.97 & 269.12 & 266.97 & 0.81 & $*$ & 0.00 & \\
87 & 284.09 & 282.61 & 294.64 & 282.61 & 4.26 & $*$ & 0.00 & \\
88 & 308.49 & 309.06 & 309.06 & 317.54 & 0.00 & & 2.74 & $*$ \\
89 & 310.61 & 309.74 & 309.74 & 326.12 & 0.00 & & 5.29 & $*$ \\
90 & 322.24 & 322.07 & 322.07 & 329.87 & 0.00 & & 2.42 & $*$ \\
91 & 353.58 & 353.57 & 376.39 & 353.57 & 6.45 & $*$ & 0.00 & \\
& & & & & & & & \\
\hline
\end{tabular}

Based on the estimates from the locally weighted estimation, Figure 20

plots the net excess demand $(\hat{D}-\hat{S})$ with the two-standard-error range from the equilibrium (zero excess demand). As discussed earlier, excess demand and excess supply do not coexist. The negative excess demand in the figure is actually the excess supply. It is evident that the status of the Chinese consumer 


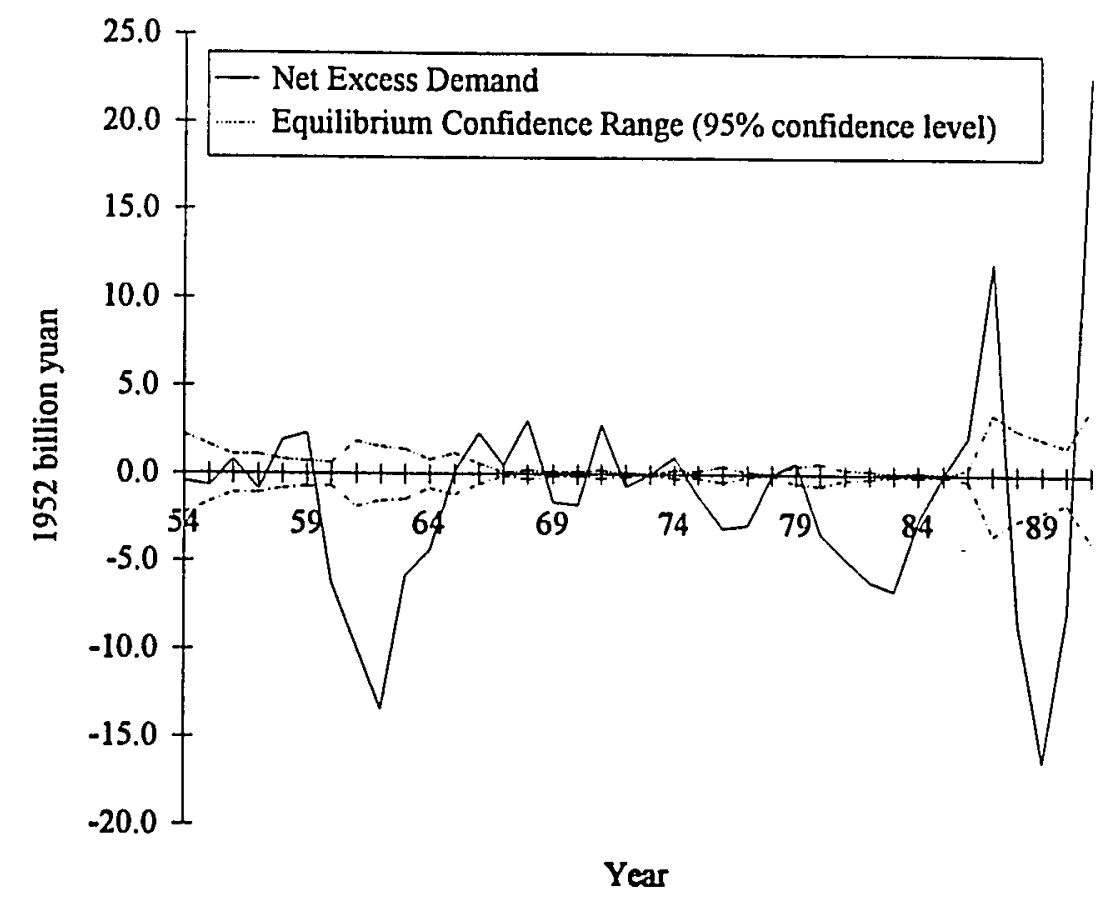

Figure 20. Estimated excess demand with two-standard-error range of equilibrium from locally weighted fitting.

goods market fluctuate between excess demand and excess supply, with neither being persistent.

As discussed earlier in Chapter III and Chapter IV, the technique of locally weighted optimization does not impose any restrictions on the functional forms of demand and supply, and it specifies only the general relationship between the dependent and independent variables. However, the present model is not purely non-parametric, since the $\mathrm{C}$ function has a specific hyperbolic functional form to enforce the short-side rule relation between $\mathrm{D}$ and $\mathrm{S}$. The comparison between Table XV and Table XVI may shed light on whether the model of structural change estimated with global fitting is correct. Table XVII 
TABLE XVII

DIFFERENCES IN ESTIMATES BY GLOBAL, FITTING AND LOCALLY WEIGHTED FITTING

\begin{tabular}{|c|c|c|}
\hline Year & $\begin{array}{l}\text { Global Fitting } \\
\text { Model 2A }\end{array}$ & $\begin{array}{l}\text { Locally Weighted } \\
\text { Fitting } \\
\text { Model 4A }\end{array}$ \\
\hline 54 & Excess Supply & \\
\hline 55 & Excess Supply & \\
\hline 58 & & Excess Demand \\
\hline 66 & & Excess Demand \\
\hline 67 & & Excess Demand \\
\hline 71 & & Excess Demand \\
\hline 73 & Excess Supply & \\
\hline 74 & Excess Supply & Excess Demand \\
\hline 78 & Excess Supply & \\
\hline 79 & Excess Supply & Excess Demand \\
\hline 84 & Excess Demand & Excess Supply \\
\hline 85 & Excess Demand & \\
\hline 90 & Excess Demand & Excess Supply \\
\hline
\end{tabular}

lists the conflicting or inconsistent results in some of the years by the two fitting methods. The blank cells indicate that the market imbalance, excess demand or excess supply, does not exist or is statistically insignificant in the corresponding years. There are four years where the claim of excess demand or excess supply 
is truly in conflict between the two methods, and eight years where one method shows significant excess demand or excess supply while another shows insignificance. The estimation in the first and last several years by the locally weighted fitting may be influenced by the boundary effect, since those years are not in the center of the locally weighted neighborhood. (Refer to Figure 14 of Chapter IV.) The differences in 1974, 1979 and 1984 may be understood as "outliers" in the sample. In Table XV, the neighboring years of 1974 and 1979 all have excess supply, significant or not. Thus, those two years may have been forced to have the same estimation outcome as their neighboring years. However, in the locally weighted fitting, they are free to take on different coefficients than others, which results in different market status. From Figure 19 of Chapter IV, there are clearly changes in response coefficient values in both 1979 and 1984.

Figures 21 and 22 plot the estimated gross excess demand $(\hat{D}-\hat{C})$ and gross excess supply $(\hat{S}-\hat{C})$ by the global fitting of structural change model and locally weighted estimation. In the 1960 's, excess demand from the locally weighted fitting method is more than that from global fitting. The locally weighted estimation also confirms that there are more years when the consumer goods market is in excess supply than in excess demand. And, in general, the extent of excess demand and excess supply estimated using the locally weighted fitting are not as great as using the global fitting. Neither global fitting nor locally weighted estimation demonstrates a pattern of persistent excess demand. 


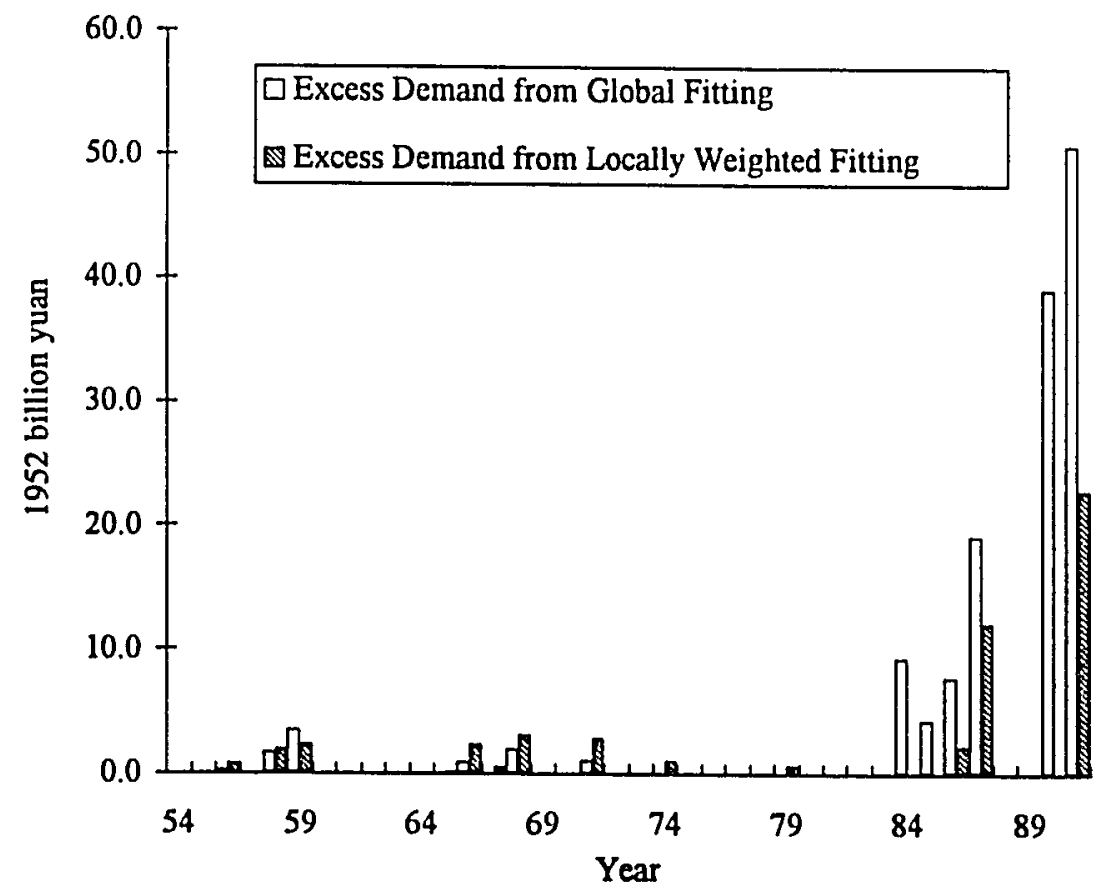

Figure 21. Estimated excess demand from global and locally weighted fittings.

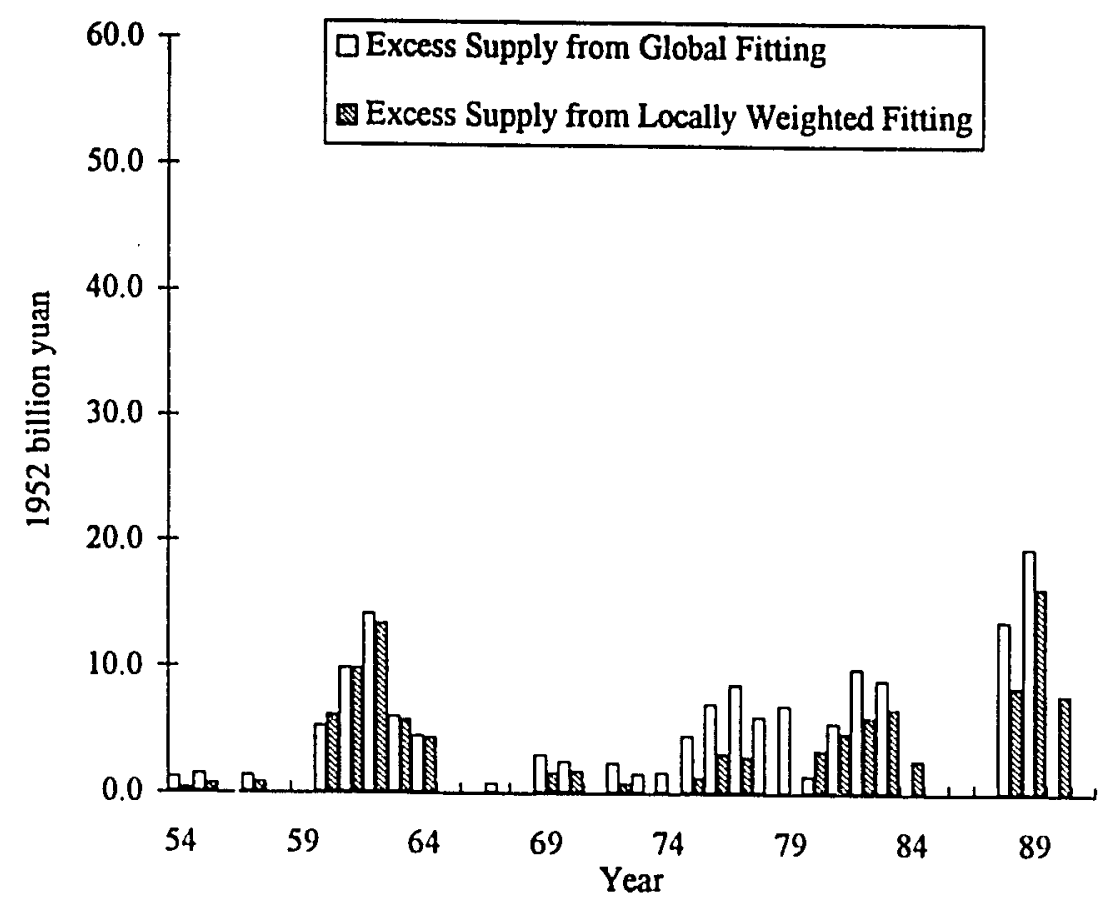

Figure 22. Estimated excess supply from global and locally weighted fittings. 
Figure 23 depicts the trends of savings and excess demand from both the global fitting and locally weighted estimation between 1954 and 1991 . The negative excess demand in the figure is the excess supply as the result of no coexistence of excess demand and excess supply. Before 1980, the estimated excess demand synchronized with the change in savings. That is, households saved more when there was not much goods to buy. During the late 1950's and the early 1960 's, households did not have enough money to make purchases even though their savings were depleted. However, in the later years, such synchrony between excess demand and savings is no longer perfect. Yet, the above discussion does not suggest the existence of forced savings where savings is built up due to a persistent shortage of goods. Savings may be "forced" in some year after the economic reform began. As shown in Table II of Chapter I, the economy took off at a very high speed in 1984 . By 1988 , the economy slowed due to a government planned retrenchment, except that the household financial assets (mainly savings) were still growing. Figure 23 shows that during the same period, from 1984 to 1988, the consumer goods market suffered from a high level of unsatisfied demand. In 1988, the degree of depletion in personal wealth may have prompted cautious spending for a short time. Then again, in the early 1990 's, accompanied by a slower production sector of the economy, the excess demand resurfaced at an even greater magnitude, and savings accumulated.

Figure 24 shows the changes in price index and excess demand estimated by both global and locally weighted fitting methods. In general, prices did not 


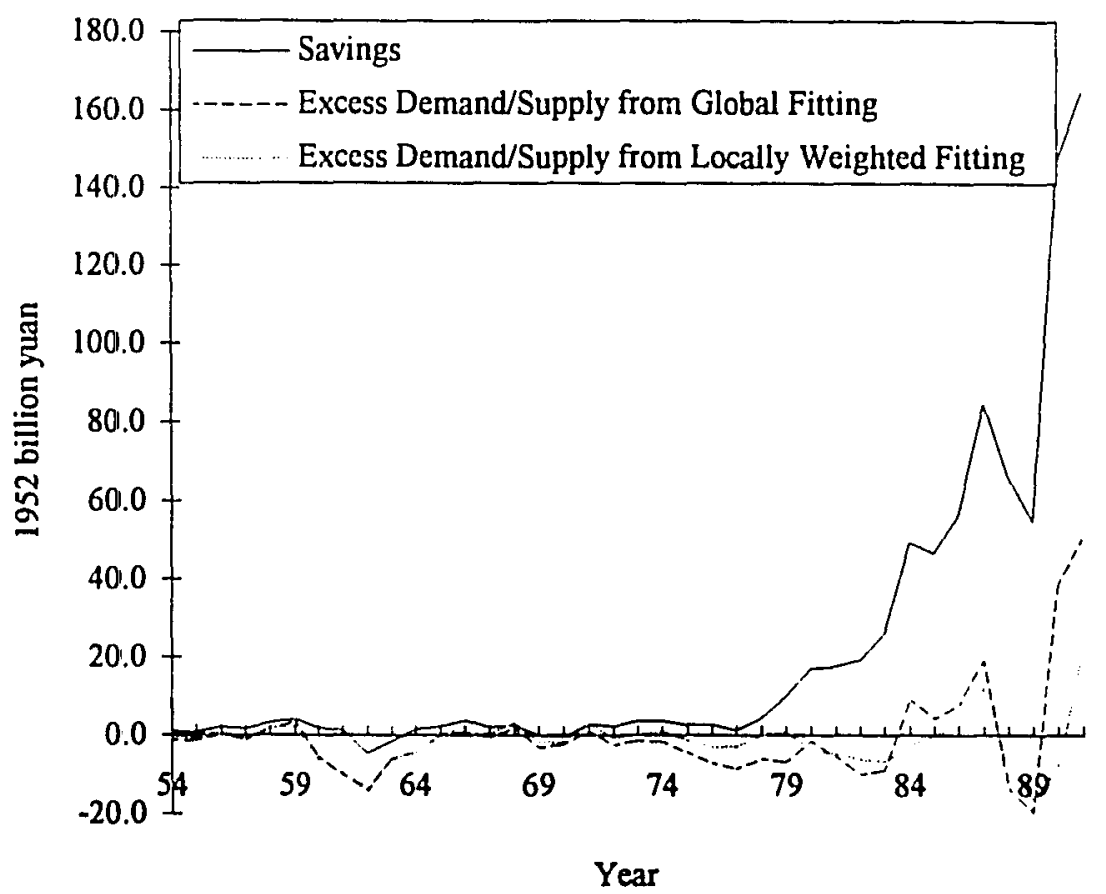

Figure 23. Savings and estimated excess demand from global and locally weighted fittings.

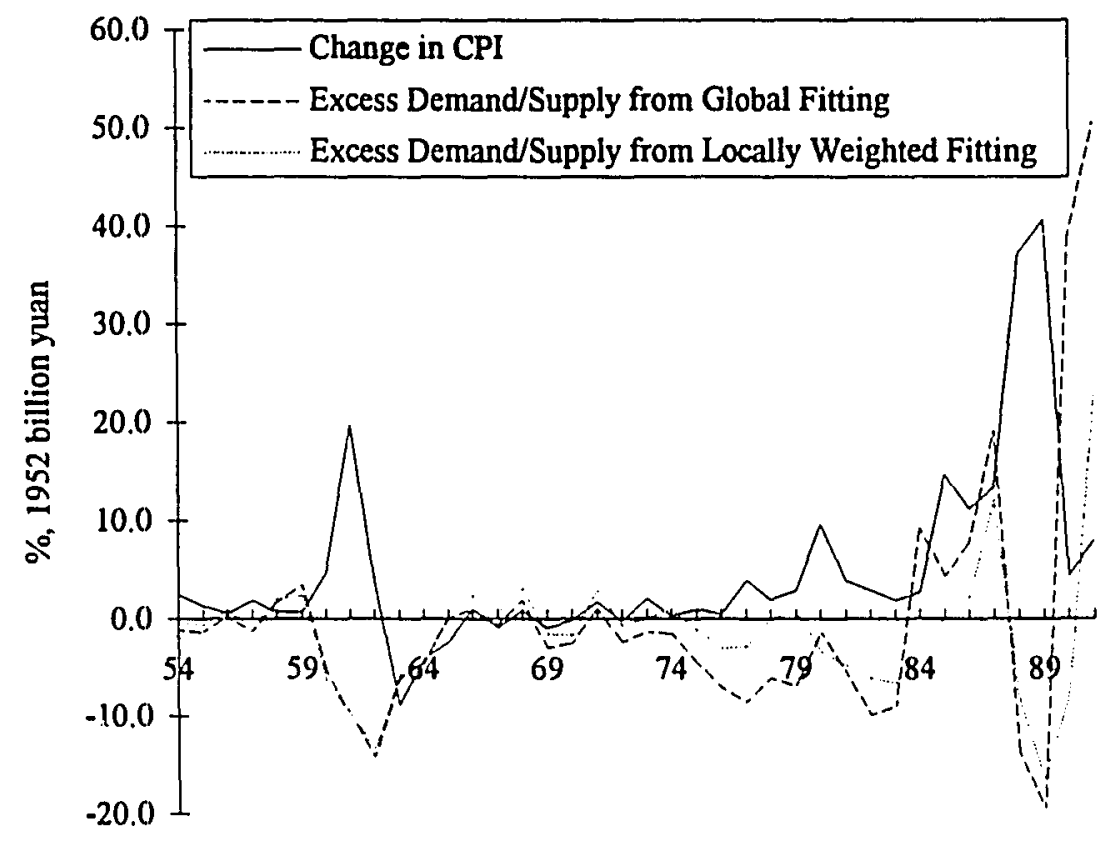

Year

Figure 24. Change in consumer price index and estimated excess demand from global and locally weighted fittings. 
fluctuate very much, even in the early years of the economic reform. Price level has been relatively rigid. But the rigidity did not cause imbalance in demand and supply in the early years when the government had overall control of economic activities. From 1960 to 1962, prices increased drastically due to the perceived shortage caused by natural disaster and debt payment. Such an increase in price level may have contributed further to the appearance of excess supply when household income was at a low level. After the economic reform was initiated, prices began to adjust. Increases in price level did not suppress demand between 1984 and 1987, but they did discourage consumption in 1988 and 1989. That is, the adjustments in price level do not seem to have been effective in regulating the demand and supply in the Chinese consumer goods market. 


\section{CHAPTER VI}

\section{SUMMARY AND CONCLUSION}

This is an in-depth study on the structural change and transition of the Chinese consumer goods market from 1954 to 1991 using disequilibrium econometric methodology. During the study period, the Chinese economy gradually changed from a pure centrally planned system toward a market competition type of economy.

For this study of consumer goods market, the Portes-Winter (1980) model for the consumer goods market in centrally planned economies is adopted. In the model, the demand function is derived from the Houthakker-Taylor savings function. The supply function is composed of approximations to the government's long-term and short-term plans. The historical trend of consumption is used to approximate the long-term plans, and levels of adjustments to national income, investment and public consumption are the approximations to short-term plans. The transaction quantity in the market is defined as the smaller of effective demand and effective supply. The model used in this research, which is a little different from the Portes-Winter model, is described in detail in Chapter III.

Major findings of the study are: 


\section{$\underline{\text { Non-Persistent Market Disequilibrium Status }}$}

Many studies have hinted that, in centrally planned economies, there have been persistent shortage of consumer goods. The consumer goods market is cleared of excess demand by means of forced substitution and quantity rationing on the demand side. Such market clearance is often accompanied by forced savings. From the discussions in Chapter V, however, it is evident that chronic shortage does not exist in the Chinese consumer goods market. If there had been forced substitution of consumer goods in the microeconomic markets, the substitution may have been close to perfect since there was no persistent savings accumulation, especially before the economic reform, and there is no coexistence of excess demand and excess supply. Figure 23 in Chapter V displays that the market status fluctuates between excess demand and excess supply, and the fluctuation synchronizes with the level of household savings. As a matter of fact, excess supply occurs in more years than excess demand, although it is not persistent either.

In later 1979 , the economic reform in the Chinese economy was initiated. The low level of consumption before 1980 and the fast accumulation of savings since 1980 can be understood as an indication that the absence of chronic shortage is the end effect of lasting control of the government on the purchasing power through repressing households' income. The strict implementation of rationing coupons and quantity quotas may have had more impact on controlling 
price levels when productivity and national output were relatively low than in controlling how much households could purchase.

\section{Non-Effective Price Change}

It is suggested that disequilibrium status in centrally planned economies are caused by a fixed price policy. It is clear that the price level in the Chinese consumer goods market has been almost unchanged over the years, especially before the economic reform. However, such rigidity not only does not regulate the level of demand and supply, but also does not cause both demand and supply in the market to be out of balance in the long run, as illustrated in Chapter V. It seems to contradict the theory that in later years when price level starts to change, the extent of excess demand and excess supply becomes greater. (See Figures 21 and 22 in Chapter V.) However, both Table XVI and Table XVII show that the relative excess demand and excess supply with respect to realized consumption has not changed in the later years. In Figure 24, change in price level and excess demand have a certain relationship, but it is not clear in which direction the causal effect is and to what extent the price change affects excess demand and/or excess supply.

\section{Market Structure Change due to Shifts of Government Policies}

Applying classical disequilibrium econometric analysis, several models with and without structural change are estimated and tested. Structural change is assumed to have occurred when the economic reform began in late 1979, and is 
tested with the dummy variable approach and the sample separation approach. As demonstrated in Table VIII, Chapter IV, all the models with structural change are better than the one without. That is, the structures of the demand and supply functions of the Chinese consumer goods market have changed since the economic reform in 1980. According to the estimates in Table VI and Table VII, and again in Table XII and Table XIII, on the demand side, the household savings in the previous year very much affects the level of demand before the economic reform, but not after, due to the changes in income level and expectations about future consumption; the change in income level and income in the previous year influences the level of demand with little difference in magnitude before and after 1980. In the supply function, the effect of adjustments to national income increases, because of the increasing deviation in the trends of national income and personal consumption resulted from the decentralized government authority in the 1980's. Table XIV shows the coefficient variations in different periods over the years.

\section{Variate Fitness of the Portes-Winter Model for the Consumer Goods Market in}

\section{CPEs}

Additional findings of the Chinese consumer goods market in transition are obtained by utilizing locally weighted optimization to the traditional disequilibrium model. As detailed in Chapter III, the locally weighted optimization is a local fitting process centered on one observation at a time with gradually changing weights based on the closeness of the observations involved. 
This non-parametric method is applied to test the variations in the response coefficients during the period between 1954 and 1991 without presumption about the functional forms of demand and supply. The estimation results in Chapter IV confirm that the Chinese consumer goods market in the early years can be fairly accurately described by the demand and supply functions designed by Portes and Winter for centrally planned economies. The structures of demand and supply functions have changed since the economic reform. The vibrant fluctuations of the coefficient values in the late 1980's may indicate the continuing change and transformation of the economy away from a pure centrally planned system, and illustrate the possibility of a redefinition of the model for such a market. 


\section{CHAPTER VII}

\section{FUTURE RESEARCH}

The present research has covered only one of the markets in the entire Chinese economy. More work can be done based on the results and conclusions discussed in the preceding chapters. Furthermore, all the previously known centrally planned economies are undergoing various degrees of economic reform. The study of the Chinese consumer goods market may provide certain insight on the transitions toward a new form of economy. The following discussion lists the problems encountered in the present research, and suggests future work in this field.

\section{Problems in the Current Research}

Although the fundamental specification and approximation of demand and supply functions are all linear, the restriction dictated by the hyperbolic transaction function or the discrete-switching transaction function makes the model non-linear. As with other non-linear models, the estimation results are sensitive to the initial solutions.

Evidently, the residuals from both Model 1 and Model 2 are serial correlated. However, up to fourth-order autoregressive and/or moving average processes have been tried and failed to correct the problems. This implies that 
the structure of serial correlation may be different in order and/or in type over the entire period. The results from the locally weighted optimization also exhibit the same problem. Although the hyperbolic transaction function makes it possible to handle the autocorrelation problem, the correction to the model is inherently impossible due to the limited number of observations available and the complicated non-linear structure of the model.

\section{Further Research based on Current Results}

On the current model, the future improvement can be made on estimation methodology to correct for autocorrelation and to enhance the convergence process in the non-linear estimation.

In addition, future research may include a cross-section model by region. Due to geographic and climatic differences, as well as to different strategic and economic development emphases of the central and local governments, consumption behavior of households will be different in various regions. A timeseries model considering the entire country as a whole may not reflect the regional characteristics of such consumption patterns. The supply function of a regional model should incorporate the local governments' plans in addition to the restrictions dictated by the central government.

\section{Multi-Market Model}

Beyond the single consumption goods market, labor and investment markets may be added and integrated to investigate multi-market interactions in 
a disequilibrium framework. Theoretically, households' income earned from the participation in labor market determines the households' consumption behavior, and activities in the investment market compete with the consumption market for the same production factors. In China, the labor market has become active only in recent years, and the investment market is no longer dominated by the government plans and funding. Moreover, it may be fruitful to construct a model incorporating the money market in China, and compare the results with those proposed by Yi (1993) and others. 


\section{REFERENCES}

Adelman, Irma and David Sunding: "Economic Policy and Income Distribution in China," Chinese Economic Reform -.. How Far, How Fast? ed. by Bruce L. Reynolds. Academic Press, 1988.

Artus, P., G. Laroque and G. Michel: "Estimation of a Quarterly Macro Model with Quantity Rationing," Econometrica, 52(1984), 1387-1414.

Altman, N. S.: "An Introduction to Kernel and Nearest-Neighbor Nonparametric Regression," The American Statistician, 46(1992), 175-185.

Balassa, Bela: "China's Economic Reform in a Comparative Perspective," in Chinese Economic Reform ... How Far, How Fast? ed. by Bruce L. Reynolds. Academic Press, 1988.

Benassy, J. P.: "The Disequilibrium Approach to Monopolistic Price Setting and General Monopolistic Equilibrium," Review of Economic Studies, 43(1976), 69-81.

- The Economics of Market Disequilibrium. Academic Press, 1982.

- : Macroeconomics: an introduction to the non-Walrasian Approach. Academic Press, 1986.

Bonnin, Michel and Michel Cartier: "Urban Employment in Post-Maoist China," in Transforming China's Economy in the Eighties, Vol. I: The Rural Sector, Welfare and Employment, ed. by Stephan Feuchtwang, Athar Hussain and Thierry Pairault. Westview Press, 1988.

Bowden, Roger J.: The Econometrics of Disequilibrium. North-Holland, 1978.

Broer, D. P. and J. C. Siebrand: "A Macroeconometric Disequilibrium Model of Product Market and Labor Market for the Netherlands," Applied Economics, 17(1985), 633-646.

Burkett, John P.: "Slack, Shortage, and Discouraged Consumers in Eastern Europe: Estimates Based on Smoothing by Aggregation," Review of Economic Studies, LV(1988), 493-505. 
Chang, Gene Hsin: "The Inconsistencies among Disequilibrium Aggregates," Joumal of Comparative Economics, 17(1992), 70-91.

Chang, Gene Hsin: "Immiserizing Growth in Centrally Planned Economies," Journal of Comparative Economics, 15(1991), 711-717.

Chang, Hsin: Shortage, Repressed Inflation, and Distorted Growth: a general disequilibrium model of centrally planned economies. Dissertation, University of Michigan, 1989.

Charemza, Wojciech: "Maximum Likelihood Methods of Estimation for Disequilibrium Models in a Centrally Planned Economy," Economics of Planning, 21(1987), 87-99.

_- : "Parallel Markets, Excess Demand and Virtual Prices --- an empirical approach," European Economic Review, 34(1990), 331-339.

: "Disequilibrium Modelling of Consumption in the Centrally Planned Economy," in Models of Disequilibrium and Shortage in Centrally Planned Economies, ed. by C. M. Davis, and W. Charemza. Chapman and Hall, 1989.

Charemza, W. and M. Gronicki: Plans and Disequilibria in Centrally Planned Economies (Empirical Investigation for Poland). North-Holland, 1988.

Charemza, W. and R. Quandt: "Models and Estimation of Disequilibrium for Centrally Planned Economies," Review of Economic Studies, 49(1982), 109-116.

Cheema, G. Shabbir and Dennis A. Rondinelli: Decentralization and Development: policy implementation in developing cour.iries. Sage Publishers, 1983.

Chow, Gregory C.: "A Model of Chinese National Income Determination," Journal of Political Economy, 93(1985a), 782-792.

_ : The Chinese Economy. Harper \& Row, 1985b.

__ : "Chinese Statistics," The American Statistician, 40(1986), 191-196.

- : "Money and Price Level Determination in China," Joumal of Comparative Economics, 11(1987), 319-333.

_ : "Money and Prices in China," in Chinese Economic Reform -.. How Far, How Fast? ed. by Bruce L. Reynolds. Academic Press, 1988.

Clemson, Barry: Cybernetics: a new management tool. Abacus Press, 1984. 
Cleveland, William S., Susan J. Devlin and Eric Grosse: "Regression by Local Fitting," Journal of Econometrics, 37(1988), 87-114.

Cleveland, W. S.: "Robust Locally Weighted Regression and Smoothing Scatterplots," Journal of the American Statistical Association, 74(1979), 829-836.

Cohen, G.: "Optimization Techmiques in Large-scale Systems," in Systems Sciences and Modelling ed. by A. Ruberti, Dordrecht, 1984.

Croll, Elisabeth J.: "The New Peasant Economy in China," in Transforming China's Economy in the Eighties, Vol. I: The Rural Sector, Welfare and Employment, ed. by Stephan Feuchtwang, Athar Hussain and Thierry Pairault. Westview Press, 1988.

Davis, C. M. and W. Charemzal ed.: Models of Disequilibrium and Shortage in Centrally Planned Economies. Chapman and Hall, 1989.

Diebold, Francis X., James Nason: "Nonparametric Exchange Rate Prediction?," Journal of International Economics, 28(1990), 315-332.

Dlouhý, Vladimir: "An Equilibrium Alternative to a Permanent Shortage," European Economic Review, 34(1990), 340-348.

— : "Disequilibrium Models 'of the Czechoslovak Economy," in Models of Disequilibrium and Shortage in Centrally Planned Economies, ed. by C. M. Davis, and W. Charemza. Chapman and Hall, 1989.

Drazen, Allan: "Recent Development in Macroeconomic Disequilibrium Theory," Econometrica, 48(1980), 283-306.

Drèze, J. H.: "Existence of an Equilibrium under Price rigidity and Quantity

Rationing," International Economic Review, 16(1975), 301-320.

Dumenil, Gerard and Dominique Levy: "The Macroeconomics of

Disequilibrium", Journal of Economic Behavior \& Organization, 8(1987), 377-395.

Ellman, Michael: Socialist Planning. Cambridge University Press, 1989.

Fair, Ray C.: Specification, Estimation, and Analysis of Macroeconometric Models. Harvard University Press, 1983.

Fair, R. and D. Jaffee: "Methods of Estimation for Markets in Disequilibrium," Econometrica, 40(1972), 497-514. 
Fan, J.: "Design-adaptive Nonparametric Regression," Joumal of the American Statistical Association, 87(1992a), 998-1004.

Fan, J., N. E. Heckman and M. P. Wand: "Local Polynomial Kernel Regression for Generalized Linear Models and Quasi-Likelihood Functions," mimeo \#2089, Department of Statistics, University of North Carolina, 1992b.

Felderer, Bernhard and Stefan Homburg: Macroeconomics and New Macroeconomics. Springer-Verlag, 1987. Ch XI.

Fisher, Franklin M.: Disequilibrium Foundations of Equilibrium Economics. Cambridge University Press, 1983.

Fitoussi, Jean-Paul ed.: Modern Macroeconomic Theory. Barnoe \& Noble Books, 1983.

Fox, Karl A. and Don G. Miles ed.: Systems Economics: Concepts, Models, and Multidisciplinary Perspectives. Iowa State University Press, 1987.

Franz, Wolfgang and Heinz König: "A Disequilibrium Approach to Unemployment in the Federal Republic of Germany," European Economic Review, 34(1990), 413-422.

Gipouloux, Francois: "Industrial Restructuring and Autonomy of Enterprises in China: Is Reform Possible?," in Transforming China's Economy in the Eighties, Vol. II: Management, Industry and the Urban Economy, ed. by Stephan Feuchtwang, Athar Hussain and Thierry Pairault. Westview Press, 1988.

Goldfeld, S. and R. Quandt: "Estimation in a Disequilibrium Model and the Value of Information," Journal of Econometrics, 3(1975), 325-348.

Gourieroux, C., J. J. Laffont and A. Monfort: "Disequilibrium Econometrics in Simultaneous Equations Systems," Econometrica, 48(1980), 75-96.

Grandmont, J. M.: "Temporary General Equilibrium Theory," Econometrica, 45(1977), 535-573.

_ : " Equilibrium with Quantity Rationing and Recontracting," Journal of Economic Theory, 19(1978), 84-102.

Grandmont, J. M., and G. Laroque: "On Keynesian Temporary Equilibria," Review of Economic Studies, 43(1976), 53-67.

Greene, William H.: Econometric Analysis. MacMillan Publishing Company, 1990. 
Grosfeld, Irena: "Modeling Planners' Investment Behavior: Poland, 1956-1981," Journal of Comparative Economics, 11(1987), 180-191.

Guardabassî, G.: "Interconnected Systems Analysis," in Systems Sciences and Modelling, ed. by A. Ruberti. Dordrecht, 1984.

Hahn, F. H.: "On Non-Walrasian Equilibria," Review of Economic Studies, 45(1978), 1-17.

Härdle, W., Applied Nonparametric Regression. Cambridge University Press, 1990.

Hare, Paull G.: "Investrnent and Quality of Output in an Economy with Shortage," European Economic Review, 34(1990), 349-354.

Hastie, Trevor and Clive Loader: "Local Regression: Automatic Kernel Carpentry," Statistical Sicience, 8(1993), 120-143.

Hastie, T. J. and R. J. 'Tibshirani: Generalized Additive Models. Chapman and Hall, 1990.

Hastie, Trevor and Robert Tibshirani: "Non-parametric Logistic and Proportional Odds Regression," Applied Statistics, 2(1987), 260-276.

Hey, John Denis: Economics in Disequilibrium. New York University Press, 1981.

Howard, David H.: "The Disequilibrium Model in a Controlled Economy: an empirical test of the Barro-Grossman Model," The American Economic Review, 66(1976), 871-879.

- : "The Disequilibrium Model in a Controlled Economy: reply and further results," The American Economic Review, 69(1979), 733-738.

Ickes, Barry W.: "A Macroeconomic Model for Centrally Planned Economies," Journal of Macroeconornics, 12(1990), 23-45.

Ito, Takatoshi: "Methods of Estimation for Multi-Market Disequilibrium Models," Econometrica, 48(1980), 97-126.

Johnston, J.: Econometric Methods. McGraw-Hill, 1984. 
Judge, George G., R. Carter Hill, William Griffiths, Helmut Lütkepohl and Tsoung-Chao Lee: Introduction to the Theory and Practice of Econometrics. John Wiley \& Sons, 1982.

Katz, Barbara Goody: "The Disequilibrium Model in a Controlled Economy: comment," The American Economic Review, 69(1979), 721-725.

Kelley, Allen C., Warren C. Sanderson and Jeffery G. Williamson ed.: Modeling Growing Economies in Equilibrium and Disequilibrium. Duke Press Policy Studies, 1983.

Klenner, Wolfgang and Kurt Wiesegart: The Chinese Economy --- structure and reform in the domestic economy and foreign trade. Transaction Books, 1985.

Kooiman, P.: "Smoothing the Aggregate Fixed-Price Model and the Use of Business Survey Data," Economic Journal, 94(1984), 899-913.

Kornai, János: Anti-equilibrium: on economics systems theory and the tasks of research. North-Holland, 1971.

— Economics of Shortage. North-Holland, 1980.

_ : Growth, Shortage and Efficiency. Basil Blackwell, 1982.

- : "Shortage as a Fundamental Problem of Centrally Planned Economies and the Hungarian Reform," Economic of Planning, 18(1982), 103-113.

Lambert, Jean-Paul: Disequilibrium Macroeconomic Models --- theory and estimation of rationing models using business survey data. Cambridge University Press, 1988.

: "The French Unemployment Problem --- lessons from a rationing model relying on business survey information," European Economic Review, 34(1990), 423-433.

Laroque, Guy: "Comparative Estimates of a Macroeconomic Disequilibrium Model -.- France, Germany, the U.K. and the U.S.A.," European Economic Review, 33(1989), 963-995.

Laroque, Guy and Bernard Salanie: "Estimation of Multi-market Fixed-price Models: an application of psudo maximum likelihood methods," Econometrica, 57(1989), 831-860. 
Lee, Lung-Fei: "The Specification of Multi-market Disequilibrium Econometric Models," Journal of Econometrics, 32(1986), 297-332.

Leijonhufvud, Axel: Information and Coordination. Oxford University Press, 1981.

Lin, Kuan-Pin: "Disequilibrium Analysis of Consumption Goods and Labor Markets in China," working paper, Portland State University, 1990.

Lin, Kuan-Pin: "Disequilibrium Econometric Analysis for the U.S. Energy Consumption: 1973 - 1980," working paper, Portland State University, 1981.

Liu Guoguang, Liang Wensen and others: China's Economy in 2000. New World Press, 1987.

Madden, Paul: "A Diagrammatic Introduction to Disequilibrium

Macroeconomics," Bulletin of Economic Research, 39(1987), 121-149.

Malinvaud, Edmond: The Theory of Unemployment Reconsidered. Halsted Press, 1977.

Muellbauer, John and Richard Portes: "Macroeconomic Models with Quantity Rationing," The Economic Journal, 88(1978), 788-821.

Nadiri, M. Ishag and Sherwin Rosen: $A$ Disequilibrium Model of Demand for Factors of Production. New York, National Bureau of Economic Research, 1973.

Negishi, Takashi: Economic Theories in a non-Walrasian Tradition. Cambridge University Press, 1985.

Nissanke, Machiko K.: "The Disequilibrium Model in a Controlled Economy: comment," The American Economic Review, 69(1979), 726-732.

Pindyck, Robert S. and Daniel L. Rubinfeld: Econometric Models and Economic Forecasts. McGraw-Hill Book Company, 1981.

Podkaminer, Leon: "Macraeconomic Disequilibria in Centrally Economies: Identifiability of Econometric Models Based on the Theory of Household Behavior under Quantity Constraints," Joumal of Comparative Economics, 13(1989), 47-60.

Portes, Richard: "Internal and External Balance in a Centrally Planned Economy," Joumal of Comparative Economics, 3(1979), 325-345. 
- : "Macroeconomic Equilibrium and Disequilibrium in Centrally Planned Economies," Economic Inquiry, 19(1981), 559-578.

— : "The Theory and Measurement of Macroeconomic Disequilibrium in Centrally Planned Economies," in Models of Disequilibrium and Shortage in Centrally Planned Economies, ed. by C. M. Davis, and W. Charemza. Chapman and Hall, 1989.

Portes, Richard and Richard E. Quandt, David Winter, and Stephen Yeo: "Macroeconomic Planning and Disequilibrium: Estimates for Poland, 1955 1980," Econometrica, 55(1987), 19-41.

Portes, Richard and Anita Santorum: "Money and the Consumption Goods Market in China," in Chinese Economic Reform --- How Far, How Fast? ed. by Bruce L. Reynolds. Academic Press, 1988.

Portes, Richard and David Winter: "Disequilibrium Estimates for Consumption Goods Markets in Centrally Planned Economies," Review of Economic Studies, 47(1980), 137-159.

Portes, Richard and David Winter: "The Supply of Consumption Goods in Centrally Planned Economies," Journal of Comparative Economics, 1(1977), 351365.

Quandt, Richard: "Test of the Equilibrium Versus the Disequilibrium Hypothesis," International Economic Review, 19(1978), 435-452.

: "A Note on Estimating Disequilibrium Models with Aggregation," Empirical Economics, 11(1986), 223-243.

— : The Econometrics of Disequilibrium. Blackwell Inc., 1988.

_ : "Disequilibrium Econometrics for Centrally Planned Economies," in Models of Disequilibrium and Shortage in Centrally Planned Economies, ed. by C. M. Davis, and W. Charemza. Chapman and Hall, 1989.

Quandt, Richard E. and Harvey S. Rosen: The Conflict Between Equilibrium and Disequilibrium Theories. W. E. Upjohn Institute for employment research, 1988.

Rabushka, Alvin: The New China: comparative economic development in mainland China, Taiwan, and Hong Kong. Pacific Research Institute for Public Policy, Westview Press, 1987. 
Reynolds, Bruce L. ed.: Reform in China --- challenges \& choices. M. E. Sharpe, Inc., 1987.

Rudebusch, Gleen D.: The Estimation of Macroeconomic Disequilibrium Models with Regime Classification Information. Springer-Verlag, 1987.

Schioppa, Fiorella Padoa: "Classical, Keynesian and Mismatch Unemployment in Italy," European Economic Review, 34(1990), 434-442.

Siebrand, Jan C.: Towards Operational Disequilibrium Macro Economics. Martinus Nijhoff. 1979.

Silberberg, Eugene: The Structure of Economics --- a mathematical analysis. McGraw-Hill Book Company, 1978.

Sneessens, Henri R.: Theory and Estimation of Macroeconomic Rationing Models. Springer-Verlag, 1981.

Stalder, Peter: "A Disequilibrium Model with Smooth Regime Transitions and a Keynesian Spillover for Switzerland's Labor Market," European Economic Review, 33(1989), 863-893.

Staniswalis, Joan G.: "The Kernel Estimate of a Regression Function in Likelihood-Based Models," Journal of the American Statistical Association, 84(1989), 276-283.

State Statistical Bureau of the People's Republic of China: China Statistical Yearbook, 1989, 1990, 1991, 1992.

Stone, C. J.: "Consistent Nonparametric Regression," The Annals of Statistics, 5(1977), 595-620.

Tibshirani, Robert and Trevor Hastie: "Local Likelihood Estimation," Joumal of the American Statistical Association, 82(1987), 559-567.

Vinod, H. D., A. Ullah: "Flexible Production Function Estimation by Nonparametric Kernel Estimators," in Advances in Econometrics: Robust and Nonparametric Statistical Inference, ed. by Fomby TB and Rhodes CF, JAI Press, 1988.

Ullah, A.: "Nonparametric Estimation and Hypothesis Testing in Econometric Models," Empirical Economics, 13(1988a), 223-249. 
Ullah, Aman: "Non-parametric Estimation of Econometric Functionals," Canadian Journal of Economics, 3(1988b), 625-658.

van Brabant, Jozef M.: "Socialist Economics: The Disequilibrium School and the Shortage Economy," Journal of Economic Perspectives, 4(1990), 157-175.

van den Heuvel, Paul: Lecture Notes on Economics and Mathematical Systems. Springer-Verlag, 1983.

van der Lijn, N. J. (Nick): "Note, Repressed Inflation on the Consumption Goods Markets: Disequilibrium Estimation for the German Democratic Republic, 19571985," Journal of Comparative Economics, 14(1990), 120-129.

Varian, H.: "Non-Walrasian Equilibria," Econometrica, 45(1977), 573-590.

Waelbroeck, Jean: "Some Pitfalls in Applied General Equilibrium Modeling," in Advances in Econometrics Fifth World Congress, Vol. II ed. by Truman F. Bewley. Cambridge University Press, 1987, Ch17.

White, Gordon: "Evolving Relations between State and Markets in the Reform of China's Urban-Industrial Economy," in Transforming China's Economy in the Eighties, Vol. II: Management, Industry and the Urban Economy, ed. by Stephan Feuchtwang, Athar Hussain and Thierry Pairault. Westview Press, 1988.

World Bank Report: China --- long-term development issues and options. John Hopkins University Press, 1985.

Wright, A. Ll.: An Introduction to the Theory of Dynamic Economics -.. a theoretical study in long-run disequilibrium analysis. Clarendon Press, 1984.

Yi, Gang: "Towards Estimating the Demand for Money in China," Economics of Planning, 26(1993), 243-270. 
APPENDIX A

INPUT DATA SERIES

Quantity Variables of the Chinese Consumer Goods Market

Price Deflators 


\section{QUANTITY VARIABLES OF THE CHINESE CONSUMER GOODS MARKET}

This input file contains the quantity variables describing the Chinese consumer goods market. It is referred to as CHINAC.NEW in the computer prograrns. The variables are:

NMP $=$ National Income Available

$\mathrm{C}=$ Personal Consumption

$\mathrm{G}=$ Public Consumption

$\mathrm{I}=$ Investment of Fixed Assets

WC $=$ Investment of Working Capital

MY = Household Monetary Income: wages, sales of agricultural products, loans, etc., excluding income in the form of physical goods and services

$\mathrm{ME}=$ Household Monetary Expenditure: purchases of goods and services, taxes, repayment of loans, etc., excluding exchanges of physical goods and services

$M=$ Financial Assets

All terms are in nominal billion Chinese yuan. Monetary Income and Expenditure are survey data. Source: China Statistical Yearbook, 1989, 1990, 1991 and 1992. 
129

\begin{tabular}{|c|c|c|c|c|c|c|c|c|}
\hline YEAR & NMP & C & G & I & WC & MY & $\mathrm{ME}$ & M \\
\hline 1952 & 60.7 & 43.4 & 4.3 & 5.7 & 7.3 & 30.77 & 29.65 & 3.06 \\
\hline 1953 & 72.7 & 50.8 & 5.1 & 8.5 & 8.3 & 38.35 & 36.93 & 4.48 \\
\hline 1954 & 76.5 & 52.7 & 4.3 & 10.9 & 8.6 & 41.15 & 40.45 & 5.18 \\
\hline 1955 & 80.7 & 57.5 & 4.7 & 10.9 & 7.6 & 42.12 & 41.75 & 5.55 \\
\hline 1956 & 88.8 & 61.3 & 5.8 & 17.9 & 3.8 & 51.13 & 49.21 & 7.47 \\
\hline 1957 & 93.5 & 64.9 & 5.3 & 14.0 & 9.3 & 52.25 & 50.85 & 8.87 \\
\hline 1958 & 111.7 & 68.3 & 5.5 & 28.0 & 9.9 & 61.57 & 58.49 & 11.95 \\
\hline 1959 & 127.4 & 64.1 & 7.5 & 37.2 & 18.6 & 73.27 & 69.56 & 15.66 \\
\hline 1960 & 126.4 & 68.3 & 8.0 & 39.9 & 10.2 & 77.01 & 75.03 & 17.64 \\
\hline 1961 & 101.3 & 75.5 & 6.3 & 14.8 & 4.7 & 69.36 & 66.84 & 20.16 \\
\hline 1962 & 94.8 & 78.1 & 6.8 & 9.6 & 0.3 & 61.43 & 66.16 & 15.43 \\
\hline 1963 & 104.7 & 79.3 & 7.1 & 13.3 & 5.0 & 64.69 & 65.58 & 14.54 \\
\hline 1964 & 118.4 & 84.1 & 8.0 & 20.3 & 6.0 & 70.12 & 69.08 & 15.58 \\
\hline 1965 & 134.7 & 89.5 & 8.7 & 25.3 & 11.2 & 74.99 & 72.86 & 17.71 \\
\hline 1966 & 153.5 & 96.9 & 9.6 & 30.7 & 16.3 & 82.23 & 78.48 & 21.46 \\
\hline 1967 & 142.8 & 102.6 & 9.8 & 20.2 & 10.2 & 83.71 & 81.76 & 23.41 \\
\hline 1968 & 140.9 & 102.0 & 9.1 & 16.6 & 13.2 & 80.98 & 78.43 & 25.96 \\
\hline 1969 & 153.7 & 106.8 & 11.2 & 27.8 & 7.9 & 84.53 & 84.85 & 25.64 \\
\hline 1970 & 187.6 & 114.5 & 11.3 & 41.9 & 19.9 & 90.65 & 91.24 & 25.05 \\
\hline 1971 & 200.8 & 119.5 & 12.9 & 46.8 & 21.6 & 101.54 & 98.82 & 27.77 \\
\hline 1972 & 205.2 & 126.3 & 14.1 & 47.9 & 16.9 & 110.89 & 108.73 & 29.93 \\
\hline 1973 & 225.2 & 136.4 & 14.7 & 50.2 & 23.9 & 121.09 & 117.36 & 33.66 \\
\hline 1974 & 229.1 & 139.6 & 15.4 & 55.3 & 18.8 & 126.92 & 123.34 & 37.24 \\
\hline 1975 & 245.1 & 145.0 & 17.1 & 64.8 & 18.2 & 137.10 & 134.40 & 39.94 \\
\hline 1976 & 242.4 & 150.2 & 17.4 & 62.3 & 12.5 & 144.76 & 142.32 & 42.38 \\
\hline 1977 & 257.3 & 155.3 & 18.8 & 64.5 & 18.7 & 154.17 & 152.91 & 43.64 \\
\hline 1978 & 297.5 & 167.3 & 21.5 & 78.3 & 30.4 & 171.67 & 167.24 & 48.07 \\
\hline 1979 & 335.6 & 191.0 & 28.5 & 83.8 & 32.3 & 204.40 & 192.62 & 58.52 \\
\hline 1980 & 369.6 & 222.3 & 30.8 & 89.3 & 27.2 & 248.74 & 228.21 & 79.05 \\
\hline 1981 & 390.5 & 247.3 & 32.6 & 77.8 & 32.8 & 269.73 & 250.73 & 98.05 \\
\hline 1982 & 429.0 & 268.8 & 36.6 & 96.9 & 26.7 & 297.11 & 277.26 & 117.90 \\
\hline 1983 & 477.9 & 295.7 & 40.1 & 112.5 & 29.6 & 338.08 & 310.91 & 145.07 \\
\hline 1984 & 570.1 & 339.5 & 51.0 & 145.3 & 34.3 & 437.06 & 384.70 & 197.43 \\
\hline 1985 & 750.7 & 424.0 & 63.9 & 188.3 & 74.5 & 553.68 & 498.68 & 252.43 \\
\hline 1986 & 849.6 & 477.3 & 77.9 & 219.6 & 74.8 & 629.00 & 550.50 & 320.96 \\
\hline 1987 & 968.4 & 550.2 & 88.4 & 271.8 & 58.0 & 751.80 & 649.30 & 423.46 \\
\hline 1988 & 1226.9 & 699.5 & 104.3 & 336.0 & 87.1 & 954.07 & 828.07 & 549.46 \\
\hline 1989 & 1359.6 & 776.1 & 124.4 & 283.5 & 175.6 & 1073.36 & 924.30 & 698.52 \\
\hline 1990 & 1438.3 & 820.2 & 146.1 & 300.8 & 171.2 & 1181.06 & 967.26 & 912.32 \\
\hline 1991 & 1606.1 & 924.4 & 167.5 & 379.6 & 134.6 & 1351.86 & 1102.09 & 1162.09 \\
\hline
\end{tabular}




\section{PRICE DEFLATORS}

This input file includes all the price deflators for the variables in file CHINAC.NEW. The base year of the deflators is 1952. The file is called

CHINAP.PRN in the computer programs. The variables are:

PNMP52 = National Income Deflator, derived from National Income Index

PC52 = Personal Consumption Deflator, derived from Personal Consumption Index

CPI52 $=$ Consumer Goods Price Index

CPISW52 $=$ Consumer Goods Price Index for Employees in State-owned Units PG52 = Public Consumption Deflator, derived from Public Consumption Index Source: China Statistical Yearbook, 1989, 1990, 1991 and 1992.

$\begin{array}{rrrrrr}\text { YEAR } & \text { PNMP52 } & \text { PC52 } & \text { CPI52 } & \text { CPISW52 } & \text { PG52 } \\ 1952 & 100.00 & 100.00 & 100.00 & 100.00 & 100.00 \\ 1953 & 105.59 & 106.31 & 103.40 & 105.11 & 98.26 \\ 1954 & 105.30 & 107.27 & 105.81 & 106.58 & 94.52 \\ 1955 & 104.28 & 107.63 & 106.89 & 106.93 & 92.47 \\ 1956 & 102.29 & 107.74 & 106.89 & 106.84 & 94.06 \\ 1957 & 100.76 & 108.60 & 108.50 & 109.61 & 93.09 \\ 1958 & 101.67 & 109.97 & 108.77 & 108.40 & 92.96 \\ 1959 & 102.71 & 112.32 & 109.75 & 108.74 & 92.28 \\ 1960 & 104.03 & 127.02 & 113.15 & 111.52 & 93.96 \\ 1961 & 120.79 & 150.88 & 131.48 & 129.52 & 101.32 \\ 1962 & 119.84 & 148.23 & 136.49 & 134.46 & 101.18 \\ 1963 & 117.17 & 133.18 & 128.44 & 126.49 & 104.44 \\ 1964 & 117.28 & 129.97 & 123.70 & 121.82 & 101.50 \\ 1965 & 119.29 & 123.63 & 120.39 & 120.35 & 100.16 \\ 1966 & 116.57 & 125.08 & 120.04 & 118.87 & 99.49 \\ 1967 & 117.81 & 125.02 & 119.14 & 118.10 & 99.35\end{array}$




$\begin{array}{rrrrrr}1968 & 119.94 & 125.28 & 119.23 & 118.18 & 99.87 \\ 1969 & 114.87 & 124.35 & 117.89 & 119.31 & 98.55 \\ 1970 & 111.00 & 124.56 & 117.62 & 119.31 & 98.50 \\ 1971 & 111.84 & 125.10 & 116.73 & 119.22 & 98.23 \\ 1972 & 111.83 & 125.49 & 116.46 & 119.39 & 98.00 \\ 1973 & 112.06 & 125.81 & 117.17 & 119.48 & 98.41 \\ 1974 & 112.23 & 126.34 & 117.80 & 120.26 & 98.47 \\ 1975 & 110.46 & 126.60 & 117.98 & 120.78 & 98.78 \\ 1976 & 110.03 & 126.86 & 118.34 & 121.13 & 98.48 \\ 1977 & 111.20 & 128.07 & 120.75 & 124.42 & 98.83 \\ 1978 & 112.71 & 129.57 & 121.56 & 125.28 & 98.97 \\ 1979 & 117.25 & 136.84 & 123.97 & 127.62 & 99.83 \\ 1980 & 121.28 & 143.68 & 131.40 & 137.23 & 104.43 \\ 1981 & 123.56 & 147.62 & 134.53 & 140.69 & 104.93 \\ 1982 & 123.41 & 150.40 & 137.12 & 143.55 & 104.42 \\ 1983 & 124.82 & 152.63 & 139.18 & 146.41 & 104.22 \\ 1984 & 131.11 & 155.86 & 143.11 & 150.39 & 104.69 \\ 1985 & 143.49 & 169.64 & 155.72 & 168.31 & 107.27 \\ 1986 & 149.17 & 180.47 & 165.03 & 180.09 & 110.08 \\ 1987 & 160.41 & 193.67 & 177.10 & 195.93 & 112.57 \\ 1988 & 181.63 & 226.75 & 209.84 & 236.45 & 124.19 \\ 1989 & 196.71 & 249.86 & 247.23 & 274.98 & 140.43 \\ 1990 & 204.28 & 254.53 & 252.42 & 278.53 & 141.52 \\ 1991 & 212.71 & 261.44 & 259.75 & 292.73 & 143.49\end{array}$




\section{APPENDIX B}

\section{COMPUTER PROGRAMS}

With or Without Dummy Variable Using Hyperbolic and DiscreteSwitching Transaction Functions: Models 1A, 1B, 2A and 2B

Locally Weighted Optimization Using Hyperbolic and Discrete-

Switching Transaction Functions: Models 4A and 4B 


\section{WITH OR WITHOUT DUMMY VARIABLE USING HYPERBOLIC AND DISCRETE-SWITCHING TRANSACTION FUNCTIONS: MODELS 1A, 1B, 2A AND 2B}

The following is the GAUSS program for estimating models with or without structural change, using hyperbolic or discrete-switching transaction functions: Models 1A, 1B, 2A and 2B. NLOPT.GCG used in this program is a nonlinear optimization library in GAUSS, which is available from the

Econometrics Lab at Portland State University.

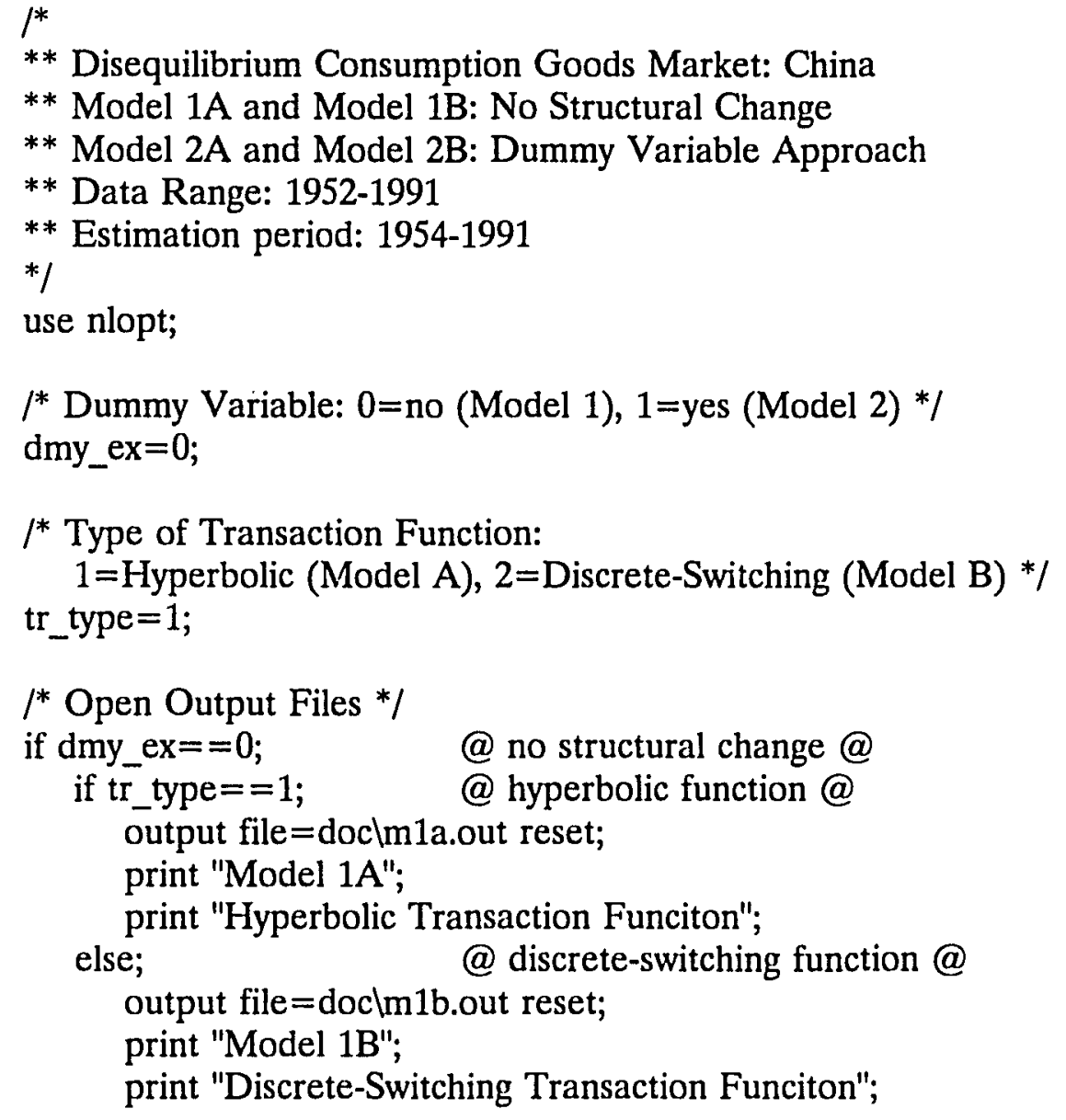


$\mathrm{ct}=\operatorname{trend} 2(\mathrm{c})$;

$\mathrm{nmpt}=$ trend2(nmp);

$\mathrm{nmpx}=(\mathrm{ct} . / \mathrm{nmpt}){ }^{*}(\mathrm{nmp}-\mathrm{nmpt})$

$\mathrm{czx}=(((\mathrm{g}+\mathrm{i}+\mathrm{wc}) . / \mathrm{nmp})-(\operatorname{trend} 2(\mathrm{~g}+\mathrm{i}+\mathrm{wc}) . / \mathrm{nmpt})) .{ }^{*} \mathrm{nmp}$

$\mathrm{mx}=\mathrm{m}$-trend2(m);

/* Explanatory Variables in Demand and Supply Equations */

$\mathrm{xcd}=\operatorname{lagn}(\mathrm{ms}, 1) \sim(\mathrm{yd}-\operatorname{lagn}(\mathrm{yd}, 1)) \sim \operatorname{lagn}(\mathrm{yd}, 1) ;$

@ Houthakker-Taylor CD specification @

$\mathrm{xcs}=\mathrm{ct} \sim \mathrm{nmpx} \sim \mathrm{czx}$

if dmy_ex; @ @ structural change @

dmy=dummydn(year,1979,1);

$\mathrm{xcd}=\mathrm{xcd} \sim\left(\mathrm{dmy} .{ }^{*} \mathrm{xcd}\right)$;

$\mathrm{xcs}=\mathrm{xcs} \sim\left(\mathrm{dmy} .{ }^{*} \mathrm{xcs}\right)$;

else;

print;

print "Demand Function";;

print year $\sim \mathrm{xcd}$;

print;

print "Supply Function";;

print year $\sim \mathrm{xcs}$;

endif;

/ Initial Solution from OLS Estimation */

ols_s=1954-1952+1; @ @s lost one, lag(ms) lost another @

$\mathrm{c} 1=\mathrm{c}\left[\mathrm{ols} \_\right.$s:rows(c)];

xcd1 $1=x c \bar{d}[$ ols_s:rows $(x c d),$.$] ;$

xcs1=xcs[ols_s:rows(xcs),.];

$\mathrm{bcd}=\mathrm{c} 1 / \mathrm{xcd} 1 ;$

$\mathrm{bcs}=\mathrm{c} 1 / \mathrm{xcs} 1$;

/* Maximum Likelihood Estimation */

max_s=1954-1952+1;

year=year[max_s:rows(year)];

$\mathrm{c}=\mathrm{c}\left[\max \_\right.$s:rows $\left.(\mathrm{c})\right]$;

xcd =xcd[max_s:rows(xcd),..];

xcs $=x c s\left[\max \_s: r o w s(x c s),.\right]$;

$\mathrm{xc}=\mathrm{xcd} \sim \mathrm{xcs}$

if dmy_ex;

dmy=dmy[max_s:rows(dmy),.];

$\mathrm{xc}=\mathrm{xc} \sim \mathrm{dmy}$; 
print year dmy;

endif;

call reset;

-iter $=100$;

-conv $=1$;

tol $=0.001$;

@ convergence in function value and solution @

deriv $=2$;

@ use both symmetric first and second derivatives @

-riter $=20$;

@ iteration limit for R-value in QHC @

$\mathrm{nd}=\operatorname{cols}(\mathrm{xcd})$;

$\mathrm{ns}=\operatorname{cols}(\mathrm{xcs})$;

if $\operatorname{tr}$ type $==1 ;$ @

$\overline{\mathrm{bc}}=\mathrm{bcd}|\mathrm{bcs}| 0$

if dmy_ex; $\mathrm{bc}=\mathrm{bc} \mid 0$;

endif;

_method=6; @ modified Quadratic Hill-Climbing method @

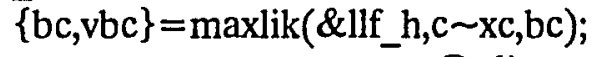

else;

$\mathrm{bc}=\mathrm{bcd}|\mathrm{bcs}| 1 \mid 10$;

method=6;

$\overline{\{b c}, \mathrm{vbc}\}=\operatorname{maxlik}\left(\& l l f \_\mathrm{d}, \mathrm{c} \sim \mathrm{xc}, \mathrm{bc}\right)$;

endif;

$\{\mathrm{bcd}, \mathrm{bcs}, \mathrm{cd}, \mathrm{cs}, \mathrm{cc}\}=\operatorname{result}(\mathrm{c} \sim \mathrm{xc}, \mathrm{bc})$;

print;

$/$ Final results */

$\left.\right|^{* * * * * * *} \mid$

print "Final Results";

print "-..-.-.-.-.-.-";

@ Variance-Covariance Matrix of D, S and D-S @

vbcd =vbc[1:nd,1:nd];

vbcs $=v b c[n d+1: n d+n s$, nd $+1:$ nd + ns] ;

vbcdcs $=v b c[1: n d, n d+1: n d+n s]$;

$v c d=x^{*}{ }^{*} v_{b c d}^{*} x c d ;$

$\mathrm{vcs}=\mathrm{xcs}{ }^{*} \mathrm{vbcs}{ }^{*} \mathrm{xcs} ;$

$\mathrm{vcdcs}=\mathrm{xcd}^{*} \mathrm{vbcdcs}^{*} \mathrm{xcs}$;

print;

print " $\quad \operatorname{VAR}(\mathrm{CD}) \quad \operatorname{VAR}(\mathrm{CS}) \quad \operatorname{VAR}(\mathrm{CD}-\mathrm{CS})^{\prime \prime} ;$ 


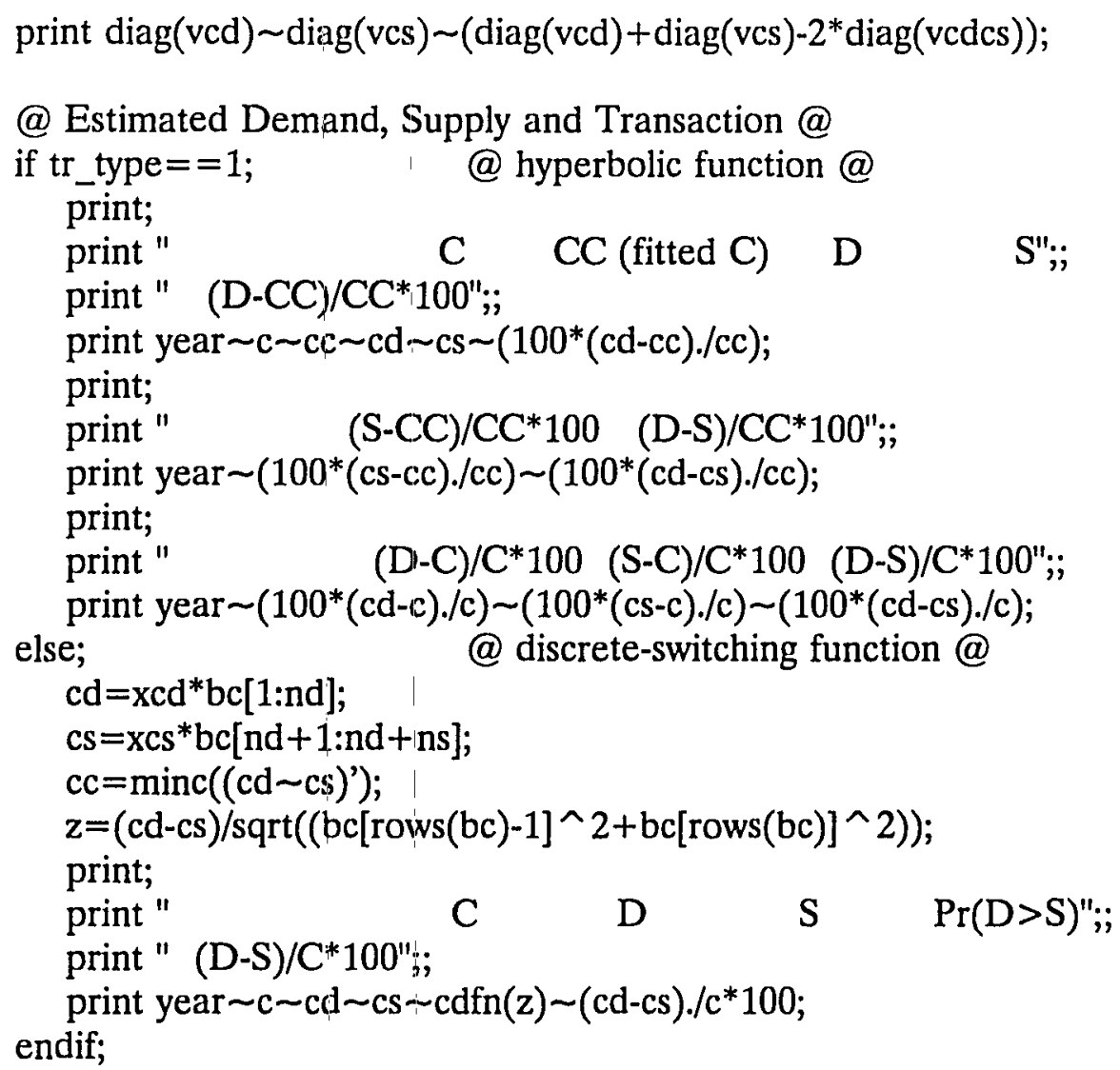




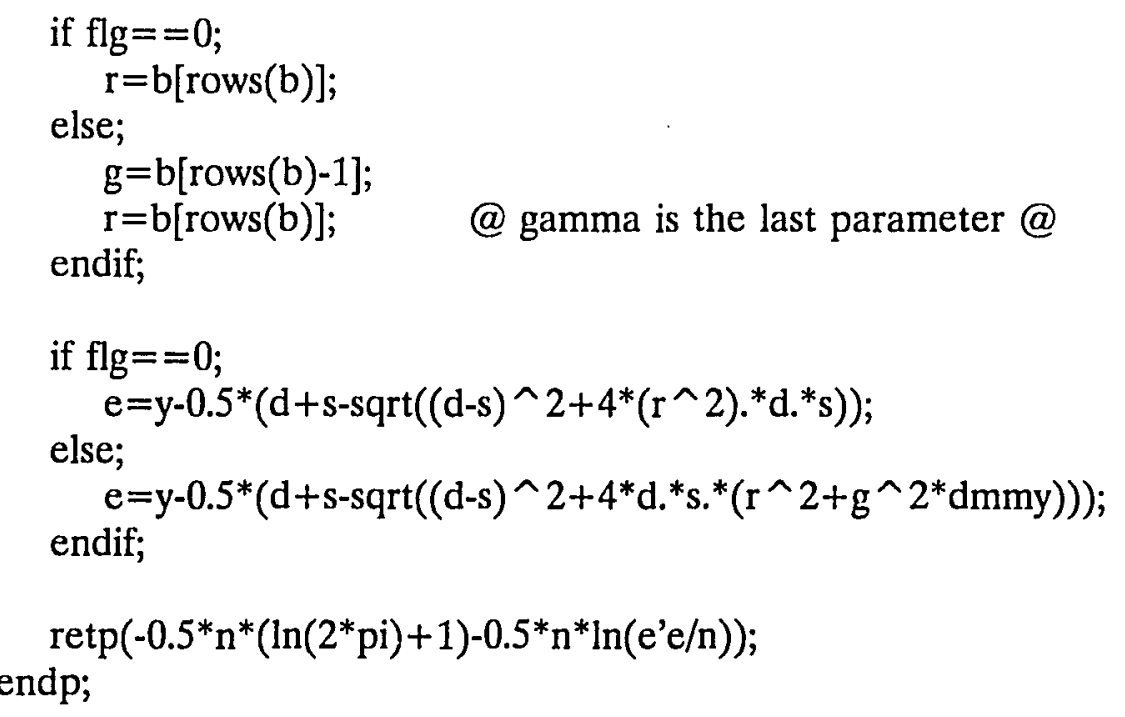

@ Log-Likelihood Function of Discrete-Switching Transaction Funciton @ proc llf_d(x,b);

local- y,xd,xs,d,s,sig1,sig2,z1,z2,g1,g2;

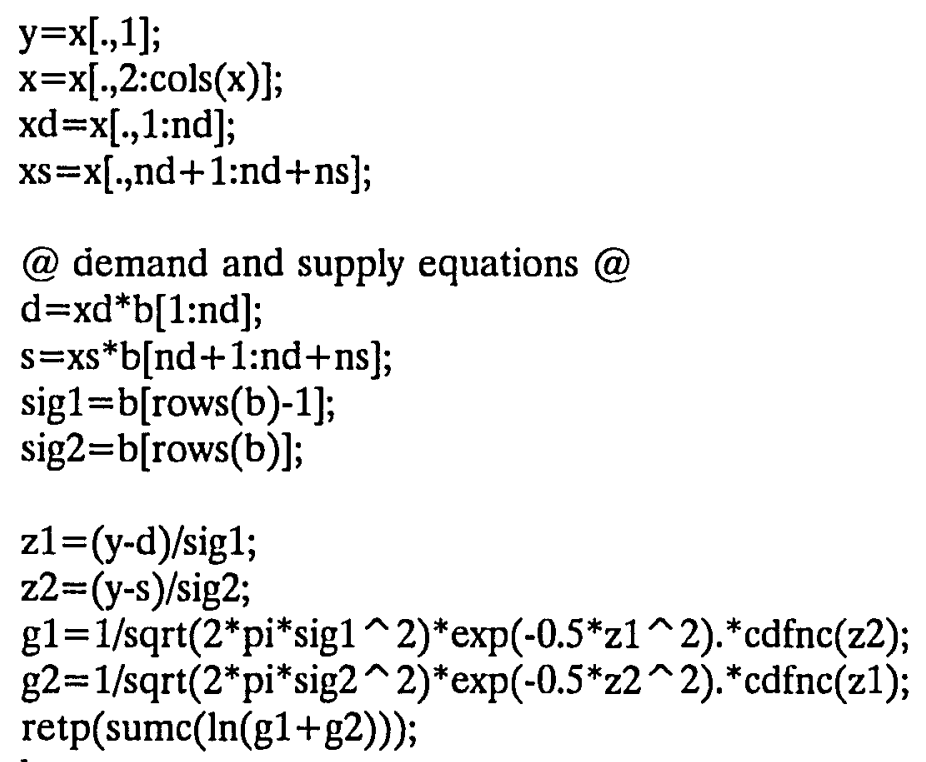

@ Estimated Demand, Supply and Transaction @ $\operatorname{proc}(5)=\operatorname{result}(\mathrm{x}, \mathrm{b})$;

local y,xd,xs,dmmy,d,s,d1,s1,r,g,z,e,i,flg;

$\mathrm{y}=\mathrm{x}[., 1]$

$\mathrm{x}=\mathrm{x}[., 2: \operatorname{cols}(\mathrm{x})]$; 


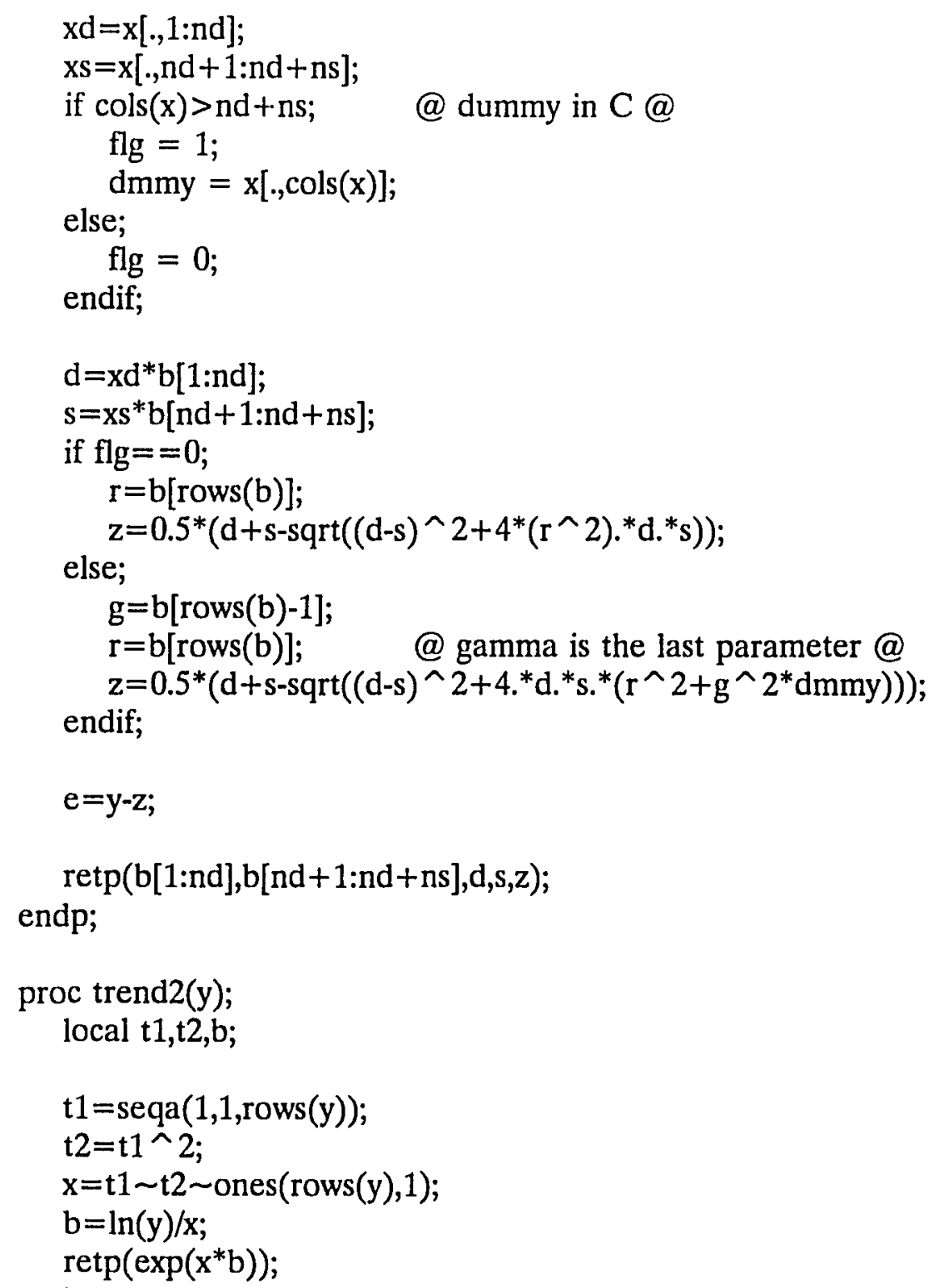




\section{LOCALLY WEIGHTED OPTIMIZATION USING HYPERBOLIC AND DISCRETE-SWITCHING TRANSACTION FUNCTIONS: MODELS 4A AND 4B}

The following is the GAUSS program for Models 4A and 4B: locally weighted optimization, using hyperbolic and discrete-switching transaction functions, respectively. NLOPT.GCG used in this program is a nonlinear optimization library in GAUSS, which is available from the Econometrics Lab at Portland State University.

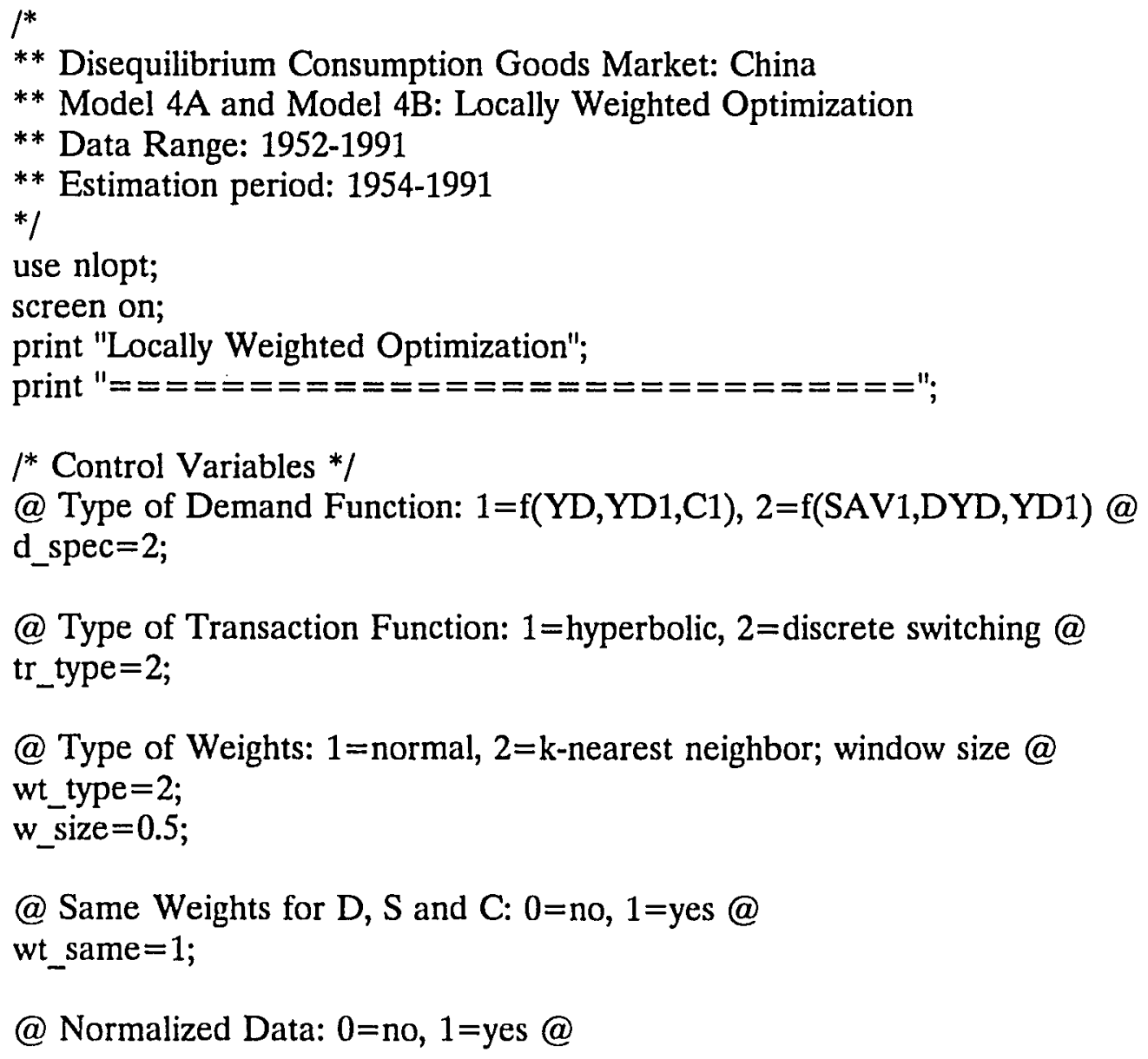

@ Type of Transaction Function: 1=hyperbolic, 2=discrete switching @ tr_type $=2$;

@ Type of Weights: 1=normal, 2=k-nearest neighbor; window size @ wt_type $=2$; w_size $=0.5$;

@ Same Weights for D, S and C: 0=no, 1=yes @ wt_same $=1$;

@ Normalized Data: 0=no, 1=yes @ 


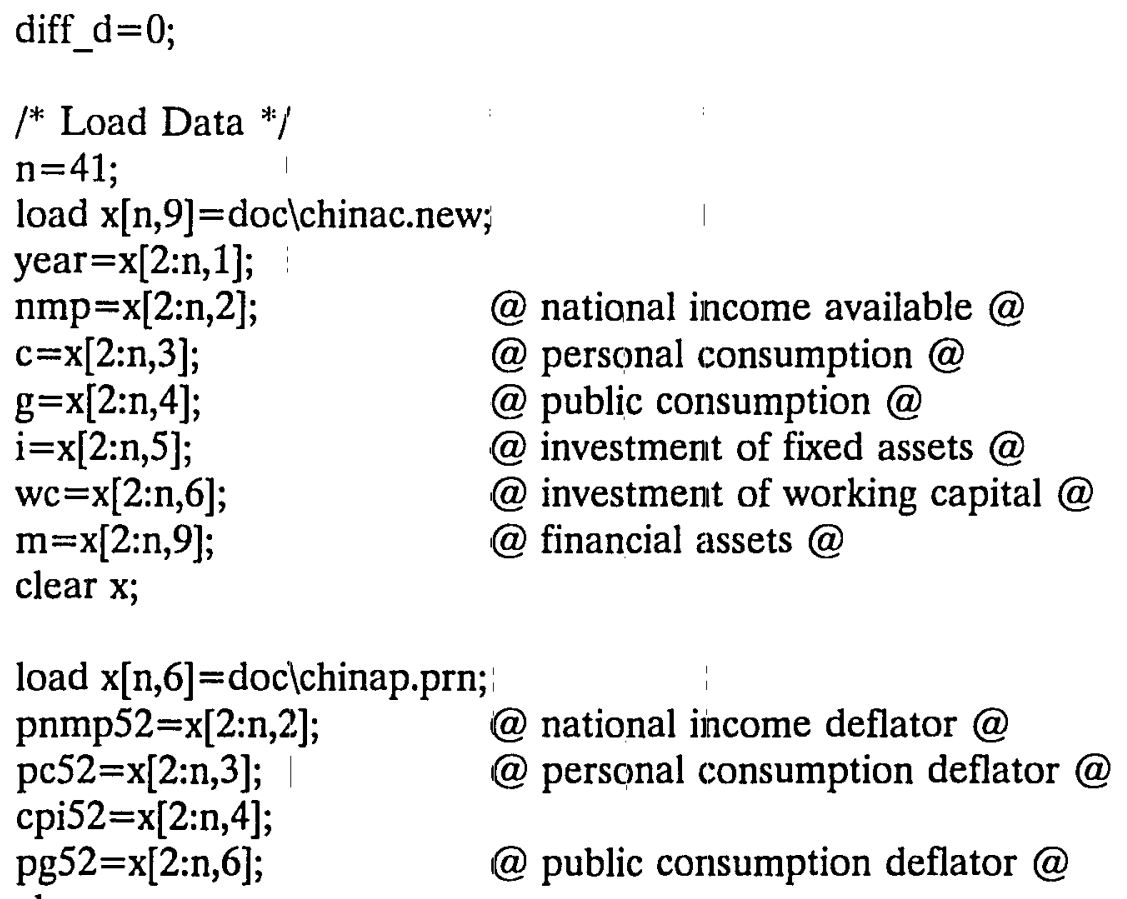

/* Explanatory Variables in Demand and Supply Equations */

if d_spec $==1$;

$$
\overline{x c d}=y d \sim \operatorname{lagn}(y d, 1) \sim \operatorname{lagn}(c, 1)
$$




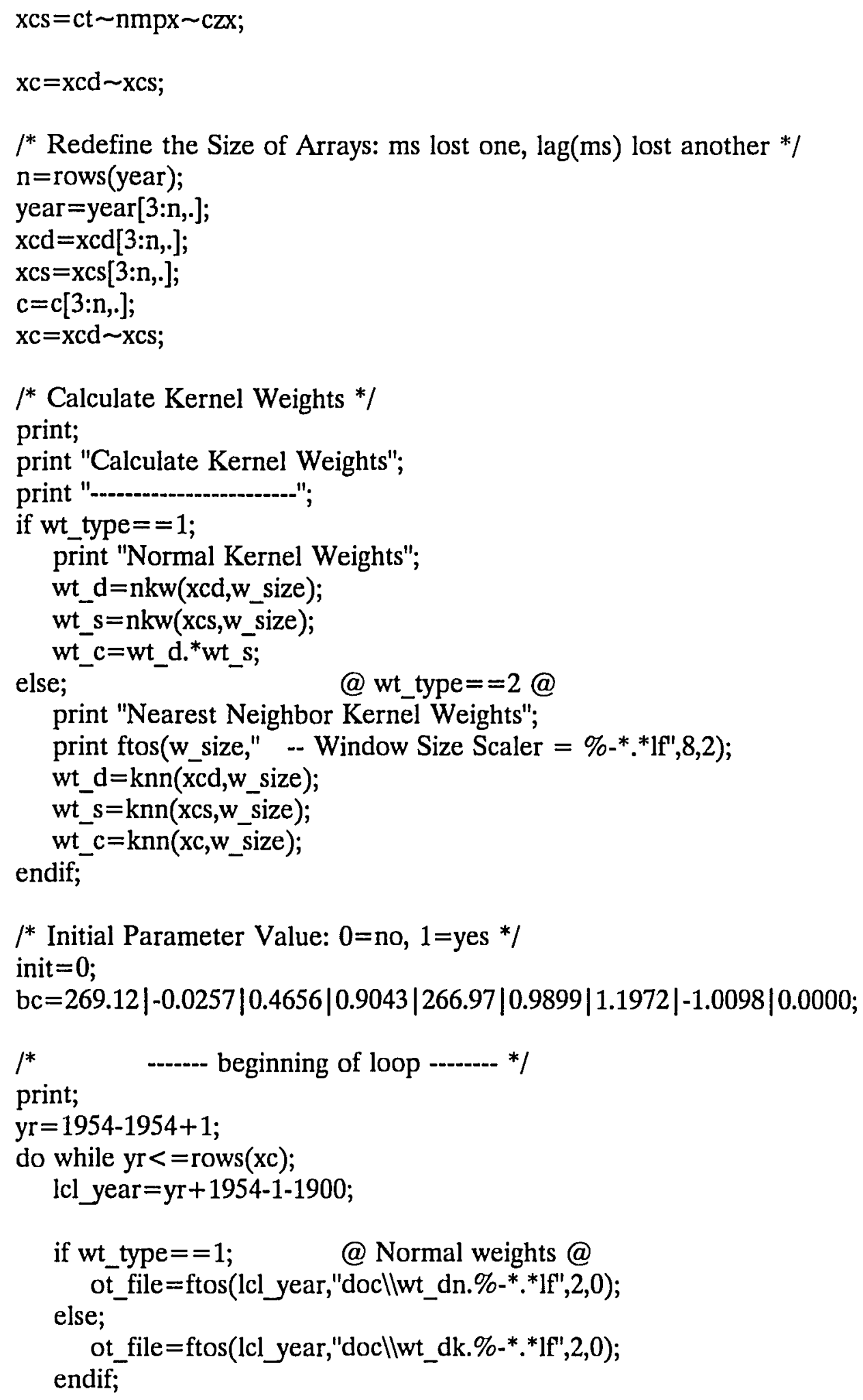


output file $={ }^{\wedge}$ ot_file reset;

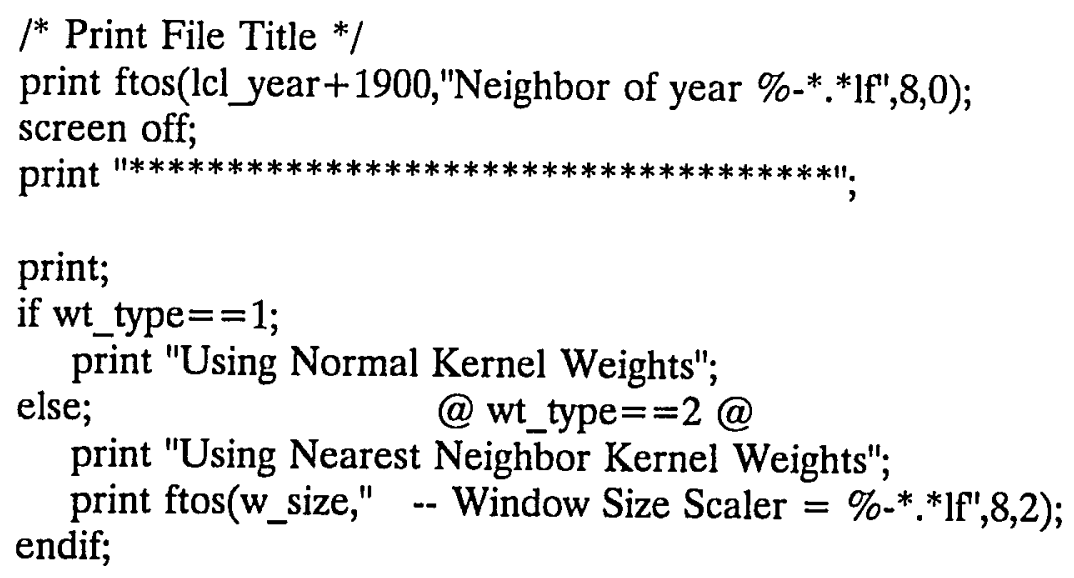

if diff_d; @ after weighting, 1 is no longer $1 @$ $\mathrm{c} 1=\mathrm{c} 1-\operatorname{meanc}(\mathrm{c} 1)^{\prime}$ 


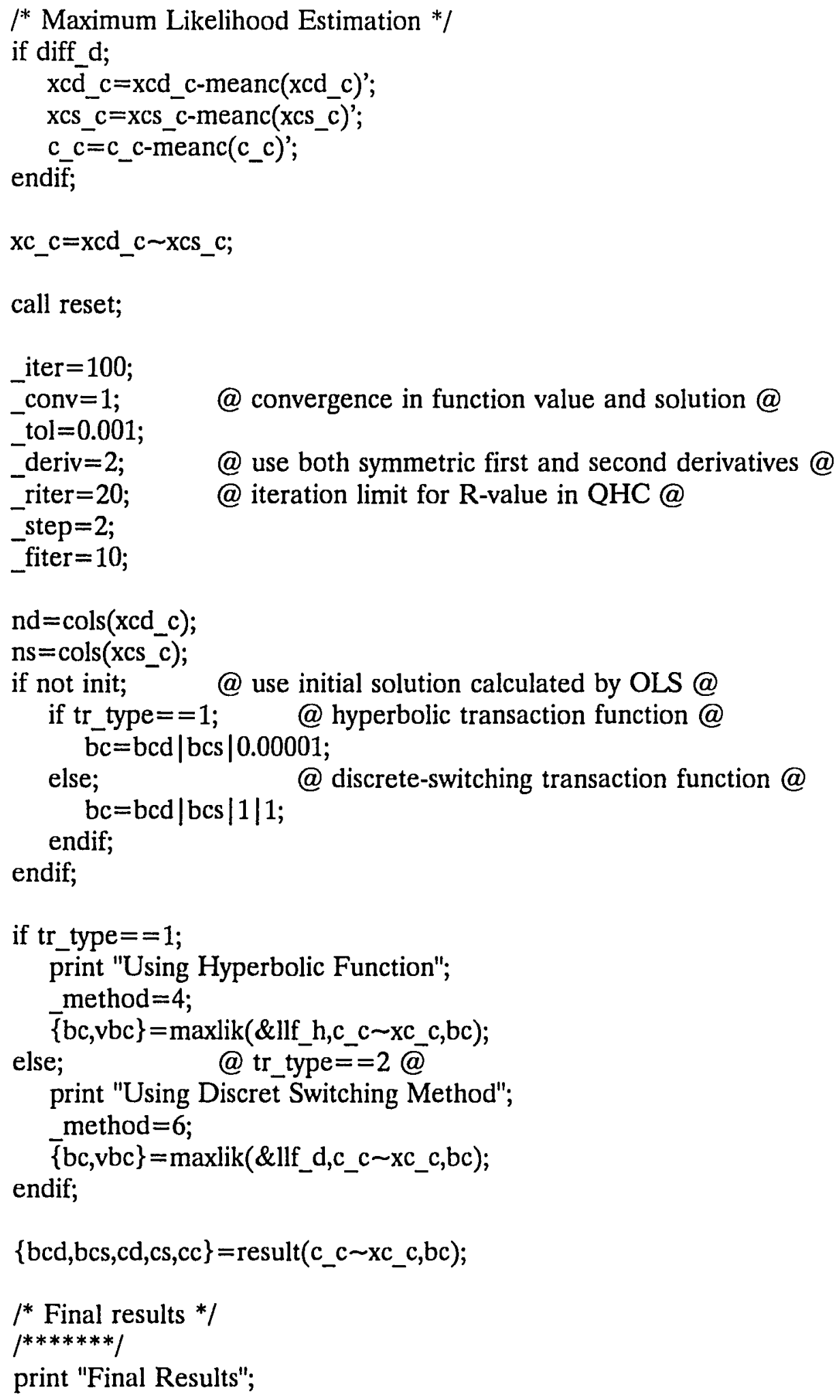




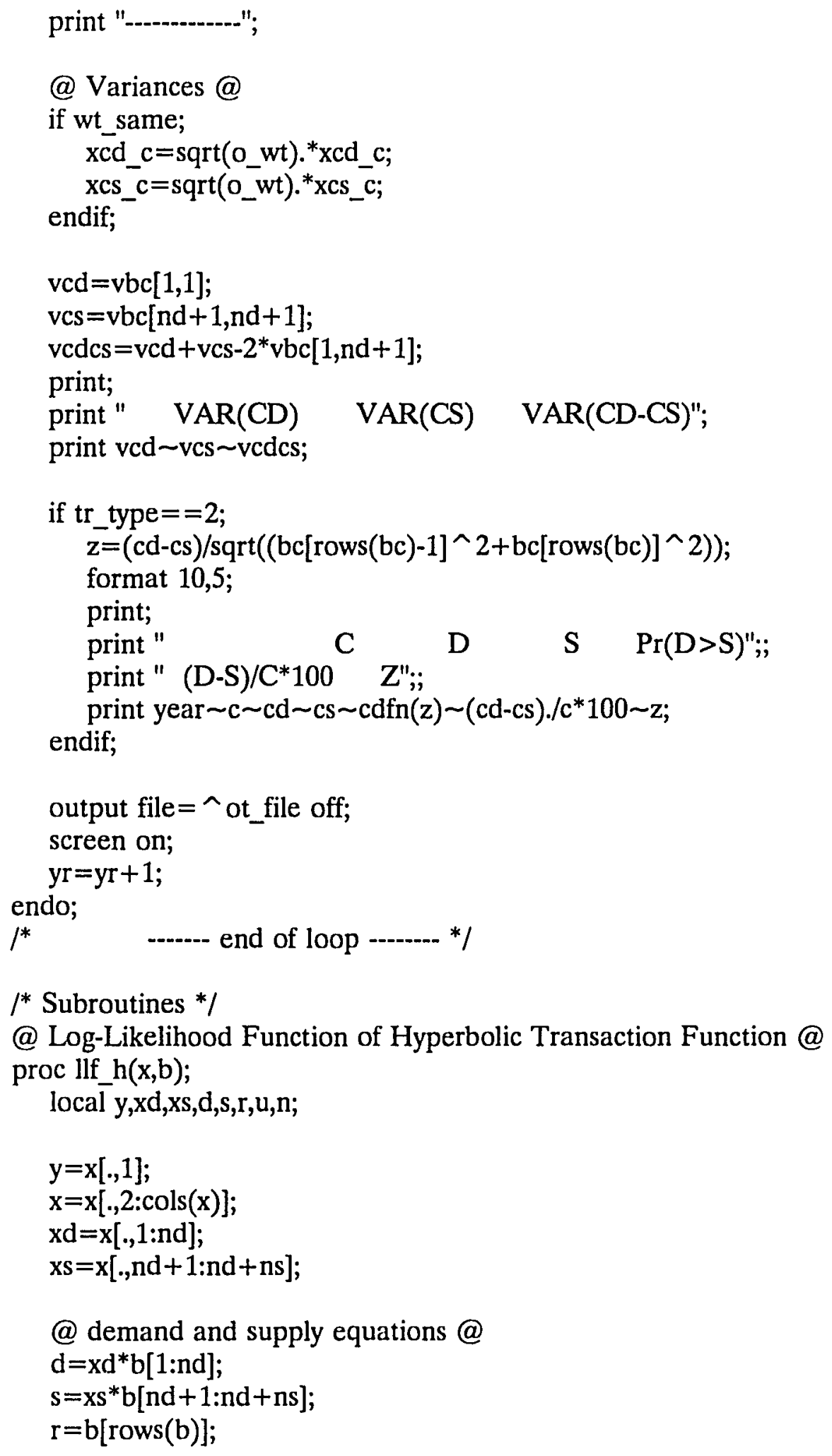

$I^{*}$ Subroutines */

@ Log-Likelihood Function of Hyperbolic Transaction Function @ proc llf_h(x,b);

local $y, x d, x s, d, s, r, u, n ;$

$\mathrm{y}=\mathrm{x}[., 1]$

$\mathrm{x}=\mathrm{x}[., 2: \operatorname{cols}(\mathrm{x})]$;

$\mathrm{xd}=\mathrm{x}[., 1: \mathrm{nd}]$;

$\mathrm{xs}=\mathrm{x}[., \mathrm{nd}+1: \mathrm{nd}+\mathrm{ns}]$;

@ demand and supply equations @

$\mathrm{d}=x \mathrm{~d}^{*} \mathrm{~b}[1: \mathrm{nd}]$;

$\mathrm{s}=\mathrm{xs} * \mathrm{~b}[\mathrm{nd}+1: \mathrm{nd}+\mathrm{ns}]$;

$\mathrm{r}=\mathrm{b}[\operatorname{rows}(\mathrm{b})]$; 
$\mathrm{u}=\mathrm{y}-0.5^{*}\left(\mathrm{~d}+\mathrm{s}-\mathrm{sqrt}\left((\mathrm{d}-\mathrm{s})^{\wedge} 2+4^{*}\left(\mathrm{r}^{\wedge} 2\right){ }^{*} \mathrm{~d} .{ }^{*} \mathrm{~s}\right)\right)$

$\mathrm{n}=\operatorname{rows}(\mathrm{u})$;

if wt_same;

$u=u .{ }^{*}$ sqrt(o_wt);

endif;

endp;

$\operatorname{retp}\left(-0.5^{*} n^{*}\left(\ln \left(2^{*} p i\right)+1\right)-0.5^{*} n^{*} \ln \left(u^{\prime} u / n\right)\right)$

@ Log-Likelihood Function of Discrete-Switching Transaction Funciton @ proc llf_d( $x, b)$;

local y,xd,xs,d,s,sig1,sig2,z1,z2,g1,g2;

$\mathrm{y}=\mathrm{x}[., 1]$

$\mathrm{x}=\mathrm{x}[., 2: \operatorname{cols}(\mathrm{x})]$

$\mathrm{xd}=\mathrm{x}[., 1: \mathrm{nd}]$

$\mathrm{xs}=\mathrm{x}[., \mathrm{nd}+1: \mathrm{nd}+\mathrm{ns}]$;

@ demand and supply equations @

$\mathrm{d}=\mathrm{xd} \mathrm{d}^{*} \mathrm{~b}[1: \mathrm{nd}]$;

$\mathrm{s}=\mathrm{xs} * \mathrm{~b}[\mathrm{nd}+1: \mathrm{nd}+\mathrm{ns}]$

$\operatorname{sig} 1=b[\operatorname{rows}(b)-1]$

$\operatorname{sig} 2=\mathrm{b}[\operatorname{rows}(\mathrm{b})]$;

$\mathrm{z} 1=(\mathrm{y}-\mathrm{d}) / \mathrm{sig} 1 ; @$ sig1 and sig2 are stds @

$\mathrm{z} 2=(\mathrm{y}-\mathrm{s}) / \mathrm{sig} 2$

if wt_same;

$\mathrm{z} \overline{1}=\operatorname{sqrt}\left(\mathrm{o}_{-} \mathrm{wt}\right){ }^{*} \mathrm{z} 1$;

$\mathrm{z} 2=\operatorname{sqrt}\left(\mathrm{o}_{-} \mathrm{wt}\right){ }^{*} \mathrm{z} 2$

endif;

$g 1=1 / \operatorname{sqrt}\left(2^{*} \mathrm{pi}^{*} \operatorname{sig} 1 \wedge 2\right) * \exp \left(-0.5^{*} z 1^{\wedge} 2\right) .{ }^{*} \operatorname{cdfnc}(z 2) ;$

$\mathrm{g} 2=1 / \mathrm{sqrt}\left(2^{*} \mathrm{pi}^{*} \mathrm{sig} 2^{\wedge} 2\right)^{*} \exp \left(-0.5^{*} \mathrm{z} 2^{\wedge} 2\right) .{ }^{*} \operatorname{cdfnc}(\mathrm{z} 1)$;

endp;

$\operatorname{retp}(\operatorname{sumc}(\ln (g 1+g 2)))$;

@ Estimated Demand, Supply and Transaction @ $\operatorname{proc}(5)=\operatorname{result}(\mathrm{x}, \mathrm{b})$;

local y,xd,xs,d,s,r,c,e,i;

$\mathrm{y}=\mathrm{x}[., 1]$

$\mathrm{x}=\mathrm{x}[., 2: \operatorname{cols}(\mathrm{x})]$; 
$\mathrm{xd}=\mathrm{x}[., 1: \mathrm{nd}]$

$\mathrm{xs}=\mathrm{x}[., \mathrm{nd}+1: \mathrm{nd}+\mathrm{ns}]$;

$\mathrm{d}=\mathrm{xd} \mathrm{d}^{*} \mathrm{~b}[1: \mathrm{nd}]$;

$\mathrm{s}=\mathrm{xs} * \mathrm{~b}[\mathrm{nd}+1$ :nd $+\mathrm{ns}]$;

$\mathrm{r}=\mathrm{b}[\operatorname{rows}(\mathrm{b})]$;

if tr_type $==1$;

else;

$$
c=0.5^{*}\left(d+s-\operatorname{sqrt}\left((d-s)^{\wedge} 2+4^{*}\left(r^{\wedge} 2\right) .{ }^{*} d . * s\right)\right) ;
$$

$c=\operatorname{minc}\left((d \sim s)^{\prime}\right)$

endif;

$\operatorname{retp}(b[1: n d], b[n d+1: n d+n s], d, s, c)$;

endp;

(a) Function for Calculating Gradiants and Hessians @ proc fgrd(b);

local y,xd,xs,d,s,r,u,n;

$\mathrm{y}=\mathrm{c} \_\mathrm{c}$;

$\mathrm{xd}=\mathrm{xc} \_\mathrm{c}[., 1: \mathrm{nd}]$;

$\mathrm{xs}=\mathrm{xc} \_\mathrm{c}[., \mathrm{nd}+1: \mathrm{nd}+\mathrm{ns}]$;

@ demand and supply equations@

$\mathrm{d}=\mathrm{xd} \mathrm{d}^{*} \mathrm{~b}[1: \mathrm{nd}]$;

$\mathrm{s}=\mathrm{xs} \mathrm{b}^{\mathrm{b}}[\mathrm{nd}+1$ :nd $+\mathrm{ns}]$;

$\mathrm{r}=\mathrm{b}[\mathrm{rows}(\mathrm{b})]$;

$\mathrm{ul}=\mathrm{y}-0.5^{*}\left(\mathrm{~d}+\mathrm{s}-\mathrm{sqrt}\left((\mathrm{d}-\mathrm{s})^{\wedge} 2+4^{*}\left(\mathrm{r}^{\wedge} 2\right) .{ }^{*} \mathrm{~d} .{ }^{*} \mathrm{~s}\right)\right) ;$

$\mathrm{n}=\operatorname{rows}(\mathrm{u})$;

iff wt_same;

$$
u=u .{ }^{*} \operatorname{sqrt}\left(0 \_w t\right) \text {; }
$$

endif;

$\operatorname{retp}\left(-0.5^{*} n^{* k}\left(\ln \left(2^{*} p i\right)+1\right)-0.5^{*} n^{*} \ln \left(u^{\prime} u / n\right)\right)$ endp;

$\rho^{*}$

** Normal Kernel Weight

** $\mathrm{x}=$ matrix of dependent variables

** $\mathrm{r}=$ scaler for window size, between 0 and inf

** Weights are symetric over the years 
*/

proc $n k w(x, r)$

local k,h,i,k_w;

$\mathrm{h}=\operatorname{sqrt}\left(\operatorname{meanc}\left(\left(\mathrm{x}-\mathrm{meanc}(\mathrm{x})^{\prime}\right)^{\wedge} 2\right)^{\prime}\right) ; \quad @ \mathrm{r}=\inf @$

@ $\mathrm{h}=\operatorname{sqrt}\left(\operatorname{meanc}\left(\left(\mathrm{x}-\mathrm{meanc}(\mathrm{x})^{\prime}\right)^{\wedge} 2\right)^{\prime}\right)^{*} \operatorname{rows}(\mathrm{x})^{\wedge}\left(-1 /\left(2^{*} \mathrm{r}+\operatorname{cols}(\mathrm{x})\right)\right)$; @

$\mathrm{i}=1$;

@ $h$ is $1 x \operatorname{cols}(x) @$

do while $\mathrm{i}<=\operatorname{rows}(\mathrm{x})$;

k_w=-sumc $\left(\left(((x-x[i, \cdot]) \wedge 2) \cdot /\left(2^{*} h \wedge 2\right)\right) '\right) ; @ k_{-} w=0$ for Xi @

k_w $=\exp \left(\mathrm{k} \_w\right)$;

if $\mathrm{i}==1 ; \mathrm{k}=\mathrm{k} \_\mathrm{w}$;

else; $k=k \sim k \_w ;$

endif;

$\mathrm{i}=\mathrm{i}+1$

endo;

retp $(k)$;

endp;

$/ *$

** K Nearest Neighbor Kernel Weights

${ }^{* *} \mathrm{x}=$ matrix of dependent variables

${ }^{* *} \mathrm{r}=$ scaler for window size, between 0 and 1

** Weights may not be symetric over the years due to non-common denominator

$*$ /

$\operatorname{proc} \mathrm{knn}(\mathrm{x}, \mathrm{r})$;

local k,h,i,k_w,f,hmax;

$\mathrm{i}=1$;

do while $\mathrm{i}<=\operatorname{rows}(\mathrm{x})$;

$\mathrm{h}=\operatorname{sqrt}\left(\operatorname{sumc}\left(\left((\mathrm{x}-\mathrm{x}[\mathrm{i}, .])^{\wedge} 2\right)^{\prime}\right)\right) ; @ \mathrm{~h}=0$ for Xi @

$\mathrm{f}=\operatorname{int}\left(\mathrm{r}^{*} \operatorname{rows}(\mathrm{x})\right)$; @ \# of neighbors in the sub-sample @

$\mathrm{hmax}=\operatorname{selif}(\mathrm{h},(\operatorname{rankindx}(\mathrm{h}, 1) .==\mathrm{f}))$;

$\mathrm{h}=\mathrm{h} . / \mathrm{hmax}$;

k_w $=\left(\left(1-h^{\wedge} 3\right)^{\wedge} 3\right) *^{*}(h .<1) ; \quad$ @ tricube kernel @

if $\mathrm{i}==1 ; \mathrm{k}=\mathrm{k} \_\mathrm{w}$;

else; $k=k-r k$ w;

endif;

$\mathrm{i}=\mathrm{i}+1$ 


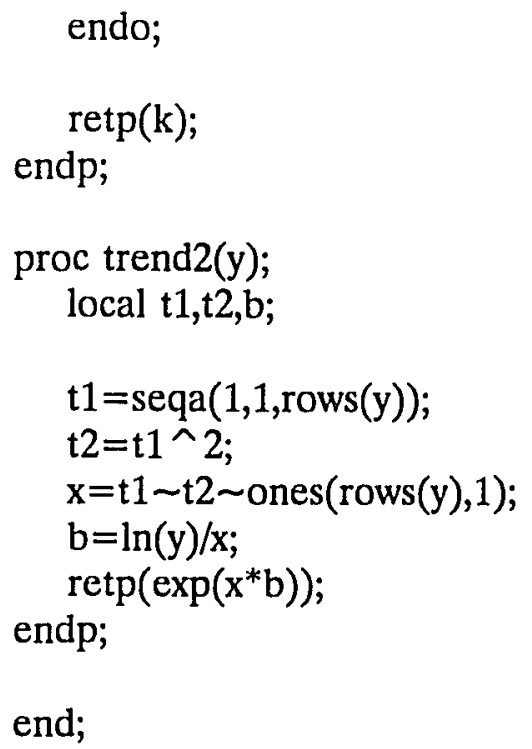




\section{APPENDIX C}

\section{SELECTED COMPUTER OUTPUTS}

Dummy Variable Approach Using Discrete-Switching Transaction Function: Model 2B

Locally Weighted Optimization Using Hyperbolic

Transaction Function: Model 4A

(Selected Years: 1963, 1980 and 1989)

Locally Weighted Optimization Using Discrete-Switching

Transaction Function: Model 4B

(Selected Years: 1963, 1980 and 1989) 


\section{DUMMY VARIABLE APPROACH USING DISCRETE-SWITCHING TRANSACTION FUNCTION: MODEL 2B}

Model 2B assumes structural change in 1980 by adding a dummy variable to the basic model, 1B. Differing from Model 2A, Model 2B uses discreteswitching transaction function. The following is a partial list of the computer output.

Model 2B

Discrete-Switching Transaction Funciton

Structural Change in D and $\mathrm{S}$

NLOPT/GAUSS Version 3.1B: Applied Data Associates.(1994/06/27/11:48:11)

Maximum Likelihood Estimation

Model: Total Log-Likelihood Function

Number of Parameters $=14$

Maximum Number of Iterations $=500$

Step Size Search Method $=0$

Convergence Criterion $=1$

Tolerance $=0.001$

Initial Result:

Log Likelihood $=\quad-82.067$

Parameters $=$

$\begin{array}{rrrrrr}-0.96826 & 0.63273 & 1.0164 & 0.88359 & 0.13230 & -0.072407 \\ 1.0724 & 0.80388 & -0.91500 & -0.066719 & 0.45051 & -0.33006 \\ 0.49863 & 1.7953 & & & & \end{array}$

Using Modified Quadratic Hill-Climbing Algorithm

Iteration $=1$ Step Size $=6.0000$ Log Likelihood $=-60.574$

$\begin{array}{llllll}\text { Parameters }= & -0.97869 & 0.63083 & 1.0179 & 0.89626 & 0.13659\end{array}$ 


\begin{tabular}{|c|c|c|c|c|c|}
\hline $\begin{array}{r}-0.074177 \\
-0.32467\end{array}$ & $\begin{array}{l}1.0825 \\
1.1142\end{array}$ & $\begin{array}{c}0.79492 \\
1.7981\end{array}$ & -0.92958 & -0.076125 & 0.45875 \\
\hline 13 & & $=1.5000 \mathrm{I}$ & Log Likelih & $\operatorname{ood}=$ & .106 \\
\hline $\begin{array}{c}\text { arameters }= \\
-0.070595 \\
-0.30030\end{array}$ & $\begin{array}{l}-0.92568 \\
1.0788 \\
10377\end{array}$ & $\begin{array}{c}0.64427 \\
0.80997 \\
18704\end{array}$ & $\begin{array}{c}1.0148 \\
-0.93252\end{array}$ & $\begin{array}{r}0.8381 \\
-0.073034\end{array}$ & $\begin{array}{l}0.12091 \\
0.44003\end{array}$ \\
\hline
\end{tabular}

Final Result:

Log Likelihood $=\quad-60.106$

Gradient of Log Likelihood =

$\begin{array}{cccccc}-0.0059465 & -0.013795 & -0.27174 & -0.0012013 & -0.00019393 & -0.011283 \\ -0.12266 & 0.0014233 & 0.00018325 & -0.091053 & 0.0035799 & 0.00057852 \\ -0.00035128 & -4.3687 \mathrm{e}-05 & & & & \end{array}$

$\begin{array}{rrr}\text { Parameter } & \text { Std. Error } & \text { t-ratio } \\ -0.9257 & 0.1899 & -4.8750 \\ 0.6443 & 0.0614 & 10.4910 \\ 1.0148 & 0.0068 & 149.2000 \\ 0.8381 & 0.2008 & 4.1731 \\ 0.1209 & 0.0766 & 1.5777 \\ -0.0706 & 0.0098 & -7.2341 \\ 1.0788 & 0.0185 & 58.4400 \\ 0.8100 & 0.2747 & 2.9489 \\ -0.9325 & 0.2998 & -3.1101 \\ -0.0730 & 0.0186 & -3.9309 \\ 0.4400 & 0.3100 & 1.4193 \\ -0.3003 & 0.4622 & -0.6497 \\ 1.0377 & 0.1464 & 7.0900 \\ 1.8704 & 0.4508 & 4.1489\end{array}$

Final Results

$\begin{array}{rrr}\text { VAR(CD) } & \text { VAR(CS) } & \text { VAR(CD-CS) } \\ 0.0300 & 1.0895 & 1.2133 \\ 0.0259 & 1.0896 & 1.2118 \\ 0.0405 & 2.3141 & 2.4891 \\ 0.0380 & 4.7634 & 4.9051 \\ 0.0314 & 4.3363 & 4.4904 \\ 0.2072 & 3.1944 & 3.4014 \\ 0.2350 & 1.8934 & 2.1130 \\ 0.2595 & 2.1858 & 2.7703 \\ 0.1888 & 3.2654 & 3.7819 \\ 0.6543 & 2.6693 & 3.5919\end{array}$




$\begin{array}{rrr}0.0690 & 2.1350 & 2.3446 \\ 0.1269 & 2.0623 & 2.1912 \\ 0.0938 & 1.4433 & 1.6260 \\ 0.1238 & 3.2558 & 3.5189 \\ 0.1364 & 3.9514 & 4.4843 \\ 0.0686 & 3.0446 & 3.3739 \\ 0.1477 & 2.4859 & 2.9965 \\ 0.2143 & 2.2151 & 2.8554 \\ 0.0849 & 2.6549 & 2.9971 \\ 0.1230 & 3.3662 & 3.7860 \\ 0.1435 & 3.3738 & 3.9078 \\ 0.1233 & 3.8606 & 4.3668 \\ 0.1386 & 5.7747 & 6.4875 \\ 0.2526 & 11.7380 & 12.8400 \\ 0.2313 & 17.0880 & 17.8090 \\ 0.4566 & 14.3770 & 14.6440 \\ 0.4538 & 0.5424 & 1.0284 \\ 0.1671 & 6.1388 & 6.2760 \\ 0.1640 & 8.7397 & 8.8789 \\ 0.4194 & 11.0490 & 11.3990 \\ 2.2694 & 2.9054 & 5.1375 \\ 1.5794 & 1.1981 & 2.9285 \\ 0.6038 & 1.3558 & 2.0497 \\ 1.7688 & 0.9446 & 2.8452 \\ 1.0934 & 10.7530 & 11.8890 \\ 1.0554 & 9.0190 & 10.1010 \\ 6.3746 & 1.7584 & 8.2888 \\ 12.5690 & 2.0944 & 14.6070\end{array}$

\begin{tabular}{|c|c|c|c|c|c|}
\hline & $\mathrm{C}$ & $\mathrm{D}$ & $\mathrm{S}$ & $\operatorname{Pr}(\mathrm{D}>\mathrm{S})$ & $\begin{array}{c}\text { (D-S) } \\
/ C^{*} 100\end{array}$ \\
\hline 1954 & 49.128 & 49.016 & 50.976 & 0.1798 & -3.989 \\
\hline 1955 & 53.424 & 52.504 & 55.216 & 0.1024 & -5.077 \\
\hline 1956 & 56.896 & 57.447 & 58.799 & 0.2637 & -2.376 \\
\hline 1957 & 59.761 & 59.354 & 62.511 & 0.0700 & -5.282 \\
\hline 1958 & 62.108 & 63.313 & 63.132 & 0.5338 & 0.292 \\
\hline 1959 & 57.069 & 60.338 & 56.852 & 0.9484 & 6.109 \\
\hline 1960 & 53.771 & 54.821 & 60.491 & 0.0040 & -10.545 \\
\hline 1961 & 50.040 & 51.267 & 62.617 & 0.0000 & -22.683 \\
\hline 1962 & 52.688 & 50.036 & 66.143 & 0.0000 & -30.568 \\
\hline 1963 & 59.543 & 60.133 & 67.935 & 0.0001 & -13.102 \\
\hline 1964 & 64.707 & 64.567 & 70.416 & 0.0031 & -9.039 \\
\hline 1965 & 72.393 & 71.276 & 72.219 & 0.3296 & -1.303 \\
\hline 1966 & 77.470 & 77.605 & 77.899 & 0.4454 & -0.379 \\
\hline
\end{tabular}




$\begin{array}{rrrrrr}1967 & 82.067 & 80.966 & 83.666 & 0.1034 & -3.290 \\ 1968 & 81.418 & 83.252 & 83.155 & 0.5181 & 0.119 \\ 1969 & 85.887 & 84.311 & 89.180 & 0.0114 & -5.668 \\ 1970 & 91.924 & 90.774 & 95.158 & 0.0202 & -4.769 \\ 1971 & 95.524 & 97.464 & 98.027 & 0.3962 & -0.589 \\ 1972 & 100.650 & 100.090 & 104.290 & 0.0247 & -4.178 \\ 1973 & 108.420 & 108.040 & 111.460 & 0.0546 & -3.161 \\ 1974 & 110.500 & 111.540 & 115.040 & 0.0512 & -3.162 \\ 1975 & 114.530 & 114.580 & 120.870 & 0.0016 & -5.490 \\ 1976 & 118.400 & 118.740 & 127.960 & 0.0000 & -7.784 \\ 1977 & 121.260 & 121.130 & 131.350 & 0.0000 & -8.430 \\ 1978 & 129.120 & 130.140 & 137.030 & 0.0006 & -5.344 \\ 1979 & 139.580 & 140.820 & 148.770 & 0.0001 & -5.695 \\ 1980 & 154.720 & 154.000 & 155.520 & 0.2382 & -0.984 \\ 1981 & 167.520 & 166.810 & 172.040 & 0.0073 & -3.119 \\ 1982 & 178.720 & 177.940 & 187.500 & 0.0000 & -5.350 \\ 1983 & 193.740 & 195.410 & 203.980 & 0.0000 & -4.422 \\ 1984 & 217.820 & 228.840 & 219.490 & 1.0000 & 4.296 \\ 1985 & 249.940 & 251.820 & 247.710 & 0.9726 & 1.644 \\ 1986 & 264.480 & 274.120 & 266.580 & 0.9998 & 2.851 \\ 1987 & 284.090 & 301.850 & 282.830 & 1.0000 & 6.695 \\ 1988 & 308.490 & 308.410 & 321.890 & 0.0000 & -4.370 \\ 1989 & 310.610 & 310.830 & 329.990 & 0.0000 & -6.168 \\ 1990 & 322.240 & 364.450 & 325.590 & 1.0000 & 12.059 \\ 1991 & 353.580 & 401.250 & 350.770 & 1.0000 & 14.277\end{array}$




\section{LOCALLY WEIGHTED OPTIMIZATION USING HYPERBOLIC}

TRANSACTION FUNCTION: MODEL 4A

(Selected Years: 1963, 1980 and 1989)

Model 4A applies locally weighted optimization technique with hyperbolic transaction function. Three outputs included here are selected among the total of 38 outputs. They are the outputs for the focal years of 1963, 1980 and 1989.

Neighborhood of year 1963

Using Nearest Neighbor Kernel Weights

-- Window Size Scaler $=0.50$

Using Hyperbolic Function

NLOPT/GAUSS Version 3.1B: Applied Data Associates.(1994/10/21/10:25:11)

Maximum Likeinhood Estimation

Model: Total Log-Likelihood Function

Number of Parameters $=9$

Maximum Number of Iterations $=200$

Step Size Search Method $=0$

Convergence Criterion $=1$

Tolerance $=0.001$

Initial Result:

Log Likelihood $=\quad-77.334$

Parameters $=$

$\begin{array}{llllll}56.741 & -0.59533 & 0.22805 & 0.98517 & 60.883 & 0.98827\end{array}$

$0.91092 \quad-0.66128 \quad 1.0000 \mathrm{e}-05$

Using Newton-Raphson Algorithm

Iteration $=1$ Step Size $=0.5000$ Log Likelihood $=-49.692$

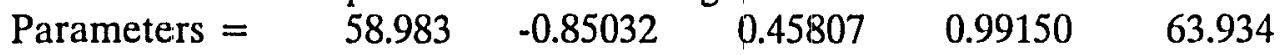

$\begin{array}{llll}1.0552 & 0.78179 & -0.67856 & 0.00028214\end{array}$ 


$$
\begin{array}{cccccc}
\text { Iteration }= & 15 & \text { Step Size }= & 1.5000 & \text { Log Likelihood } & \multicolumn{2}{c}{-30.121} \\
\text { Parameters }= & 60.293 & -0.81750 & 0.66883 & 1.0168 & 66.148 \\
1.1276 & 0.75303 & -0.76329 & 4.6726 \mathrm{e}-07 & &
\end{array}
$$

Final Result:

Log Likelihood $=\quad-30.121$

Gradient of Log Likelihood =

$\begin{array}{cccccc}0.0023079 & 0.011868 & -0.019104 & 0.025062 & 0.0026305 & -0.0019590 \\ 0.027127 & 0.022160 & -0.034550 & & & \end{array}$

$\begin{array}{rrr}\text { Parameter } & \text { Std. Error } & \begin{array}{r}\text { Asymptotic } \\ \text { t-ratio }\end{array} \\ 60.293 & 0.479 & 125.840 \\ -0.818 & 0.192 & -4.252 \\ 0.669 & 0.065 & 10.260 \\ 1.017 & 0.027 & 37.942 \\ 66.148 & 0.529 & 124.980 \\ 1.128 & 0.027 & 41.436 \\ 0.753 & 0.083 & 9.051 \\ -0.763 & 0.115 & -6.639 \\ 0.000 & 0.004 & 0.000\end{array}$

Neighbor of year 1980

$* * * * * * * * * * * * * * * * * * * * * *$

Using Nearest Neighbor Kernel Weights

-- Window Size Scaler $=0.50$

Using Hyperbolic Function

NLOPT/GAUSS Version 3.1B: Applied Data Associates.(1994/10/21/11:49:14)

Maximum Likelihood Estimation

Model: Total Log-Likelihood Function

Number of Parameters $=9$

Maximum Number of Iterations $=200$

Step Size Search Method $=0$

Convergence Criterion $=1$

Tolerance $=0.001$

Initial Result: 
Log Likelihood $=\quad 10.538$

Parameters $=$

$\begin{array}{llllll}154.77 & -0.52735 & 0.57243 & 0.95699 & 158.14 & 0.97504\end{array}$

$\begin{array}{lll}0.93250 & -0.95014 & -7.9479 \mathrm{e}-08\end{array}$

Using Newton-Raphson Algorithm

Iteration $=1$ Step Size $=1.5000$ Log Likelihood $=10.539$

$\begin{array}{llllll}\text { Parameters }= & 154.77 & -0.52709 & 0.57249 & 0.95695 & 158.15\end{array}$

$\begin{array}{llll}0.97495 & 0.93246 & -0.95032 & 4.2443 \mathrm{e}-07\end{array}$

Iteration $=3$ Step Size $=0.5000$ Log Likelihood $=10.539$

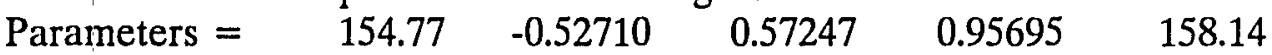

$\begin{array}{llll}0.97495 & 0.93235 & -0.95030 & -1.8851 \mathrm{e}-07\end{array}$

Final Result:

Log Likelihood $=\quad 10.539$

Gradient of Log Likelihood $=$

$\begin{array}{llllll}0.092479 & -0.19095 & -0.98931 & -1.2240 & -0.080994 & 6.0738 \\ -0.48712 & -0.49470 & 0.90786 & & & \end{array}$

$\begin{array}{rrr}\text { Parameter } & \text { Std. Error } & \text { Asymptotic } \\ 154.770 & 0.164 & 944.880 \\ -0.527 & 0.054 & -9.675 \\ 0.572 & 0.015 & 37.940 \\ 0.957 & 0.011 & 87.305 \\ 158.140 & 0.277 & 571.130 \\ 0.975 & 0.007 & 130.500 \\ 0.932 & 0.050 & 18.648 \\ -0.950 & 0.025 & -38.724 \\ 0.000 & 0.001 & 0.000\end{array}$

Neighbor of year 1989

Using Nearest Neighbor Kernel Weights

-- Window Size Scaler $=0.50$

Using Hyperbolic Function

NLOPT/GAUSS Version 3.1B: Applied Data Associates.(1994/10/21/15:31:43)

Maximum Likelihood Estimation 
Model: Total Log-Likelihood Function

Number of Parameters $=9$

Maximum Number of Iterations $=200$

Step Size Search Method $=0$

Convergence Criterion $=1$

Tolerance $=0.001$

Initial Result:

Log Likelihood $=\quad-36.562$

Parameters $=$

$\begin{array}{llllll}309.74 & 0.043646 & 0.17673 & 0.82719 & 326.12 & 1.0320\end{array}$

$0.96624 \quad-0.45053 \quad 2.7072 \mathrm{e}-09$

Using Newton-Raphson Algorithm

Iteration $=1$ Step Size $=1.5000$ Log Likelihood $=\quad-36.562$

$\begin{array}{llllll}\text { Parameters }= & 309.74 & 0.043647 & 0.17673 & 0.82720 & 326.12\end{array}$

$$
\begin{array}{llll}
1.0320 & 0.96620 & -0.45049 & 7.8583 \mathrm{e}-09
\end{array}
$$

Iteration $=3$ Step Size $=1.5000$ Log Likelihood $=-36.562$

$\begin{array}{llllll}\text { Parameters }= & 309.74 & 0.043646 & 0.17673 & 0.82719 & 326.12\end{array}$ $\begin{array}{llll}1.0320 & 0.96621 & -0.45050 & -2.9201 \mathrm{e}-10\end{array}$

Final Result:

Log Likelihood $=\quad-36.562$

Gradient of Log Likelihood =

$\begin{array}{cccccc}0.0029261 & 0.019755 & 0.067200 & -0.085364 & -0.0047460 & 0.42588 \\ 0.041907 & -0.0082427 & -0.00039080 & & & \end{array}$

Parameter 309.740

0.044

0.177

0.827

326.120

1.032

0.966

$-0.451$

0.000
Std. Error

0.599

0.037

0.013

0.009

0.844

0.006

0.043

0.078

0.002
Asymptotic

t-ratio

516.960

1.170

13.217

92.958

386.400

181.600

22.666

$-5.745$

0.000 
LOCALLY WEIGHTED OPTIMIZATION USING DISCRETE-SWITCHING TRANSACTION FUNCTION: MODEL 4B

(Selected Years: 1963, 1980 and 1989)

Model 4B applies the same optimization technique as Model 4A. But it uses discrete-switching transaction function. Three outputs included here are selected among the total of 38 outputs. They are the same focal years used for Model 4A: 1963, 1980 and 1989.

Neighbor of year 1963

$* * * * * * * * * * * * * * * * * * * * *$

Using Nearest Neighbor Kernel Weights

-- Window Size Scaler $=0.50$

Using Discret Switching Method

NLOPT/GAUSS Version 3.1B: Applied Data Associates.(1994/07/15/14:52:54)

Maximum Likelihood Estimation

Model: Total Log-Likelihood Function

Number of Parameters $=10$

Maximum Number of Iterations $=200$

Step Size Search Method $=0$

Convergence Criterion $=1$

Tolerance $=0.001$

Initial Result:

Log Likelihood $=\quad-73.207$

Parameters $=$

$\begin{array}{cccccc}60.306 & -0.78315 & 0.70192 & 0.99738 & 60.739 & 1.1926 \\ 1.2180 & -0.99584 & 1.0000 & 1.0000 & & \end{array}$

Using Newton-Raphson Algorithm

Iteration $=1$ Step Size $=1.0000$ Log Likelihood $=-70.722$ 


\begin{tabular}{|c|c|c|c|c|c|}
\hline $\begin{array}{c}\text { Parameters }= \\
1.0976\end{array}$ & $\begin{array}{l}58.476 \\
0.75373\end{array}$ & $\begin{array}{l}-0.26810 \\
-0.78272\end{array}$ & $\begin{array}{l}0.75719 \\
0.61687\end{array}$ & $\begin{array}{l}0.98271 \\
0.97043\end{array}$ & 64.829 \\
\hline & Step Size & $1.5000 \mathrm{I}$ & Log Likeliho & \multicolumn{2}{|c|}{-57.212} \\
\hline $\begin{array}{c}\text { Parameters } \\
1.1555\end{array}$ & $\begin{array}{l}60.446 \\
1.0489\end{array}$ & $\begin{array}{l}-0.81921 \\
-0.92699\end{array}$ & $\begin{array}{l}0.69141 \\
0.65338\end{array}$ & $\begin{array}{l}1.0081 \\
2.7073\end{array}$ & .074 \\
\hline
\end{tabular}

Final Result:

Log Likelihood $=\quad-57.212$

Gradient of Log Likelihood $=$

$\begin{array}{cccccc}0.00059126 & 0.0040943 & -0.0031303 & 0.012329 & -1.0508 \mathrm{e}-05 & -0.00010853 \\ 0.00045386 & 0.00032922 & 0.0012240 & 0.00013031 & \end{array}$

$\begin{array}{rrr}\text { Parameter } & \text { Std. Error } & \text { t-ratio } \\ 60.446 & 0.934 & 64.704 \\ -0.819 & 0.272 & -3.007 \\ 0.691 & 0.079 & 8.775 \\ 1.008 & 0.035 & 29.150 \\ 62.074 & 2.712 & 22.893 \\ 1.156 & 0.116 & 9.958 \\ 1.049 & 0.385 & 2.723 \\ -0.927 & 0.477 & -1.942 \\ 0.653 & 0.101 & 6.447 \\ 2.707 & 1.264 & 2.141\end{array}$

Neighbor of year 1980

Using Nearest Neighbor Kernel Weights

-- Window Size Scaler $=0.50$

Using Discret Switching Method

NLOPT/GAUSS Version 3.1B: Applied Data Associates.(1994/07/15/15:27:32)

Maximum Likelihood Estimation

Model: Total Log-Likelihood Function

Number of Parameters $=10$

Maximum Number of Iterations $=200$

Step Size Search Method $=0$ 
Convergence Criterion $=1$

Tolerance $=0.001$

Initial Result:

Log Likelihood $=\quad-40.861$

Parameters $=$

$\begin{array}{rrrrrr}154.20 & -0.65985 & 0.53059 & 0.98481 & 154.66 & 0.95280 \\ 0.96183 & -0.66855 & 1.0000 & 1.0000 & & \end{array}$

Using Newton-Raphson Algorithm

Iteration $=1$ Step Size $=0.0625$ Log Likelihood $=-31.614$

Parameters $=\begin{array}{lllll}154.22 & -0.59819 & 0.54237 & 0.96699 & 155.25\end{array}$

$\begin{array}{lllll}0.96640 & 1.0103 & -0.71338 & 0.74825 & 0.50009\end{array}$

Iteration $=14$ Step Size $=1.5000$ Log Likelihood $=-19.480$

Parameters $=\begin{array}{lllll}154.77 & -0.59997 & 0.56701 & 0.97535 & 154.43\end{array}$

$\begin{array}{lllll}0.95310 & 0.90333 & -0.63377 & 0.21484 & 1.0972\end{array}$

Final Result:

Log Likelihood $=\quad-19.480$

Gradient of Log Likelihood $=$

$\begin{array}{cccccc}-0.00088778 & -0.036661 & -0.045644 & -0.35492 & 0.00039159 & 0.029445 \\ -0.0034944 & -0.0088533 & 0.011401 & 0.00060353 & & \end{array}$

$\begin{array}{rrr}\text { Parameter } & \text { Std. Error } & \text { t-ratio } \\ 154.770 & 0.180 & 857.640 \\ -0.600 & 0.051 & -11.773 \\ 0.567 & 0.017 & 33.698 \\ 0.975 & 0.010 & 94.364 \\ 154.430 & 0.647 & 238.710 \\ 0.953 & 0.020 & 47.097 \\ 0.903 & 0.125 & 7.240 \\ -0.634 & 0.084 & -7.583 \\ 0.215 & 0.031 & 6.903 \\ 1.097 & 0.303 & 3.625\end{array}$

Neighbor of year 1989

Using Nearest Neighbor Kernel Weights

-- Window Size Scaler $=0.50$ 
Using Discret Switching Method

NLOPT/GAUSS Version 3.1B: Applied Data Associates.(1994/07/15/15:43:26)

Maximum Likelihood Estimation

Model: Total Log-Likelihood Function

Number of Parameters $=10$

Maximum Number of Iterations $=200$

Step Size Search Method $=0$

Convergence Criterion $=1$

Tolerance $=0.001$

Initial Result:

Log Likelihood $=\quad-124.25$

Parameters $=$

$\begin{array}{llllll}313.71 & -0.35721 & 0.11538 & 0.88046 & 317.07 & 0.97396\end{array}$

$\begin{array}{llll}0.68486 & 0.045670 & 1.0000 & 1.0000\end{array}$

Using Newton-Raphson Algorithm

Iteration $=1$ Step Size $=0.2500$ Log Likelihood $=-122.93$

$\begin{array}{llllll}\text { Parameters }= & 309.59 & 0.077433 & 0.18843 & 0.84714 & 316.04\end{array}$

$\begin{array}{lllll}0.96816 & 0.67908 & 0.062998 & 0.57060 & 1.1953\end{array}$

Iteration $=14$ Step Size $=1.5000$ Log Likelihood $=\quad-75.008$

$\begin{array}{llllll}\text { Parameters }= & 309.75 & 0.00077791 & 0.17546 & 0.85020 & 319.98\end{array}$

$\begin{array}{lllll}0.99489 & 0.69407 & 0.016235 & 1.7267 & 1.4101\end{array}$

Final Result:

Log Likelihood $=\quad-75.008$

Gradient of Log Likelihood $=$

$\begin{array}{cccccc}-0.00016148 & -0.0021316 & -0.0041914 & 0.0083800 & -0.00025371 & -0.012266 \\ 0.0097818 & 0.0021008 & 0.0015592 & 0.0015328 & & \end{array}$

Parameter

309.750

0.001

0.175

0.850

319.980

0.995
Std. Error

1.666

0.090

0.034

0.015

1.882

0.014

Asymptotic

t-ratio

185.980

0.009

5.188

55.997

170.000

70.164 


$\begin{array}{lll}0.694 & 0.107 & 6.513 \\ 0.016 & 0.215 & 0.075 \\ 1.727 & 0.476 & 3.630 \\ 1.410 & 0.362 & 3.898\end{array}$




\section{APPENDIX D \\ ESTIMATED RESPONSE COEFFICIENTS FROM LOCALLY WEIGHTED OPTIMIZATION}

Using Hyperbolic Transaction Function: Model 4A, 1954-1991

Using Discrete-Switching Transaction Function: Model 4B, 1954 to 1991 


\section{USING HYPERBOLIC TRANSACTION FUNCTION: MODEL 4A, 1954-1991}

The following lists the response coefficients estimated using locally weighted optimization with the hyperbolic transaction function. There are 38 observations in the sample. Therefore, there are 38 sets of response coefficients resulted from 38 locally weighted fittings. $\alpha$ 's and B's are the response coefficients in the demand and supply functions, respectively. $\quad \gamma$ is the measure of market friction in the transaction function.

$\begin{array}{llllllll} & \alpha_{1} & \alpha_{2} & \alpha_{3} & \mathcal{B}_{1} & \mathcal{B}_{2} & \mathcal{B}_{3} & \gamma \\ 54 & -0.858 & 0.694 & 1.017 & 1.113 & 0.737 & -0.785 & 0.000 \\ 55 & -0.854 & 0.693 & 1.018 & 1.113 & 0.735 & -0.782 & 0.000 \\ 56 & -0.841 & 0.703 & 1.017 & 1.114 & 0.736 & -0.785 & 0.000 \\ 57 & -0.836 & 0.713 & 1.019 & 1.113 & 0.737 & -0.785 & 0.000 \\ 58 & -0.751 & 0.767 & 1.011 & 1.120 & 0.737 & -0.794 & 0.000 \\ 59 & -0.592 & 0.892 & 1.022 & 1.075 & 0.641 & -0.769 & 0.016 \\ 60 & -0.712 & 0.813 & 1.003 & 1.125 & 0.736 & -0.799 & 0.002 \\ 61 & -0.876 & 0.677 & 1.026 & 1.101 & 0.711 & -0.743 & 0.000 \\ 62 & -0.826 & 0.672 & 1.019 & 1.126 & 0.755 & -0.762 & 0.000 \\ 63 & -0.818 & 0.669 & 1.017 & 1.128 & 0.753 & -0.763 & 0.000 \\ 64 & -0.880 & 0.661 & 1.030 & 1.081 & 0.654 & -0.672 & 0.000 \\ 65 & -0.837 & 0.683 & 1.038 & 1.067 & 0.628 & -0.649 & 0.000 \\ 66 & -0.447 & 0.841 & 1.060 & 0.994 & 0.600 & -0.682 & 0.000 \\ 67 & -0.727 & 0.710 & 1.053 & 0.949 & 0.732 & -0.787 & 0.000 \\ 68 & -0.761 & 0.691 & 1.049 & 0.954 & 0.738 & -0.792 & 0.000 \\ 69 & -0.833 & 0.685 & 1.056 & 0.960 & 0.848 & -0.936 & 0.000 \\ 70 & -1.057 & 0.527 & 1.024 & 0.968 & 1.026 & -1.171 & 0.000 \\ 71 & -1.033 & 0.575 & 0.990 & 0.971 & 0.978 & -1.110 & 0.000 \\ 72 & -1.017 & 0.557 & 0.976 & 0.972 & 0.886 & -0.986 & 0.000 \\ 73 & -1.018 & 0.565 & 0.975 & 0.975 & 0.882 & -0.979 & 0.000 \\ 74 & -0.945 & 0.602 & 0.976 & 0.976 & 0.883 & -0.978 & 0.000 \\ 75 & -0.924 & 0.650 & 0.979 & 0.973 & 0.882 & -0.972 & 0.000 \\ 76 & -0.721 & 0.608 & 0.977 & 0.971 & 0.878 & -0.965 & 0.000\end{array}$




$\begin{array}{llllllll}77 & -0.622 & 0.579 & 0.973 & 0.980 & 0.910 & -0.994 & 0.000 \\ 78 & -0.611 & 0.583 & 0.974 & 0.973 & 0.898 & -0.971 & 0.000 \\ 79 & -0.615 & 0.623 & 0.974 & 0.909 & 0.728 & -0.661 & 0.000 \\ 80 & -0.527 & 0.573 & 0.957 & 0.975 & 0.932 & -0.950 & 0.000 \\ 81 & -0.347 & 0.571 & 0.928 & 0.983 & 0.938 & -0.857 & 0.000 \\ 82 & -0.013 & 0.581 & 0.878 & 0.985 & 1.123 & -0.894 & 0.000 \\ 83 & -0.126 & 0.545 & 0.911 & 0.984 & 1.107 & -0.882 & 0.000 \\ 84 & 0.012 & 0.387 & 0.890 & 1.001 & 1.068 & -1.076 & 0.000 \\ 85 & -0.054 & 0.487 & 0.909 & 0.988 & 1.181 & -0.972 & 0.000 \\ 86 & -0.026 & 0.466 & 0.904 & 0.990 & 1.197 & -1.010 & 0.000 \\ 87 & -0.052 & 0.500 & 0.913 & 0.997 & 1.176 & -1.028 & 0.000 \\ 88 & 0.046 & 0.177 & 0.827 & 1.032 & 0.967 & -0.451 & 0.000 \\ 89 & 0.044 & 0.177 & 0.827 & 1.032 & 0.966 & -0.451 & 0.000 \\ 90 & 0.041 & 0.176 & 0.828 & 1.032 & 0.968 & -0.454 & 0.000 \\ 91 & 0.034 & 0.175 & 0.829 & 1.031 & 0.958 & -0.438 & 0.000\end{array}$




\section{USING DISCRETE-SWITCHING TRANSACTION: \\ MODEL 4B, 1954-1991}

The following lists the response coefficients estimated using locally

weighted optimization with the discrete-switching transaction function. There are 38 observations in the sample. Therefore, there are 38 sets of response coefficients resulted from 38 locally weighted fittings. $\alpha$ 's and B's are the response coefficients in the demand and supply functions, respectively. $\sigma$ 's are the standard deviation of the error terms in the demand and supply functions, respectively.

$\begin{array}{lllllllll} & \alpha_{1} & \alpha_{2} & \alpha_{3} & B_{1} & B_{2} & B_{3} & \sigma_{1} & \sigma_{2} \\ 54 & -0.834 & 0.719 & 1.000 & 1.135 & 1.074 & -1.073 & 0.656 & 2.946 \\ 55 & -0.823 & 0.718 & 1.001 & 1.136 & 1.069 & -1.070 & 0.658 & 2.934 \\ 56 & -0.818 & 0.724 & 1.002 & 1.134 & 1.052 & -1.060 & 0.644 & 2.928 \\ 57 & -0.818 & 0.731 & 1.004 & 1.134 & 1.037 & -1.050 & 0.632 & 2.852 \\ 58 & -0.772 & 0.767 & 1.001 & 1.117 & 0.957 & -0.992 & 0.499 & 2.608 \\ 59 & -0.768 & 0.816 & 0.998 & 1.094 & 0.821 & -0.885 & 0.259 & 1.711 \\ 60 & -0.791 & 0.789 & 0.999 & 1.108 & 0.903 & -0.948 & 0.379 & 2.257 \\ 61 & -0.840 & 0.703 & 1.010 & 1.150 & 1.076 & -1.055 & 0.678 & 2.743 \\ 62 & -0.843 & 0.691 & 1.011 & 1.163 & 1.079 & -0.951 & 0.660 & 2.751 \\ 63 & -0.819 & 0.691 & 1.008 & 1.156 & 1.049 & -0.927 & 0.653 & 2.707 \\ 64 & -0.835 & 0.688 & 1.018 & 1.161 & 1.035 & -0.927 & 0.646 & 2.691 \\ 65 & -0.783 & 0.706 & 1.026 & 1.152 & 0.972 & -0.907 & 0.516 & 2.274 \\ 66 & -0.696 & 0.796 & 1.054 & 1.034 & 0.683 & -0.792 & 0.199 & 1.151 \\ 67 & -0.763 & 0.716 & 1.036 & 1.037 & 0.823 & -0.890 & 0.289 & 1.627 \\ 68 & -0.773 & 0.697 & 1.025 & 1.034 & 0.857 & -0.943 & 0.304 & 1.487 \\ 69 & -0.752 & 0.693 & 1.017 & 0.992 & 0.791 & -0.859 & 0.322 & 1.021 \\ 70 & -0.802 & 0.707 & 1.000 & 0.978 & 0.773 & -0.851 & 0.432 & 0.332 \\ 71 & -0.850 & 0.701 & 0.986 & 0.969 & 0.892 & -0.978 & 0.366 & 0.387 \\ 72 & -0.890 & 0.637 & 0.980 & 0.959 & 0.937 & -1.000 & 0.291 & 0.466 \\ 73 & -0.905 & 0.613 & 0.977 & 0.959 & 0.892 & -0.928 & 0.259 & 0.519 \\ 74 & -0.858 & 0.607 & 0.977 & 0.951 & 0.852 & -0.861 & 0.258 & 0.584\end{array}$




$\begin{array}{lllllllll}75 & -0.803 & 0.613 & 0.976 & 0.942 & 0.829 & -0.809 & 0.250 & 0.592 \\ 76 & -0.707 & 0.604 & 0.978 & 0.930 & 0.793 & -0.748 & 0.275 & 0.589 \\ 77 & -0.659 & 0.597 & 0.977 & 0.926 & 0.797 & -0.722 & 0.242 & 0.528 \\ 78 & -0.635 & 0.591 & 0.978 & 0.928 & 0.811 & -0.708 & 0.232 & 0.538 \\ 79 & -0.607 & 0.584 & 0.975 & 0.928 & 0.822 & -0.682 & 0.216 & 0.530 \\ 80 & -0.600 & 0.567 & 0.975 & 0.953 & 0.903 & -0.634 & 0.215 & 1.097 \\ 81 & -0.370 & 0.544 & 0.935 & 0.996 & 1.107 & -0.694 & 0.390 & 0.763 \\ 82 & 0.091 & 0.519 & 0.859 & 1.000 & 1.131 & -0.706 & 0.662 & 0.574 \\ 83 & 0.296 & 0.497 & 0.818 & 1.002 & 1.128 & -0.705 & 0.738 & 0.577 \\ 84 & 0.347 & 0.438 & 0.812 & 1.006 & 1.099 & -0.659 & 0.622 & 0.769 \\ 85 & 0.108 & 0.337 & 0.870 & 0.970 & 0.991 & -0.413 & 0.754 & 2.031 \\ 86 & 0.182 & 0.224 & 0.847 & 0.963 & 0.814 & -0.067 & 0.989 & 1.721 \\ 87 & 0.082 & 0.196 & 0.848 & 0.991 & 0.754 & -0.067 & 1.387 & 1.738 \\ 88 & 0.020 & 0.179 & 0.849 & 0.994 & 0.691 & 0.027 & 1.671 & 1.431 \\ 89 & 0.001 & 0.176 & 0.850 & 0.995 & 0.694 & 0.016 & 1.727 & 1.410 \\ 90 & -0.024 & 0.171 & 0.851 & 0.995 & 0.692 & 0.017 & 1.739 & 1.347 \\ 91 & -0.072 & 0.158 & 0.849 & 0.992 & 0.651 & 0.095 & 1.805 & 1.111\end{array}$

